\title{
Management as a Technology?
}

Nicholas Bloom

Raffaella Sadun

John Van Reenen

Working Paper 16-133 


\title{
Management as a Technology?
}

\author{
Nicholas Bloom
}

Stanford University

Raffaella Sadun

Harvard Business School

John Van Reenen

Massachusetts Institute of Technology

Working Paper 16-133 


\title{
MANAGEMENT AS A TECHNOLOGY?*
}

\author{
Nicholas Bloom (Stanford), Raffaella Sadun (Harvard), John Van Reenen (MIT, CEP)
}

October 8, 2017

\begin{abstract}
Are some management practices akin to a technology that can explain firm and national productivity, or do they simply reflect contingent management styles? We collect data on core management practices from over 11,000 firms in 34 countries. We find large cross-country differences in the adoption of management practices, with the US having the highest size-weighted average management score. We present a formal model of "Management as a Technology", and structurally estimate it using panel data to recover parameters including the depreciation rate and adjustment costs of managerial capital (both found to be larger than for tangible non-managerial capital). Our model also predicts (i) a positive impact of management on firm performance; (ii) a positive relationship between product market competition and average management quality (part of which stems from the larger covariance between management with firm size as competition strengthens); and (iii) a rise in the level and a fall in the dispersion of management with firm age. We find strong empirical support for all of these predictions in our data. Finally, building on our model, we find that differences in management practices account for about $30 \%$ of total factor productivity differences both between countries and within countries across firms.
\end{abstract}

JEL No. L2, M2, O32, O33.

Keywords: management practices, productivity, competition

*Acknowledgments: We would like to thank Ufuk Ackigit, Orazio Attanasio, Marianne Bertrand, Robert Gibbons, John Haltiwanger, Rebecca Henderson, Bengt Holmström, Michael Peters, Michele Tertilt and Fabrizio Zilibotti for helpful comments as well as participants in seminars at the AEA, Barcelona, Berkeley, Birmingham, Bocconi, Brussels, CEU, Chicago, Dublin, Duke, Essex, George Washington, Harvard, Hong Kong, IIES, LBS, Leuven, LSE, Madrid, Mannheim, Michigan, Minnesota, MIT, Munich, Naples, NBER, NYU, Peterson, Princeton, Stockholm, Sussex, Toronto, Uppsala, USC, Yale and Zurich. The Economic and Social Research Council, the Kauffman Foundation, PEDL and the Alfred Sloan Foundation have given financial support. We received no funding from the global management consultancy firm (McKinsey) we worked with in developing the survey tool. Our partnership with Pedro Castro, Stephen Dorgan and John Dowdy has been particularly important in the development of the project. We are grateful to Renata Lemos and Daniela Scur for ongoing discussion and feedback on the paper. Anna Valero and Chiara Criscuolo have been generous in providing us with data. We thank Yo-Jud Cheng for excellent research assistance. Any opinions and conclusions expressed herein are those of the authors and do not necessarily represent the view of the U.S. Census Bureau. All results have been reviewed to ensure that no confidential information is disclosed. 


\section{Introduction}

Productivity differences between firms and between countries remain startling. For example, within the average four-digit U.S. manufacturing industries, Syverson (2011) finds that labor productivity for plants at the $90^{\text {th }}$ percentile was four times as high as plants at the $10^{\text {th }}$ percentile. Even after controlling for other factors, Total Factor Productivity (TFP) was almost twice as high. These differences persist over time and are robust to controlling for plant-specific prices in homogeneous goods industries. ${ }^{1}$ Such TFP heterogeneity is evident in all other countries where data is available. ${ }^{2}$ One explanation is that these persistent within industry productivity differentials are due to "hard" technological innovations, as embodied in patents or the adoption of advanced equipment. Another explanation, which is the focus of this paper, is that productivity differences reflect variations in management practices.

We advance the idea that some forms of management practices are like a "technology", in the sense that they raise TFP. This has a number of empirical implications that we examine and find support for in the data. Our perspective on management is distinct from the common "Design" paradigm in organizational economics, which views management as a question of optimal design depending on the very contingent features of a firm's environment (Gibbons and Roberts, 2013). In this view of management practices, there is no sense in which any management styles are on average better than any others. Our data provides some support for Design perspective, but we show that-at least within the very stylized version of this perspective that we consider-this delivers only a partial explanation of the patterns that we can observe in our data.

To date, empirical work to measure differences in management practices across firms and countries has been limited. Despite this lack of data, the core theories in many fields such as international trade, labor economics, industrial organization and macroeconomics are now incorporating firm heterogeneity as a central component. ${ }^{3}$

To address the lack of management data, we collect original survey data on management practices on over 11,000 firms in 34 countries. Besides its rich cross sectional nature, both in terms of countries and industries covered, this dataset also features a significant panel component built through four

\footnotetext{
${ }^{1}$ These are revenue based measures of TFP ("TFPR") so will also reflect firm-specific mark-ups. Foster, Haltiwanger and Syverson (2008) show large differences in TFP even within very homogeneous goods industries such as cement and block ice where they can observe plant specific prices ("TFPQ"). In what follows we will refer simply to TFP acknowledging that empirical measures usually be TFPR. König, Lorenz and Zilibotti (2016) give an example of how these could reflect technology differences even for ex ante identical firms. Hall and Jones (1999) show how the stark differences in productivity across countries account for a substantial fraction of the differences in average income.

${ }^{2}$ Usually productivity dispersion is even greater than in the U.S.-see Bartelsman, Haltiwanger and Scarpetta (2013), Hsieh and Klenow (2009) and OECD (2016).

${ }^{3}$ Different fields have different labels for what we regard as heterogeneity in management. In trade, the focus is on an initial productivity draw when the plant enters an industry that persists over time (e.g. Melitz, 2003). In industrial organization, the focus has traditionally been on cost heterogeneity due to entrepreneurial/managerial talent (e.g. Lucas, 1978). In macro, organizational capital is sometimes related to the firm specific managerial know-how built up over time (e.g. Prescott and Visscher 1980). In labor, there is a growing focus on how the wage distribution requires an understanding of the heterogeneity of firm productivity (e.g. Card, Heining and Kline, 2013).
} 
different survey waves from 2004 to 2014. One purpose of this paper is to provide public use data to enable other researchers to address long-standing questions regarding firm organization. ${ }^{4}$ We first present some stylized facts from this database in the cross country and cross firm dimensions. One of the striking features of the data is that the average management score, just like TFP, is higher in the U.S. than it is in other countries (see Figure 1). A second striking feature is that management, like TFP, shows a wide dispersion across firms within each country (see Figure 2). Interestingly, this dispersion is lower in countries like the U.S., with lower levels of market frictions, than it is in countries like India and Brazil.

We detail a simple model of "Management As a Technology" (MAT) which incorporates both a heterogeneous initial draw of managerial ability when a firm starts up, and the endogenous response of ongoing firms who change their level of managerial capital in response to shocks to the environment (modeled as as idiosyncratic TFP shocks). The model is useful to formalize our theoretical intuitions and enable structural estimation of key parameters. In particular, thanks to the panel variation present in the management data, we are able to identify the depreciation rate and adjustment costs of managerial capital, using Simulated Method of Moments (SMM). A further benefit of the structural model is that it enables us to derive some additional predictions on moments we did not target in the structural estimation.

We find that the data supports the predictions from the MAT model. First, management is positively associated with improved firm performance (productivity, profitability and survival) and, from experimental evidence, the management effect appears to be causal. Second, firm management rises with more intense product market competition, both through reallocating more economic activity to the better managed firms (an Olley and Pakes (1996) covariance term), and also through a higher unweighted average level of management. Third, older firms have a higher level of management, but lower dispersion due to selection effects. We contrast our MAT model to the predictions arising from a very stylized version of the "Management by Design" model, an alternative approach which sees management as a contingent feature, rather than an output-increasing factor of production. There are some elements consistent with this second design approach, especially when we disaggregate the management score into elements relating to monitoring compared relative to incentives. However, overall the MAT model seems a better description of our data.

Finally, using our MAT model we show that on average just under a third of cross country TFP differences with the U.S. are accounted for by management, with this fraction being higher in OECD countries than in less developed nations. Thus, management practices can account for a substantial portion of cross-country differences in development. Similarly when we look within countries, about $30 \%$ of the $90-10$ difference in productivity between firms is accounted for by differences in management practices.

In summary, this paper makes three major contributions over the existing literature. First, it

\footnotetext{
${ }^{4}$ The methods and data are open source and available on our website http://worldmanagementsurvey.org/surveydata/download-data/.
} 
develops and structurally estimates a model of management practices in the production function. Second, it uses this model to determine the extent to which management can account for variations in productivity across firms and across a large number of countries. Finally, it produces a set of Public Use Micro Data which should facilitate future quantitative research in the area of managerial and organizational economics.

Our paper relates to several literatures. First, there is a large body of empirical literature on the importance of management for variations in firm and national productivity, going back to Walker (1887) through to more recent papers like Ichniowski, Shaw and Prennushi (1997), Bertrand and Schoar (2003), Adhvaryu, Kala and Nyshadham (2016) and Bruhn, Karlan and Schoar (2016). Second, there is a growing macro literature on aggregate implications of firm management and organizational structure, ranging from Lucas (1978), to Gennaioli et al (2013), Guner and Ventura (2014), Garicano and Rossi-Hansberg (2015) and Akcigit, Alp and Peters (2016). Third, there is a long literature on the causes of the slow diffusion of new technologies and the implications for productivity differences (e.g. Griliches, 1957; Gancia, Mueller and Zilibotti, 2013). Finally, there is another growing literature focusing on explaining cross-country TFP in terms of the degree of reallocation of inputs to more productivity firms, most notably Hsieh and Klenow (2009) and Restuccia and Rogerson (2008).

The structure of the paper is as follows. We first describe some theories of management (Section 2 ) and implements our structural approach. Section 3 describes the data and Section 4 details our empirical results. Section 5 uses the framework to quantify the degree to which management can account for the cross country and within country dispersion of productivity and Section 6 offers some concluding comments. The online Appendices describe the data and how it can be accessed (A), further econometric analysis (B), details of the SMM procedure (C) and the CEO compensation data $(\mathrm{D})$.

\section{Models of Management}

\subsection{Conventional approaches to modeling heterogeneity in firm productivity}

Econometricians have often labeled the fixed effect in panel data estimates of production functions "management ability". For the most part, however, economists have focused on how technological innovations influence growth; for example, correlating TFP with observable innovation indicators such as Research and Development (R\&D), patents, or information technology (IT). There is robust evidence of the impact of such "hard" technologies for productivity growth (e.g. Griliches, 1998). Nevertheless, there are at least two major problems in focusing on these aspects of technical change as the sole driver of productivity. First, even after controlling for a wide range of observable measures of hard technologies, a large residual in measured TFP still remains. Second, many studies have found that the impact of technology on productivity varies widely across firms and 
countries. In particular, information technology has much larger effects on the productivity of firms that have complementary managerial structures which enable IT to be more efficiently exploited. ${ }^{5}$ Furthermore, a large body of case study work also suggests a major role for management in raising firm performance (e.g. Baker and Gil, 2013).

In light of these issues, we believe it is worth directly considering management practices as an independent factor in raising productivity.

\subsection{Formal models of management}

It is useful to analytically distinguish between two broad approaches that we can embed in a simple production function framework where value added, $Y$, is produced as follows:

$$
Y=F(\widetilde{A}, L, K, M)
$$

where $\widetilde{A}$ is an efficiency term, labor is $L$, non-management capital is $K$, and $M$ is management capital.

We begin with the "Management as Technology" perspective, where some types of management (or bundles of management practices) enhance productivity for the average firm across a wide range of environments. There are three types of these "best practices". First, there are some practices that have always been better (e.g. not promoting incompetent employees to senior positions, or collecting some information before making decisions). Second, there may be genuine managerial process innovations (e.g. Taylor's Scientific Management; Lean Manufacturing; Deming's Total Quality Management, etc.). Third, many management practices may have become optimal due to changes in the economic environment over time. Incentive pay may be an example of this, as the incidence of piece rates declined from the late 19th century, but appears to be making a comeback today. ${ }^{6}$

The alternative framework is the more traditional approach in Organizational Economics which we label the "Management by Design" perspective, where differences in practices are simply styles optimized to a firm's environment. For any indicator of $M$, such as the measures we gather, the Design approach would not assume that output is monotonically increasing in $M$. In some circumstances, higher levels of what we would regard as good practices will explicitly reduce output. To take a simple example, consider $M$ as a discrete variable which is equal to one if promotion takes

\footnotetext{
${ }^{5}$ In their case study of retail banking, for example, Autor et al (2002) found that banks who failed to re-organize the physical and social relations within the workplace reaped little reward from their adoption of IT. More generally, Bresnahan, Brynjolfsson and Hitt (2002) found that decentralized organizations tended to enjoy a higher productivity pay-off from IT across a wide range of sectors. Similarly, Bloom, Sadun and Van Reenen (2012) found that IT productivity was higher for firms with stronger incentives management, using some of the measures we detail below in Section 3.

${ }^{6}$ Lemieux, MacLeod and Parent (2009) suggest that this may be due to advances in IT. Software companies like SAP have made it much easier to measure output in a timely and robust fashion, making effective incentive pay schemes easier to design and implement.
} 
into account effort and ability and zero otherwise (e.g. purely seniority based promotions). The Design perspective could find that pure tenure-based promotion, which ignores effort and ability, increases output in some sectors, for example by reducing influence activities (Milgrom, 1988), but increases it in others. Under the Design approach, the production function can be written as equation (1), but for some firms and practices $F^{\prime}(M) \leq 0$. Even if $M$ were costless, output would fall if it was exogenously increased. The Design approach emphasizes that the reason for heterogeneity in the adoption of different practices is that firms face different environments. This is in the same spirit as the "contingency" paradigm in management science (Woodward, 1958).

The Design and the Technology perspectives can be nested within a common basic set-up but have, as we show, very different theoretical and empirical implications. Leaving aside for the moment the specific modeling choice of $F(M)$, we formalize these ideas by treating $M$ as an intangible capital (as in Corrado and Hulten, 2010), which has a market price and also a cost of adjustment. We allow firms to have an exogenous initial draw of $M$ when they enter the economy. This creates $e x$ ante heterogeneity between firms (generalizing the approach in Hopenhayn, 1992, for TFP). Factor inputs and outputs are firm specific (we do not use $t$ subscripts for simplicity unless needed). We consider a single industry, so firm-specific values are indicated by an $i$ subscript

$$
Y_{i}=\widetilde{A_{i}} K_{i}^{\alpha} L_{i}^{\beta} \widetilde{G}\left(M_{i}\right)
$$

where $\widetilde{G}\left(M_{i}\right)$ is a management function common to all firms. Demand is assumed to derive from a final good sector (or equivalently a representative consumer) using a CES aggregator across individual inputs:

$$
Y=N^{\frac{1}{1-\rho}}\left(\sum_{i=1}^{N} Y_{i}^{\frac{\rho-1}{\rho}}\right)^{\frac{\rho}{\rho-1}}
$$

where $\rho>1$ is the elasticity of substitution, $N$ is the number of firms and $N^{\frac{1}{1-\rho}}$ is the standard adjustment factor to make the degree of substitution scale free (e.g. Alessandria and Choi, 2007). Applying the first order conditions gives each firm an inverse demand curve with elasticity $\rho$ where we have normalized the industry price to be $P=1$

$$
P_{i}=\left(\frac{Y}{N}\right)^{\frac{1}{\rho}} Y_{i}^{\frac{-1}{\rho}}=B Y_{i}^{-\frac{1}{\rho}}
$$

where the demand shifter is $B=\left(\frac{Y}{N}\right)^{\frac{1}{\rho}}$. These production and demand curves generate the firm's revenue function:

$$
P_{i} Y_{i}=A_{i} K_{i}^{a} L_{i}^{b} G\left(M_{i}\right)
$$

where for analytical tractability we defined $A_{i}={\widetilde{A_{i}}}^{1-1 / \rho}\left(\frac{Y}{N}\right)^{\frac{1}{\rho}}, a=\alpha(1-1 / \rho), b=\beta(1-1 / \rho)$ and $G\left(M_{i}\right)=\widetilde{G}\left(M_{i}\right)^{(1-1 / \rho)}$. Profits, defined as revenues less capital, labor and management costs 
$\left(c_{K}(K), c_{L}(L)\right.$ and $\left.c_{M}(M)\right)$, and fixed costs $F$ are: ${ }^{7}$

$$
\Pi_{i}=A_{i} K_{i}^{a} L_{i}^{b} G\left(M_{i}\right)-c_{K}\left(K_{i}\right)-c_{L}\left(L_{i}\right)-c_{M}\left(M_{i}\right)-F
$$

\subsection{Models of management in production}

In terms of the management function $G\left(M_{i}\right)$, we consider two broad classes of models. First, Management as a Technology where management is an intangible capital input in which output is monotonically increasing. Second, Management by Design in which management is a choice of production approach. We focus on the first as this fits the data better (as we show below), but lay out both approaches in what follows.

\subsubsection{Management as a Technology (MAT)}

In Lucas (1978) or Melitz (2003) style models, firm performance is increasing continuously in the level of managerial quality, which is synonymous with productivity. Firms draw a level of management quality when they are born, and this continues with them throughout their lives. Since these types of models assume $G\left(M_{i}\right)$ is increasing in $M_{i}$, we simplify the revenue function by assuming $G\left(M_{i}\right)=M_{i}^{c}$

$$
P_{i} Y_{i}=A_{i} K_{i}^{a} L_{i}^{b} M_{i}^{c}
$$

More generally, we want to allow for the possibility that management can also be endogenously improved; for example, by hiring management consultants, spending time developing or reinforcing improved organizational processes (e.g. Toyota's Kaizen meetings), or paying for a better CEO. Although managerial capital can be improved in this way, failure to invest may mean it depreciates over time like other tangible and intangible assets such as physical capital, R\&D, and advertising. Hence, we set up a more general model which still has initial heterogeneous draws of management when firms enter, but treats management as an intangible capital stock with depreciation:

$$
M_{i t}=\left(1-\delta_{M}\right) M_{i t-1}+I_{i t}^{M} \quad I_{i t}^{M} \geq 0
$$

where $I_{i t}^{M}$ reflects investment in management practices, which has a non-negativity constraint reflecting the fact that managerial capital cannot be sold. The physical capital accumulation equation is similar except it allows for capital resale (at a cost which we discuss later).

$$
K_{i t}=\left(1-\delta_{K}\right) K_{i t-1}+I_{i t}^{K}
$$

\footnotetext{
${ }^{7}$ Since firms in our data are typically small in relation to their input and output markets, for tractability we ignore any general equilibrium effects, taking all input prices (for capital, labor and management) as constant.
} 


\subsubsection{Management by Design}

An alternative approach is to assume that management practices are contingent on a firm's environment, so that increases in $M$ do not always increase output. In some sectors, high values of $M$ will increase output, and in others they will reduce output depending on the specific features of the industry. We assume that optimal management practices may vary by industry and country, but this could also occur across other characteristics like firm age, size, or growth rate. For example, industries employing large numbers of highly skilled employees, like pharmaceuticals, will require large investments in careful hiring, tying rewards to performance and monitoring output, while low-tech industries can make do without these costly human resource practices. Likewise, optimal management practices could vary by country if, for example, some cultures are more comfortable with firing persistently under-performing employees (e.g. the U.S.) while others emphasize loyalty to long-serving employees (e.g. Japan).

There are many ways to set up a Design model. As a simple example we define $G\left(M_{i}\right)=1 /(1+$ $\left.\theta\left|M_{i}-\bar{M}\right|\right)$ where $\theta \geq 0$ and $G\left(M_{i}\right) \in(0,1]$ is decreasing in the absolute deviation of $M$ from its optimal level $\bar{M}{ }^{8}$ There are of course many other ways to model this idea, and our approach is certainly not meant to represent the wide range of Design approaches, rather we see it as a simple example to illustrate the implications of a $\widetilde{G}\left(M_{i}\right)$ function which attains an interior maximum.

\subsubsection{Management as Capital?}

We initially debated calling our main approach "Management as Capital" (rather than "Management as a Technology"), viewing management as an intangible capital stock (see for example Bruhn, Karlan and Schoar, 2016). In the end, because of the evidence suggesting management spillovers across plants within firms and between different firms ${ }^{9}$ we thought modeling management as a technology seemed more appropriate. However, we recognize that either terminology could be used. Indeed, the classic technology input-the R\&D knowledge stock-is recorded as an intangible capital input by the Bureau of Economic Activity in U.S. National Accounts.

\subsection{Adjustment costs and dynamics}

In general, changing a capital stock will involve adjustment costs. This could reflect, for example, the costs of the organizational resistance to new management practices (e.g. Cyert and March, 1963, or Atkin et al., 2017). We assume changing management practices involves a quadratic adjustment cost:

$$
C_{M}\left(M_{t}, M_{t-1}\right)=\gamma_{M} M_{t-1}\left(\frac{\Delta M_{t}}{M_{t-1}}-\delta_{M}\right)^{2}-\Delta M
$$

\footnotetext{
${ }^{8}$ Our baseline case also assumes that $M$ is a choice variable that does not have to be paid for on an ongoing basis so that $\delta_{M}=0$ although this assumption is not material.

${ }^{9}$ For example, Greenstone, Hornbeck and Moretti (2010), Atalay, Hortascu and Syverson (2014), Braguinsky et al. (2015) and Bloom et al. (2017).
} 
where the cost is proportional to the squared change in management net of depreciation, and scaled by lagged management to avoid firms outgrowing adjustment costs. This style of adjustment costs is common for capital (e.g. Chirinko, 1993) and seems reasonable for management where incremental changes in practices are likely to meet less resistance than large changes. Likewise, we also assume similar quadratic adjustment costs for non-managerial capital:

$$
C_{K}\left(K_{t}, K_{t-1}\right)=\gamma_{K} K_{t-1}\left(\frac{K_{t}-K_{t-1}}{K_{t-1}}-\delta_{K}\right)^{2}-I_{t}\left(1-\phi_{K} D\left(I_{t}<0\right)\right)
$$

where $I_{t}$ is the investment rate, $\phi_{K}$ is the resale loss on capital and $D\left(I_{t}<0\right)$ is an indicator function for disinvestment. To minimize on the number of state variables in the model, we assume labor is costlessly adjustable, but requires a per period wage rate of $w$. Given this assumption on labor, we can define the optimal choice of labor by $\frac{\partial P Y\left(A, K, L^{*}, M\right)}{\partial L}=w$. Imposing this labor optimality condition and assuming the MAT specification for management in the production function, we obtain:

$$
Y^{*}(A, K, M)=A^{*} K^{\frac{a}{1-b}} M^{\frac{c}{1-b}}
$$

where $A^{*}=b^{\frac{b}{1-b}} A^{\frac{1}{1-b}} \cdot{ }^{10}$. Finally, $\ln (A)$ is assumed to follow a standard AR(1) process so that $\ln \left(A_{i t}\right)=\ln A_{0}+\rho_{A} \ln \left(A_{i, t-1}\right)+\sigma_{A} \varepsilon_{i, t}$ where $\varepsilon_{i, t} \sim N(0,1)$. This will generate the firm-specific dynamics in the model, which alongside the random initial draw for management, which generate the stochastics in our model.

\subsection{Optimization and equilibrium}

Given the firm's three state variables-business conditions $A$, capital $K$, and management $M$-we can write a value function (dropping $i$-subscripts for brevity):

$$
\begin{aligned}
V\left(A_{t}, K_{t}, M_{t}\right) & =\max \left[V^{c}\left(A_{t}, K_{t}, M_{t}\right), 0\right] \\
V^{c}\left(A_{t}, K_{t}, M_{t}\right) & =\max _{K_{t+1}, M_{t+1}}\left[Y_{t}^{*}-w L-C_{K}\left(K_{t+1}, K_{t}\right)-C_{M}\left(M_{t+1}, M_{t}\right)-F\right. \\
& \left.+r E_{t} V\left(A_{t+1}, K_{t+1}, M_{t+1}\right)\right]
\end{aligned}
$$

where the first maximum reflects the decision to continue in operation or exit (where exit occurs when $V^{c}<0$, the value for "continuers"), the $V^{c}$ second is the optimization of capital and management conditional on operation, and $r$ is the discount factor. We assume there is a continuum of potential new entrants that would have to pay one period of fixed costs $F$ to enter. ${ }^{11}$ Upon entry, they take a stochastic draw of their productivity $(A)$ and management $(M)$ from a known joint distribution $H(A, M)$ and start with non-managerial capital $K_{0}=0$. Hence, entry occurs until the

\footnotetext{
${ }^{10}$ We define the units for labor, management and capital so that their prices are unity.

${ }^{11}$ We can allow the entry sunk cost to be different from a one period fixed cost as in Bartelsman et al (2013). In an earlier version of the paper we used firm level exit rates to estimate sunk costs and generated qualitatively results to those presented below. Since nothing in the results hinges on this, we kept the current set-up for simplicity.
} 
point that the expected value of entry equals the sunk cost of entry:

$$
F=\int V(A, 0, M) d H(A, M)
$$

We solve for the steady-state equilibrium by selecting the demand shifter $\left(B=\left(\frac{Y}{N}\right)^{\frac{1}{\rho}}\right)$ that ensures that the expected cost of entry equals the expected value of entry given the optimal capital and management decisions. This equilibrium is characterized by a distribution of firms in terms of their state values $A, K, M$. The distribution of $\ln A$ is assumed normal, while $M$ is assumed to be drawn from a uniform distribution. ${ }^{12}$

\subsection{Numerical Estimation}

Appendix $\mathrm{C}$ discusses this in more detail. In short, solving the model requires finding two nested fixed-points. ${ }^{13}$ First, we solve for the value functions for incumbent firms using the contraction mapping (e.g. Stokey and Lucas, 1986), taking demand as given for each firm. The policy correspondences for $M$ and $K$ are formed from the optimal choices given these value functions, and for $L$ from the static first-order condition. Second, we then iterate over the demand curve (3) to satisfy the zero-profit condition. ${ }^{14}$ Once both fixed points are satisfied, we simulate data for 5,000 firms over 50 years to get to an ergodic steady-state, and then discard the first 40 periods to keep the last 10 years of data (to match the time span of our management panel data).

To solve and simulate this model we also need to define a set of 14 parameter values. We pre-define nine of these from from accounting measurement (e.g. the labor share of GDP, the depreciation rate on capital) or estimates in the prior literature, we normalize two (fixed costs to 100 and the mean of $\ln$ (TFP) to 1) and estimate the remaining three parameters on our management and accounting data panel. The nine predefined parameters are listed in Table 1, and are all based on standard values in the literature. Appendix $\mathrm{C}$ describes how we cross-checked these calibration values with our own WMS data. For example, the Cooper and Haltiwanger (2006) estimates of the standard deviation $\left(\sigma_{A}\right)$ and auto-correlation of TFP $\left(\rho_{A}\right)$ implicitly include managerial capital $(M)$, which we can observe in our data. The three unknown parameters that we choose to estimate are those where much less is known from the literature. The adjustment cost $\left(\gamma_{M}\right)$ and depreciation rates $\left(\delta_{K}\right)$ for management have never been estimated before, to our knowledge. We also estimate the adjustment cost for non-managerial capital $\left(\gamma_{K}\right)$. While prior papers have estimated labor and capital adjustment costs (e.g. Bloom, 2009, and the survey therein), they have typically ignored management as an input, so it is these parameters are not directly transferable to our set-up.

\footnotetext{
${ }^{12}$ Nothing fundamental hinges on the exact distributional assumptions for $M$ and $A$.

${ }^{13}$ The full replication package for the simulation and SMM estimation is available on http://web.stanford.edu/ nbloom/MAT.zip

${ }^{14}$ If there is positive expected profit then net entry occurs and the demand shifter $B=\left(\frac{Y}{N}\right)^{\frac{1}{\rho}}$ falls, and if there is negative expected profit then net exit occurs.
} 
To estimate the model by SMM we picked three data moments to match: the variance of the fiveyear growth rates of the three state variables (management capital, non-management capital, and TFP) to tie down the adjustment cost and depreciation parameters. These data moments were generated on the matched management-accounting panel dataset for all countries from 2004 to 2014 (described in more detail in the next section). To generate standard errors, we block-bootstrapped over firms the entire process 1,000 times to generate the variance-covariance matrix, which was also used to optimally weight the SMM criterion function.

\subsection{Simulation results}

The top panel of Table 2 contains the SMM estimates and standard errors values for the three estimated parameters, and the bottom panel contains the moments from the data used to estimate these. Because the model is exactly identified we can precisely match the moments within numerical rounding errors.

The estimation of the adjustment costs for management is one of the novel contributions of this paper. We obtain a slightly higher level of adjustment costs for management of 0.212 (compared to 0.195 for capital) which, alongside the irreversibility of management, helps generate smoother management five-year growth moments compared to capital five-year growth moments (see the bottom panel of Table 2). ${ }^{15}$ These magnitudes are prima facie plausible as prior research in this area (Cyert and March, 1963) and anecdotal evidence from the private equity and management consulting industry suggest that management practices are likely to as hard or even harder to change than plant or equipment (e.g. Davis et al, 2014). Depreciation of management capital is $12.9 \%$, similar to the level of the depreciation of capital (10\%, see Table 1$).{ }^{16}$

Having defined and estimated the main MAT model, we can proceed to examine covariances of various moments that we have not targeted in the structural estimation to later compare these with actual data. Figures 3 through 5 show some predictions arising from the simulation. In Figure 3, we start by comparing the distribution of management practices of a random draw of 15,489 firm-years from our simulation to the 15,489 firm-year surveys in the management panel data, revealing similar cross-sectional distributions. ${ }^{17}$ While this is not a formal test of our model, it does confirm it can generate the wide spread of management practices, that is a striking finding of the management survey data.

\footnotetext{
${ }^{15}$ If we allow management to be have the same $50 \%$ resale loss as capital its adjustment cost is estimated to be 0.290 , about $50 \%$ higher than the value for capital.

${ }^{16}$ One interpretation is that management capital is tied to the the identity of plant managers. The average job tenure for plant managers in our survey is 6.4 year in the post and and 13.0 years in the company, which would imply post and company quit rates of about $15 \%$ to $7 \%$ spanning the depreciation estimate of $13 \%$. Indeed, in the 8 -year follow-up to the Bloom et al. (2013) India experiment the largest reasons for a deterioration in management practices in the treatment plants was the attrition of the plant manager.

${ }^{17}$ To scale our management practices we take logs of the management variable, and normalize the lowest value to 1 and the higher value to 5 to replicate our management survey scoring tool.
} 
Figure 4 examines the relationship between management and product market competition as indexed by the elasticity of demand $(\rho)$. We run all the simulation for increasingly high levels of the absolute price elasticity of demand between three and fifteen (recall that our baseline is an elasticity is equal to five). This represents economies with increasingly high levels of competition. We see that average management scores are higher when competition is stronger. The darker bars are the unweighted means of management across firms-they rise because under higher competition poorly managed firms tend to exit, as they cannot cover their fixed cost of production. We also see that size (employment) weighted management practices rise even faster with competition, because this raises the covariance between firm size and management (a higher "Olley Pakes reallocation" term), as better managed firms acquire larger market shares (and therefore need more inputs). Finally, Figure 5 examines the relationship between management and firm age. Firms' management score rises with age, as poorly managed firms either improve or exit the market. Over time, this leads the dispersion of management practices to fall within any age cohort, because of the exit of poorly managed firms.

Panels A to C of Figure 6 provide similar figures to Figures 3 to 5 for our Management by Design model, in which we assume $G(M)$ is maximized at $M=3$ for illustrative purposes. In Panel A, we see a similar spread of management practices, suggesting the Design view can generate an equilibrium dispersion of management practices. But in Panel B we see a very different relationship with competition, where management practices are invariant with the level of competition. More specifically, there is no sense in which high levels of management are better, and therefore they are not positively selected as competition increases. In Panel C, we also see no variation in the average management score with age for similar reasons, although we do see some reduction in variance with age as extremely high and low values of management practices are modified or the firm exits. Finally, in Panel D we have also included a plot of performance in terms of sales against management, showing the inverted $U$ shape implied by the Design view of the world that firms have an optimizing level of $M$ at 3 .

\section{Data}

\subsection{WMS Survey method}

We describe the datasets in more detail in Appendix A, but sketch out the important features here. To measure management practices, we developed a survey methodology known as the World Management Survey (WMS). ${ }^{18}$ This uses an interview-based evaluation tool that defines 18 basic management practices and scores them from one ("worst practice") to five ("best practice") on a scoring grid. This evaluation tool was first developed by an international consulting firm, and scores

\footnotetext{
${ }^{18}$ More details can be found at http://worldmanagementsurvey.org/
} 
these practices in three broad areas. ${ }^{19}$ First, Monitoring: how well do companies track what goes on inside their firms, and use this for continuous improvement? Second, Target setting: do companies set the right targets, track outcomes, and take appropriate action if the two are inconsistent? Third, Incentives/people management ${ }^{20}$ : are companies promoting and rewarding employees based on performance, and systematically trying to hire and retain their best employees?

To obtain accurate responses from firms, we interview production plant managers using a "doubleblind" technique. One part of this technique is that managers are not told in advance they are being scored or shown the scoring grid. They are informed only that they are being "interviewed about management practices for a piece of work". The other side of the double blind technique is that the interviewers do not know anything about the performance of the firm.

To run this blind scoring, we used "open" questions. For example, on the first monitoring question we start by asking the open question, "tell me how your monitor your production process", rather than closed questions such as "Do you monitor your production daily? [yes/no]". We continue with open questions focused on actual practices and examples until the interviewer can make an accurate assessment of the firm's practices. For example, the second question on that performance tracking dimension is, "What kinds of measures would you use to track performance?" and the third is "If I walked around your factory, could I tell how each person was performing?". ${ }^{21}$

The other side of the double-blind technique is that interviewers are not told anything about the firm's performance in advance. They are only provided with the company name, telephone number, and industry. Since we randomly sample medium-sized manufacturing firms (employing between 50 and 5,000 workers) who are not usually reported in the business press, the interviewers will generally have not heard of these firms before, so they should have few preconceptions. ${ }^{22}$

The survey was targeted at plant managers, who are senior enough to have an overview of management practices but not so senior as to be detached from day-to-day operations. We also collected a series of "noise controls" on the interview process itself-such as the time of day, day of the week, characteristics of the interviewee, and the identity of the interviewer. Including these in our regression analysis typically helps to improve our estimation precision by stripping out some of the random measurement error.

To ensure high sample response rates and informative interviews, we hired students with some

\footnotetext{
${ }^{19}$ Bertrand and Schoar (2003) focus on the characteristics and style of the CEO and CFO, and more specifically on differences in strategic management (e.g. decision making applied to mergers and acquisitions), while Lazear, Shaw and Stanton (2016) focus on individual supervisors. The type of practices we analyze in this paper are closer to operational and human resource practices, which has a long precedent in the management and strategy literature-for example, Osterman (1994), Huselid (1995) and Capelli and Neumark (2001).

${ }^{20}$ These practices are similar to those emphasized in earlier work on management practices, by for example Ichniowski, Prennushi and Shaw (1997) .

${ }^{21}$ The full list of questions for the grid is in Table A1 and (with more examples) at http://worldmanagementsurvey.org/wp-content/images/2010/09/Manufacturing-Survey-Instrument.pdf.

${ }^{22}$ We focus on firms over a size threshold because the formal management practices we consider are likely to be less important for smaller firms. We had a maximum size threshold because we only interviewed one or two plant managers in each firm, so would have too incomplete a picture for very large firms. Below, we show tests suggesting our results are not biased by using this sampling scheme (see Appendix B).
} 
business experience and training. We obtained endorsements from respected institutions for the surveys in each country we covered. We also never asked interviewees for financial data, obtaining this instead from independent sources on company accounts. Finally, the interviewers were encouraged to be persistent-so they ran about two interviews a day lasting 45 minutes each on average, with the rest of the time (about 6 hours a day) spent repeatedly contacting managers to schedule interviews. This process, while time consuming and expensive, helped to yield a $41 \%$ response rate which was uncorrelated with the (independently collected) performance measures. Appendices A and $\mathrm{B}$ discuss and analyze selection issues for the sampling frame and responders.

\subsection{Survey waves}

We have administered the survey in several waves since 2004. There were five major waves in 2004, 2006, 2009/10, 2013, and 2014. In 2004 we surveyed four countries (France, Germany, the U.K. and the U.S.). In 2006 we expanded this to twelve countries (including Brazil, China, India, and Japan), continuing random sampling, but in addition to a refreshment sample for the 2004 countries we also re-contacted all of the original 2004 firms to establish a panel. In 2009/10 we re-contacted all the firms surveyed in 2004 and 2006, but did not do a refreshment sample (due to budgetary constraints). In 2013 we added an additional number of countries (mainly in Africa and Latin America). In 2014 we again did a refreshment sample, but also followed up the panel firms in the U.S. and some E.U. countries. The final sample includes 34 countries and a panel of up to four different years between 2004 and 2014 for some firms. In the full dataset we have 11,383 firms and 15,489 interviews where we have usable management information.

\subsection{Internal validation}

We re-surveyed a random sub-sample of firms using a second interviewer to independently survey a second plant manager in the same firm. The idea is that the two independent management interviews on different plants within the same firms reveal how consistently we are measuring management practices. We found that in this sample of 222 re-rater interviews, the correlation between our independently run first and second interview scores was 0.51 (p-value 0.001). Part of this difference across plants within the same firm is likely to be real internal variation in management practices, with the rest presumably reflecting survey measurement error. The highly significant correlation across the two interviews suggests that while our management score is clearly noisy, it is picking up significant management differences across firms.

\subsection{Some descriptive statistics}

The bar chart in Figure 1 that we referred to in the Introduction plots the average (unweighted) management practice score across countries. This shows that the U.S. has the highest average 
management practice score, with the Germans, Japanese, Swedes, and Canadians below, followed by a block of West European countries (e.g. France, Italy and the U.K.) and Australia. Below this group is Southern European countries (e.g. Portugal and Greece) and Poland. Emerging economies (e.g. Brazil, China, and India) are next, and low income countries (mainly in Africa) are at the bottom. In one sense this cross-country ranking is not surprising since it approximates the cross-country productivity ranking. But the correlation is far from perfect -Southern European countries do a lot worse than expected and other nations, like Poland and Mexico, do better. ${ }^{23}$

A key question is whether management practices are uniformly better in some countries like the U.S. compared to India, or if differences in the shape of the distribution drive the averages? Figure 2 plots the firm-level histogram of management practices (solid bars) for all countries pooled (top left) and then for each country individually. This shows that management practices, just like firmlevel productivity, display tremendous variation within countries. Of the total firm-level variation in management only $13 \%$ is explained by country of firm location, a further $10 \%$ by industry (measured at the three digit SIC level), with the remaining $77 \%$ being within country and industry. Interestingly, countries like Brazil and India have a far larger left tail of management (e.g. scores of two or less) than the U.S. ${ }^{24}$ This immediately suggests that one reason for the better average performance in the U.S. is that the American economy is better at selecting out the badly managed firms. We pursue the idea that some of the U.S. advantage may be linked to stronger forces of competition below.

Figure A1 shows average management scores in domestic firms (i.e. those who are not part of groups with overseas plants) compared to plants belonging to foreign subsidiaries. The average scores in domestic plants look similar to those in Figure 1, which is unsurprising as most of our firms are domestic. More interesting is that plants belonging to foreign multinationals appear to score highly in almost every country, suggesting that such firms are able to transplant their management practices internationally. This finding is robust to controlling for many other factors (such as firm size, age and industry) and is consistent with the idea of a subset of global, productivity enhancing practices. An interesting extension to our basic model would be to allow for this type of cross-plant transfer of management practices (e.g. Helpman, Melitz and Yeaple, 2004) but for parsimony in the current model we have not done so.

\subsection{Managerial and Organizational Practices Survey (MOPS)}

We also implemented a more traditional closed question "tick box" survey design for MOPS which gives us management data on 31,793 U.S. manufacturing plants in 2010. The question design was modeled on WMS and the response to the MOPS was very high as we worked with the U.S and replies were legally mandatory. Census Bureau. Details on MOPS is contained in Bloom et al

\footnotetext{
${ }^{23}$ Polish management appears to be better because of the influence of the large numbers of German multinational subsidiaries, while Mexico similarly benefits from a heavy U.S. multinational presence

${ }^{24}$ For example, the skewness of the firm level management distribution in the U.S. is 0.09, whereas the skewness of the distribution in Brazil is 0.16 and 0.36 in India.
} 
(2017) and Appendix A. One advantage of MOPS is that it has much more reliable information on plant and firm age than in WMS -as discussed in later sections of this paper-so we use MOPS for one of our theoretical predictions on the relationship between management and age.

\section{Implications of Management as a Technology}

\subsection{Management and firm performance}

\section{Basic results}

The most obvious implication of the MAT model is that high management scores should be associated with better firm performance. Figure A2 plots firm sales on firm management and Figure A3 does the same for conventionally measured firm TFP and management scores using local linear regressions. Both figures show a clear positive and monotonic relationship. To probe this bivariate relationship more formally, we run some simple regressions. We z-score each individual practice, average across all 18 questions, and z-scored this average so the management index has a standard deviation of unity. ${ }^{25}$ Table 3 examines the correlation between different measures of firm performance and management. To measure firm performance we used company accounts data ${ }^{26}$, estimating production functions where $Q_{i t}$ is measured by the value added of firm $i$ at time $t$ :

$$
\ln Q_{i t}=\alpha_{M} M_{i t}+\alpha_{L} \ln L_{i t}+\alpha_{K} \ln K_{i t}+\alpha_{X} x_{i t}+u_{i t}
$$

where $M_{i t}$ is the empirical management $\operatorname{score}^{27}, x_{i t}$ is a vector of other controls such as the proportion of employees with a college degree, firm age, noise controls (e.g. interviewer dummies), country and three-digit SIC industry dummies and $u_{i t}$ is an error term. In column (1) of Table 3 we regress $\ln$ (value added) on $\ln$ (employment) and the management score, finding a highly significant coefficient of 0.316 . This suggests that firms with one standard deviation of the management score are associated with $32 \mathrm{log}$ points higher labor productivity (i.e. about $37 \%$ ). In column (2) we add the capital stock and other controls which causes the coefficient on management to drop to 0.148 , although it remains significant. Column (3) conditions on a sub-sample where we observe each firm in at least two years to show the effects are stable, while column (4) re-estimates the

\footnotetext{
${ }^{25}$ We have experimented with other ways of aggregating the management scores such as using principal component analysis. Since the 18 questions are all positively correlated these more sophisticated alternatives produce broadly similar results to those developed here. Sub-section 4.5 below describes some other ways of dis-aggregating the scores into sub-components that reveals evidence for the Design perspective.

${ }^{26}$ Our sampling frame contained $90 \%$ private firms and $10 \%$ publicly listed firms. In most OECD countries both public and private firms publish basic accounts. In the U.S., Canada and India, however, private firms do not publish (sufficiently detailed) accounts so no performance data is available. Hence, these performance regressions use data for all firms except privately held ones in the U.S., Canada and India.

${ }^{27}$ Note that empirical measure of management here, $M$, corresponds to the log of the managerial capital stock ( $\ln M$ ) in the theory. This seems reasonable given the evidence of Figure 3 of the log-normal distribution of the empirical score.
} 
specification on this sub-sample including a full set of firm fixed effects to identify from changes in management over time, a very tough test given the likelihood of attenuation bias. The coefficient on management (and labor and capital) does fall, but it remains positive and significant. ${ }^{28}$ In column (5) we use the Olley and Pakes (1996) estimator of productivity and obtain a coefficient on management of 0.102 , lying between the levels OLS and fixed effects specification. ${ }^{29}$

As discussed above, one of the most basic predictions is that better managed firms should be larger than poorly managed firms. Column (6) of Table 3 shows that better managed firms are significantly larger than poorly managed firms: a one standard deviation of management is associated with a 40 log point increase in employment size. In column (7) we use profitability as the dependent variable as measured by ROCE (Return on Capital Employed) and show again a positive association with management. Considering more dynamic measures, column (8) uses sales growth as a dependent variable, revealing that better managed firms are significantly more likely to grow. Column (9) estimates a model with Tobin's average $q$ as the dependent variable, which is a forward looking measure of performance. Although this can only be implemented for the publicly listed firms, we see again a positive and significant association with this stock market based measure. Finally, column (10) examines bankruptcy/death and finds that better managed firms are significantly more likely to survive.

These are conditional correlations that are consistent with the MAT model, but are obviously not to be taken as causal. However, the randomized control trial (RCT) evidence in Indian textile firms (Bloom et al, 2013) showed that increasing WMS style management scores by one standard deviation in management caused a $10 \%$ increase in TFP. This estimate is consistent with the OlleyPakes in column (5) of Table 3. Other well identified estimates of the causal impact of management practices such as the RCT evidence from Mexico discussed in Bruhn, Karlan and Schoar (2016) and the management assistance natural experiment from the Marshall plan discussed in Giorcelli (2016) find similarly large impacts of management practices on firm productivity (see also the literature surveys by McKenzie and Woodruff, 2013, 2017, on smaller firms).

\subsection{Product Market Competition}

\subsubsection{Competition and management}

An important implication of the management as technology model is that stronger product market competition is likely to improve average management scores. To test this prediction, we estimate

\footnotetext{
${ }^{28}$ Note that these correlations are not simply driven by the "Anglo-Saxon" countries, as one might suspect if the management measures were culturally biased. We cannot reject that the coefficient on management is the same across all countries: the F-test (p-value) on the inclusion of a full set of management*country dummies is 0.790 (0.642).

${ }^{29}$ In Appendix B1 and Table A5 we discuss a variety of other robustness tests of these productivity equations such as using an output rather than value added production function and including materials as an additional input; using the System-GMM approach of Blundell and Bond (2000) as well as alternative control function approaches to OlleyPakes as discussed by Ackerberg, Caves and Frazer (2015); using a Solow-residual based measure of conventional TFP and using the wage bill instead of employment as a measure of labor services. The importance of management remained in all of these experiments.
} 
regressions of the form:

$$
M_{i c j t}=\gamma_{1} C O M P E T I T I O N_{c j t}+\gamma_{2} z_{i t}+\eta_{t}+\xi_{c j}+\nu_{i c j t}
$$

where $z_{i t}$ is a vector of other firm controls (the proportion of employees with a college degree, $\log$ firm and plant size, log firm age and noise controls), $\eta_{t}$ denotes year dummies, $\xi_{c t}$ denotes a full set of three digit SIC industry dummies by country, and $v$ is an error term.

We employ three different industry measures of competition. First, we begin with the inverse industry Lerner index measured in an industry by country by period cell. The Lerner index is a classic measure of competition (Aghion et al, 2005), and is calculated as the median price cost margin within an industry-country cell using all firms in the ORBIS accounting database. ${ }^{30}$ Since profits data is not generally reported for firms in developing countries, we focus on OECD countries. We build a time varying Lerner index using data relative to three different periods (2003-2006; 20082011; 2012-2013). ${ }^{31}$ These industry by country by period variables are then correlated with the management scores conducted over the same time periods.

As an alternative to the Lerner measure of competition, we use a measure of import penetration (imports over apparent consumption) in the country by industry by period cell, again measured in the same periods and for the same set of OECD countries using industry by country by year data from the World Input-Output Database (WIOD). Finally, to take into account the fact that observed changes in import competition may be endogenous, we build an alternative measure of import penetration from WIOD which includes only imports from China, as these have been shown in other papers (e.g. Autor, Dorn and Hansen (2013) and Bloom, Draca and Van Reenen, 2016) to be overwhelmingly driven by policy changes such as Chinese accession to the WTO and the subsequent reduction in tariffs and quotas (e.g. the dismantling of the Multi-Fiber Agreement).

We begin by just showing the raw data in Figure 7, binning the three competition measures into terciles and plotting the mean management score in each bin. Panel A shows this for cross sectional "levels" (after subtracting the overall industry means and overall country means in both the competition measure and the management score), revealing a robustly positively relationship for all three competition measures. Panel B reports a similar graphic for "changes" in management over time within a country by industry pair (i.e. subtracting the country by industry means) against changes in competition over time, again displaying a robustly positive relationship.

In Table 4, we examine this more formally in a regression context estimating equation (5). The dependent variable across all columns is the standardized value of the management score. Column

\footnotetext{
${ }^{30}$ In the simulated data we confirm that this empirical measure of the Lerner Index is highly correlated with our consumer price sensitivity parameter, $\rho$. For example, the Lerner has a correlation of 0.928 with price sensitivity across simulations in which we increase $\rho$ in unit increments from 3 to 15 .

${ }^{31}$ See the Appendix for details on the construction of the measures of competition. These roughly correspond to blocks of time before, during and after the Great Recession/Euro Crisis. 2013 is the last full year of the ORBIS database currently available.
} 
(1) reports the correlation between management and competition including industry by country fixed effects, time dummies and other standard firm-level controls. Consistent with Figure 7, the Lerner Index has a positive and significant correlation with management. The simulation model suggests that this relationship should be stronger if we size-weight management due to better reallocation in more competitive sectors. Column (2) implements this idea using as a weight the firm's share of employment in the industry by country cell, and indeed, the coefficient on the Lerner measure rises from 0.99 to 1.75 . The next four columns repeat the specifications but use import penetration, including imports from all countries in columns (3) and (4) and then just imports from China in columns (5) and (6), as an alternative measure of competition. The pattern of results shows a larger coefficient on the competition measures for the size-weighted regressions compared to the unweighted regressions, consistent with the findings from using the Lerner index. ${ }^{32}$

Overall, the results suggest that higher competition is associated with significant improvements in management, and the magnitude of the coefficient is larger when we weight the regressions by firm size. In terms of magnitudes a one standard deviation change in the Lerner index in the unweighted regression is associated with a 0.06 of a standard deviation change in management, compared to 0.02 using the import penetration measure and 0.05 using Chinese imports. The equivalent numbers for the weighted regressions are $0.11,0.05$ and $0.05 . .^{33}$

\subsubsection{Competition and reallocation towards better managed firms}

Another way to confirm the reallocative impact of competition predicted by the MAT model is to consider whether factors that reduce the degree of competition reduce the covariance between management practices and firm size, implying $\delta_{1}<0$ in the following equation:

$$
\text { FirmSize }_{i t}=\delta_{1}(M * C O M P E T I T I O N)_{i t}+\delta_{2} M_{i t}+\delta_{3} \text { COMPETITION }_{i}+\delta_{4} x_{i j t}+\nu_{i j t}
$$

The simplest method of testing this idea is to use countries grouped into regions to proxy competitive frictions, as it is likely that competition is stronger in some regions (e.g. the U.S.) than others (e.g. southern Europe).

\footnotetext{
${ }^{32}$ We also considered a fourth measure of competition from our survey data: the number of rivals as perceived by the plant manager. The advantage of this indicator is that it is available for all countries in our survey. Empirically, the variable is also linked to improvements in management. In a specification like column (1) of Table 4, the coefficient (standard error) on this measure of competition was $0.033(0.017)$ on a sample of 14,305 observations including all countries with management data, and 0.059 (0.022) on the sample of OECD countries overlapping with the one used in Table 4 (8,414 observations as there are a few some missing values on the number of competitors variable). The disadvantage of the number of rivals measure is that it is not tightly linked to the theory simulations. For example, although falls in barriers to entry will tend to increase the number of firms in the MAT model, increases in consumer sensitivity to price can lead to an equilibrium reduction in the number of firms.

${ }^{33}$ To check whether the difference between the weighted and the unweighted results was significant, we compared the distribution of the estimated coefficients with and without weights bootstrapping with 500 replications. The weighted coefficients were larger than the unweighted coefficients $84 \%$ of the times for the Lerner index, $76 \%$ of the times with the import penetration variable, and $52 \%$ of the times using imports from China.
} 
Column (1) of Table 5 reports the results of a regression of firm employment on the average management score and a set of industry, year and country dummies. ${ }^{34}$ The results indicate that increasing a firm's management score by one standard deviation is associated with an extra 183 workers. In column (2) we allow the management coefficient to vary by region, with the U.S. as the omitted base. The negative coefficients on the interactions indicate that that there is a stronger relationship between size and management in the U.S. compared to other regions. This difference is significant for Africa, Latin America and southern Europe, but not for Asia or northern Europe. A one standard deviation increase in management is associated with 268 extra employees in the U.S. but only 68 (= 268.4 - 199.5) extra workers in southern Europe. ${ }^{35}$ These results suggest that reallocation is stronger in the U.S. than in the other countries, which is consistent with the findings on productivity in Bartelsman, Haltiwanger and Scarpetta (2013) and Hsieh and Klenow (2009).

We also investigate explicit measures of market-friction variables that can reduce competition. In columns (3) to (5) of Table 5 we use country-wide measures of employment regulation from the OECD and trade costs from the World Bank. Both of these reduce the covariance between firm size and management practices. Finally in column (6) we use the more detailed country by industry measures of tariffs from Feenstra and Romalis (2012) in deviations from their country and industry mean, and again find a significant negative interaction. This implies that within a sector (like steel), countries with higher tariffs (such as Brazil) will allocate less activity to better managed firms than those with lower tariffs (such as the U.K.).

Taken as a whole, these findings on competition appear very consistent with the predictions of our MAT model.

\subsection{Firm Age}

Examining the third prediction from MAT-the relationship between firm age and management-is complicated by the fact that the "date of incorporation" information in company accounts refers to the year in which the company was formed, even if this is due to a merger or acquisition. ${ }^{36}$ Consequently, we turn to a complementary management database, the Management and Organizational Practices (MOPS) survey, which has more accurate age data based on plant age rather

\footnotetext{
${ }^{34}$ This is the measure of firm size reported by the plant manager. For a multinational this may be ambiguous as the plant manager may report the global multinational size which is not necessarily closely related to the management practices of the plant we survey. Consequently, Table 5 drops multinationals and their subsidiaries, but we show robustness of this procedure below.

${ }^{35}$ These results are for covariances based on size. Using a dynamic version of this moment-the covariance between employment growth and management-generates qualitatively similar results. For example, re-running column (2) using the growth (rather than the level) of employment also has negative interactions on all the regional interactions. For example, a one standard deviation increase in management in the U.S. raises sales growth by $6.9 \%$ compared to a (significantly lower) $0.5 \%$ faster growth in Asia from a similar increase in management.

${ }^{36}$ For example, a company like GSK is denoted as formed in 2001 when Glaxo Wellcome merged with SmithklineBeecham, even though Glaxo-Wellcome has a history dating back to late Nineteenth Century (Jason Nathan and Company, started in 1873, merged with Burroughs Wellcome and Company, started by Henry Wellcome and Silas Burroughs in 1880).
} 
than firm age. ${ }^{37}$ MOPS is a plant-level survey with management questions that we helped design in partnership with the US Census Bureau with very similar questions to those in our standard WMS telephone survey.

Figure 8 shows strong evidence that the average management score is higher in older cohorts of plants, and that the variance of management scores is lower. This relationship is particularly strong when comparing plants who have been in existence for five or less years with their older counterparts. This closely matches the predictions from the simulation model, in which the exit of establishments with low management draws after birth increases the average management score and reduces the management variation (see Figure 4). ${ }^{38}$

\subsection{Managerial Compensation and Management Practices}

One view of management practices is that they simply reflect the quality of the firm's CEO. For example, Edmans and Gabaix (2017) show that the canonical Lucas (1978) model implies a relationship between the value added of the firm and the talent, $T$, of the CEO:

$$
Y_{i}=\lambda_{1} \ln T_{i}+\lambda_{2} \ln K_{i}+\lambda_{3} L_{i}
$$

Obviously, this bears a close relationship to our MAT production function where managerial capital, $M$, is now simply CEO talent. For example, if we considered the investment in management capital $\left(I^{M}\right)$ represented the cost of managerial talent then using equation (6) in steady state $I_{M}=\delta_{M} M$ so $\ln I^{M}=\ln \delta_{M}+\ln M$. Hence, we would expect to see a positive relationship between CEO remuneration and management practices. Motivated by this idea, we gathered information on CEO pay for firms in four countries: China, India, the UK and US. We focused on publicly listed firms because CEO pay is not usually disclosed for smaller firms (see Appendix D for data details). We were able to gather data on a sample of 532 firms of our firms (912 observations). There is a statistically significant and economically important relationship between CEO pay and management practices whether or not we control for a wide variety of factors. For example, column (1) of Table A6 suggests that a 0.1 increase in the standard deviation of management is associated with a $3 \%$ increase in CEO salary. Figure A4 shows the relationship for the UK and US (where we have the richest data).

An alternative use of the CEO pay data is to compare the compensation to managers with the factor share paid to management implied by the model. The Cobb-Douglas coefficient on management- $\lambda$ in equation (2)-is calibrated at 0.1 , which implies a $10 \%$ cost share for management. To evaluate

\footnotetext{
${ }^{37}$ Plant age in the Census is measured from the first year of existence in the Census/IRS Business Registry, which is built from social security and income tax records.

${ }^{38}$ MOPS was also linked to productivity data in the Annual Survey of Manufacturers and Census of Manufacturing. (Bloom et al, 2016) show that we obtain similar results on the positive connection between higher plant level management scores and performance as shown in Table 3 above, and the positive correlation of management with competition as shown in Table 4 above.
} 
the plausibility of this figure, we look at the compensation paid to senior employees in firms, whose activities are likely to be primarily management. Using the Social Security Administration data on all employees in all US firms (public and private) from in Song et al (2017), we calculate that in 2013 the fraction of earnings going to the top 1\%, 5\% and 10\% of employees in all firms with $20+$ employees is $7 \%, 22 \%$ and $32 \%$ respectively ${ }^{39}$. Since labor accounts for $2 / 3$ of total costs, this implies a range of between $5 \%$ and $21 \%$ of total costs being spent on management-these figures bracket the implied 10\% cost share from our management parameter, suggesting our management coefficient does not seem unreasonable.

\subsection{Management by Design}

The predictions of the Management as a Technology model on performance, competition and age are all consistent with the results from the WMS and MOPS management datasets. Our admittedly extremely stylized version of the Management by Design model does less well. This Design model does successfully predict the dispersion of management (compare Figure 3 with Figure 6 Panel A) and the falling dispersion of management with age (compare Figure 8 light bars with Figure 6 Panel C). However, the predictions of a non-monotonic relationship between firm performance and management are rejected (compare Figures A2 and A3 with Figure 6 Panel D) as is the flat relationship between management and competition (compare Figure 7 with Figure 6 Panel B) and management and age (compare Figure 8 dark bars with Figure 6 Panel C). Of course, more subtle versions of the Design model could fit the stylized facts in the data better, but it is striking that the MAT model does this in a more straightforward manner.

One set of results that is instead consistent with the Design approach relates to the contingency of specific types of management practices on different industry characteristics. More specifically, the Design approach suggests we might expect sectors that make intensive use of tangible fixed capital to specialize more in monitoring/targets management, whereas human capital intensive sectors focus more on people/incentives management. This is indeed what we tend to observe when we correlate our management data with four digit U.S. industry data on the capital-labor ratio (NBER) and R\&D per employee (NSF), as shown in Panel A of Table $6 .{ }^{40}$ Although both people management (column (1)) and monitoring/targets management (column (2)) are positively associated with fixed capital intensity, the relationship is much stronger for monitoring/targets, as shown when we regress the relative variable (people/incentives score minus monitoring/targets score) on capital intensity in column (3). The opposite is true for $R \& D$ intensity as shown in

\footnotetext{
${ }^{39}$ In large firms with $10,000+$ employees these pay shares are very similar at $8 \%, 23 \%$ and $32 \%$ for the same percentiles of employee pay. We provide three different pay shares as it is not clear what fraction of top employees can be thought of as management. Certainly the top $1 \%$ of employees in larger firms will be almost exclusively focused on management, while those at the top $10 \%$ will be heavily focused on this but will also include senior engineers, lawyers etc. who are not completely (or even mainly) managers. Therefore, some mid-point in these figures is likely to provide the best guess of the wage costs of managerial inputs.

${ }^{40}$ This is implicitly assuming that the U.S. values are picking up underlying technological differences between industries that are true across countries.
} 
the next three columns: in high tech industries, people management is relatively more important. These findings are robust to including them together with skills in the final three columns.

As an alternative empirical strategy in Panel B of Table 6, we use country by industry specific values of these variables from the EU-KLEMS dataset. In these specifications we are using the country-specific variation in capital and $R \& D$ intensity within the same industry. The results are qualitatively similar to Panel A-capital intensive industries have higher monitoring/target management practices, while $R \& D$ intensive industries have higher people management practices scores, consistent with a basic Design model.

In summary, MAT appears to provide the best all around fit for the data, particularly in terms of firm performance. We will use the implications of this model in the next section to calculate what share of cross-country differences in TFP can be attributed to differences in management practices. However, there is some support for the Design model in terms of contingent management styles, suggesting that a hybrid model could offer a better fit of the empirical data at the expense of greater complexity.

\section{Accounting for cross-country TFP differences with Manage- ment}

We now return to a long-standing question in economics, stretching back to at least Walker (1887). To what degree do management practices account for the large variation in productivity both across countries and also within countries, across-firms? We begin at the national level by defining an aggregate country management index and decomposing this into a within firm and between firm component in an analogous way to the standard Olley and Pakes (1996) productivity decomposition method:

$$
M=\sum_{i} M_{i} s_{i}=\sum_{i}\left[\left(M_{i}-\overline{M_{i}}\right)\left(s_{i}-\overline{s_{i}}\right)\right]+\overline{M_{i}}=O P+\overline{M_{i}}
$$

where $M_{i}$ is the management score for firm $i, s_{i}$ is a size-weight (the firm's share of employment in the country), $\bar{M}$ is the unweighted average management score across firms and OP indicates the "Olley Pakes" covariance term, $\sum_{i}\left[\left(M_{i}-\overline{M_{i}}\right)\left(s_{i}-\overline{s_{i}}\right)\right]$. The OP term simply divides management into a within and a between/reallocation term.

Next, comparing any two countries $k$ and $k$, the difference in weighted scores can be decomposed into the difference in reallocation and unweighted management scores:

$$
M^{k}-M^{k^{\prime}}=\left(O P^{k}-O P^{k^{\prime}}\right)+\left(\bar{M}_{i}^{k}-\bar{M}_{i}^{k^{\prime}}\right)
$$

A deficit in aggregate management is composed of a difference in the reallocation effect $\left(O P^{k}-O P^{k^{\prime}}\right)$ and the average unweighted firm management scores $\left(\bar{M}_{i}^{k}-\bar{M}_{i}^{k^{\prime}}\right)$. 
Table 7 reports the results of this decomposition (more details in Appendix B) using the U.S. as the base country $\left(k^{\prime}=U S\right)$ as it has the highest management scores. In column (1) we present the employment share-weighted management scores $(M)$ in z-scores, so all differences can be read in standard deviations from the sample mean of 0 . These differ from those presented earlier in Figure 1 because we have dropped multinationals (to focus on clean national differences), size-weighted the management scores and use z-scores (normalized so that mean $=0$ and standard-deviation=1). In column (2) we show the unweighted average management score $\left(\overline{M_{i}}\right)$, and in column (3) the Olley Pakes covariance term. From this we can see that, for example, the leading country-the U.S.-has a size-weighted management score of 0.90 , which is split almost half in between a reallocation effect (0.40) and an unweighted average management score effect (0.50). Thus, the U.S. not only has the highest unweighted management score but it also has a comparatively high degree of reallocation as discussed above in sub-section $4.2 .^{41}$

We next calculate each country's management gap with the U.S. Column (4) does this for the overall management gap and column (5) reports the share of this gap arising from differences in reallocation. These results are also presented graphically in Figure 8, which shows that reallocation accounts for a non-trivial fraction of the management gap in just about all countries, ranging from $8 \%$ in Tanzania to $94 \%$ in Japan.

We can push this analysis further by examining how much management could explain cross country differences in TFP. Column (6) of Table 7 contains the country's TFP gap with the U.S. using the latest Penn World Tables (Feenstra, Inklaar and Timmer, 2015). ${ }^{42}$ Following the randomized control trial (Bloom et al, 2013) and non-experimental evidence in Table 3, we assume that a one standard deviation increase in management causes a $10 \%$ increase in TFP. For example, we can estimate that improving Greece's weighted average management score to that of the U.S. (a 1.3 standard deviation increase) would increase Greek TFP by $13 \%$, about a third of the $37.5 \%$ TFP gap between Greece and the U.S. Column (7) contains similar calculations for the other countries. Overall, on average $30 \%$ of the cross country gap in TFP appears to be management related (see base of column (7)). ${ }^{43}$ This fraction varies a lot between countries. In general we account for a smaller fraction of the TFP gap between the U.S. and low income countries like Zambia (6.2\%), Ghana (9.7\%), and Tanzania (12\%), which is likely to be because these countries have much greater productivity impediments than just management quality. We account for a larger fraction of the

\footnotetext{
${ }^{41}$ Interestingly, these results are broadly consistent with Bartelsman et al (2013) who conducted a similar analysis for productivity on a smaller number of countries but with larger samples of firms. Although the countries we examine do not perfectly overlap, the ranking in Bartelsman et al (2013) also has the U.S. at the top with Germany second and then France. Britain does somewhat better in our analysis, being above France, but our data is more recent (2006-2014 compared to their 1992-2001) and Bartelsman et al (2013) note that Britain's reallocation position improved in the 2000s (their footnote 9 ).

${ }^{42}$ We used the latest information from 2011, but qualitative results are stable if we take an average over a larger number of years. When data was missing we impute using values in Jones and Romer (2010).

${ }^{43}$ For the seven countries where it is possible to calculate manufacturing TFP, the correlation with whole economy TFP is 0.94 . The average proportion of the manufacturing TFP gap accounted for by management in these countries was $32.6 \%$. We also find that our manufacturing management scores are highly correlated with the management scores in other sectors like retail, healthcare, schools and government services (see Chong et al. 2014), so that the manufacturing management score appears to be a good measure of overall national management quality.
} 
TFP gap between the U.S. and richer countries like Sweden (43.9\%), Italy (48.9\%) and France (52.3\%). Figure A5 graphically illustrates this, showing that more developed countries have a higher share of their TFP gap accounted for by differences in management.

In Appendix B we consider a wide variety of robustness tests of these basic findings, and these are summarized in Table 8. Row 1 gives the baseline result from Table 7. Row 2 drops pre-2006 data and row 3 drops all panel observations apart from the entry year. We change the selection equation underlying the sample weights used to correct for non-random response by using only size (dropping listing status, age and industry dummies) in row 4 . Row 5 gives the results without any selection correction, Row 6 includes multinationals, and Row 7 uses an alternative measure of size, using an index of weighted inputs (capital and labor). We were concerned that we did not run our survey on very small (under 50 workers) and very large firms (over 5,000 workers), so we repeated our analysis on a sub-sample of countries where we have detailed information on the firm size distribution in the population. Knowing the full size distribution allows us to make a selection correction for the fact we only observe medium sized firms (Appendix B.2). Row 8 has the baseline results on these countries and row 8 implements the correction.

Although the exact quantitative findings change across Table 8, the qualitative results are very robust to these alternative modeling details. The fraction of the TFP gap explained by management is non-trivial, ranging from $20 \%$ to $50 \%$ (column (5)). The correlation of relative management gaps between the baseline estimates and alternatives estimation techniques (column (3)) never falls below 0.85 and the correlation of the fraction of TFP explained by management (column (6)) with baseline results never falls below 0.89 .

We can also look at the within country/cross-firm dimension for those countries where we have detailed productivity data. For example, the average industry TFP spread between the $90^{\text {th }}$ and $10^{\text {th }}$ percentiles is $90 \%$ in U.S. manufacturing (Syverson, 2011), so with our spread of management (2.55 standard deviations between the 90-10) we can account for $28 \%$ of the TFP spread $\left(=\left(2.55^{*} 0.1\right) / 0.9\right) .{ }^{44}$ Repeating the same calculations for other countries in our sample for which reliable information exists on TFP dispersion (Australia, Chile, France, Italy, Japan, New Zealand, Sweden and the U.K.) using data drawn from the OECD (2016) ${ }^{45}$ and Disney et al. (2000), shows that on average $19 \%$ of the $90-10$ TFPR spread is management-related as shown in Table 9 . Hence, variations in management practices appear to account for about one-fifth of the dispersion in TFP across firms within countries.

\footnotetext{
${ }^{44}$ We obtain a similar share of dispersion potentially accounted for by management if instead we examine TFPQ using the results from Foster, Haltiwanger and Syverson (2008). While Foster et al. (2008) do not provide data on the 90-10 spread for TFPQ in their data they do provide the standard deviation which is 0.67 (compared to 0.56 for TFP) which for a normal distribution would imply a 90-10 spread of 95\%, implying management would again account for about $27 \%$ of the dispersion.

${ }^{45}$ We are grateful to Chiara Criscuolo for making the TFP data accessible to us.
} 


\section{Conclusions}

Economists, business people and many policymakers have long believed that management practices are an important element in productivity. We collect original cross sectional and panel data on over 11,000 firms across 34 countries to provide robust firm-level measures of management in an internationally comparable way. We detail a formal model where our management measures have "technological" elements. In the model, management enters as an intangible capital stock in the production function and raises output. We allow entrants to have an idiosyncratic endowment of managerial ability, but also to endogenously change management over time (alongside other factor inputs, some of which are also costly to adjust like non-managerial capital). We show how the qualitative predictions of this model are consistent with the data, as well as presenting structural estimates to recover some key parameters (such as the cost of adjustment and depreciation rates of managerial capital).

Our empirical findings are easily summarized. First, firms who scored more highly in our management quality index improved firm performance in both non-experimental and experimental settings. Second, in the cross section and panel dimension, firms in sectors facing greater competition were more likely to have better management practices. Part of this competition effect is due to stronger reallocation effects, whereby the better managed firms are rewarded with more market share in some countries compared to others. Third, as cohorts of firms age, the average level of management increases and dispersion decreases (due to selection). Finally, we use the model to show that management accounts for about $30 \%$ of a nation's TFP deficit with the U.S. across countries.

There are many directions to take this work. It would be useful to examine the determinants of management practices in greater detail. We have focused on market-based incentives, but informational frictions and coordination may be equally if not more important. Gibbons and Henderson (2012), for example, argue that the need to coordinate a multitude of dispersed agents within a firm is critical. ${ }^{46}$

We would also like to test other implications of the management as a technology model. First, that management is at least partly non-rival, which should lead to management spillovers as firms learn from each other. This is analogous to the R\&D or peer effects literature, and techniques can be borrowed from this body of work. Second, our model will also predict that well-managed firms should take-over badly managed firms to internalize these spillovers, which should be evaluated as part of the large literature on mergers and acquisitions. Finally, while we focus on the evidence supporting our "Management as a Technology" interpretation, our contingency results support a design channel too. A richer model encompassing both the design and technology approaches would be needed to fully explore this result. We hope our work opens up a research agenda on why there appear to be so many poorly managed firms and what factors can help improve management, and thus increase the aggregate wealth of nations.

\footnotetext{
${ }^{46}$ The coordination role of CEOs is empirically explored in Bandiera et al. (2017).
} 


\section{References}

Ackerberg, Daniel, Kevin Caves and Garth Frazer "Structural Identification of Production Functions" Econometrica, 83(6): 2411-2451

Adhvaryu, Achyuta, Namrata Kala and Anant Nyshadham, 2016, "Management and shocks to worker productivity", Michigan mimeo.

Akcigit, Ufuk, Harun Alp and Michael Peters. 2016. "Lack of selection and limits to delegation: firm dynamics in developing countries", Chicago mimeo.

Aghion, Philippe, Nick Bloom, Richard Blundell, Rachel Griffith, and Peter Howitt. 2005. "Competition and Innovation: An inverted U relationship." Quarterly Journal of Economics, 120(2): 701-728.

Alessandria, George and Horag Choi. 2007. "Do Sunk Costs of Exporting Matter for Net Export Dynamics?" Quarterly Journal of Economics, 122(1): 289-336.

Autor, David, David Dorn and Gordon Hanson. 2013. "The China Syndrome: Local Labor Market Effects of Import Competition in the United States", American Economic Review, 2121-68.

Autor, David, Frank Levy and Richard Murnane. 2002. "Upstairs, Downstairs: Computers and Skills on Two Floors of a Large Bank." Industrial and Labor Relations Review, 55(3): 432-447.

Atalay, Enghin, Ali Hortascu and Chad Syverson. 2014. "Vertical integration and input flows", American Economic Review, 104(2): 1120-48

Atkin, Dave, Azam Chaudhry, Shamyla Chaudry, Amit Khandelwal and Erik Verhoogen. 2017. "Organizational barriers to technology adoption: evidence from soccer-ball production in Pakistan", Quarterly Journal of Economics, 132(3): 1101-1164

Baker, George and Ricard Gil. 2013. "Clinical papers in Organizational Economics" in Robert Gibbons and John Roberts (eds) Handbook of Organizational Economics. Princeton: Princeton University Press.

Bandiera, Oriana, Stephen Hansen, Andrea Prat and Raffaella Sadun. 2017. "CEO Behavior and Firm Performance", NBER Working Paper 23248.

Bartelsman, Erik, John Haltiwanger, and Stefano Scarpetta. 2013. "Cross Country Differences in Productivity: The Role of Allocation and Selection." American Economic Review, 103(1): 305-334.

Bertrand, Marianne and Antoinette Schoar. 2003. "Managing with Style: The Effect of Managers on Firm Policies." Quarterly Journal of Economics, 118(4): 1169-1208.

Bloom, Nick. 2009. "The impact of uncertainty shocks", Econometrica, 77(3): 623-685.

Bloom, Nicholas and John Van Reenen. 2007. "Measuring and Explaining Management Practices across Firms and Countries." Quarterly Journal of Economics, 122(4): 1341-1408.

Bloom, Nicholas, Ben Eifert, Abarjit Mahajan, David McKenzie and John Roberts. 2013. "Does management matter? Evidence from India." Quarterly Journal of Economics, 128(1): 1-51.

Bloom, Nicholas, Raffaella Sadun and John Van Reenen. 2012. "Americans do I.T. Better: American Multinationals and the Productivity Miracle." American Economic Review, 102(1): 167-201.

Bloom, Nicholas, Mirko Draca and John Van Reenen. 2016. "Trade Induced Technical Change? The Impact of Chinese Imports on Innovation, IT and Productivity?" Review of Economic Studies, 83(1): 87-117. 
Bloom, Nicholas, Erik Brynjolfsson, Lucia Foster, Ron Jarmin, Megha Patnaik, Itay SaportaEksten and John Van Reenen. 2017. "What drives Management Practices?" Center for Economic Performance Discussion Paper 1470

Blundell, Richard and Stephen Bond. 2000. "GMM Estimation with persistent panel data: an application to production functions" Econometric Reviews, 19(3): 321-340

Braguinsky, Serguey, Atsushis Ohyama, Tetsuji Okazaki and Chad Syverson. 2015. "Acquisition, Productivity and Profitability: Evidence from the Japanese Cotton Spinning Industry." American Economic Review, 105(7): 2086-2119.

Bruhn, Miriam, Dean Karlan and Antoinette Schoar. 2010. "What Capital is Missing in Developing Countries." American Economic Review, 100(2): 629-633.

Bruhn, Miriam, Dean Karlan and Antoinette Schoar. 2016. "The Impact of Consulting Services on Small and Medium Enterprises: Evidence from a Randomized Trial in Mexico." Journal of Politically Economy, forthcoming.

Bresnahan, Timothy, Erik Brynjolfsson, and Lorin Hitt. 2002. "Information Technology, Workplace Organization and the Demand for Skilled Labor: Firm-level Evidence." Quarterly Journal of Economics, 117(1), 339-376.

Capelli, Peter and David Neumark, 2001. 'Do 'High-Performance' Work Practices Improve EstablishmentLevel Outcomes?', Industrial and Labor Relations Review, 54(4): 737-775.

Card, David, Jorg Heining and Patrick Kline. 2013. "Workplace Heterogeneity and the Rise of West German Wage Inequality." Quarterly Journal of Economics, 128(3): 967-1015.

Chirinko, Robert. 1993. "Business Fixed Investment Spending: Modeling Strategies, Empirical Results, and Policy Implications." Journal of Economic Literature, 31(4): 1875-1911.

Chong, Alberto, Rafael La Porta, Florencio Lopez-de-Silanes and Andrei Shleifer. 2014. "Letter Grading Government Efficiency" Journal of the European Economic Association, 12(2): 277-299.

Corrado, Carol and Charles Hulten. 2010. "How do you Measure a Technological Revolution?" American Economic Review, 100(2): 99-104.

Davis, Steven, John Haltiwanger, Kyle Handley, Ron Jarmin, Josh Lerner, and Javier Miranda. 2014. "Private Equity, Jobs, and Productivity" American Economic Review 104(12): 3956-3990

Cyert, Richard and James March. 1963. A Behavioral Theory of the Firm. Englewood Cliffs, NJ: Prentice-Hall.

Disney, Richard, Jonathan Haskel and Ylva Heden. 2003. "Restructuring and Productivity Growth in U.K. Manufacturing," Economic Journal, 113(489): 666-694.

Edmans, Alex and Xavier Gabaix. 2017. "Executive Compensation: A Modern Primer" Journal of Economic Literature 54(4): 1232-87

Feenstra, Robert and John Romalis. 2012. "International Prices and Endogenous Quality." NBER Working Papers 18314.

Feenstra Robert, Robert Inklaar and Marcel P. Timmer. 2015. "The Next Generation of the Penn World Tables." American Economic Review, 105(10): 3150-3182.

Foster, Lucia, John Haltiwanger and Chad Syverson. 2008. "Reallocation, Firm Turnover, and Efficiency: Selection on Productivity or Profitability?" American Economic Review, 98(1): 394425. 
Gancia, Gino, Andreas Mueller and Fabrizio Zilibotti. 2013. "Structural Development Accounting" in Advances in Economics and Econometrics: Theory and Applications Daron Acemoglu, Manuel Arellano and Edward Dekel (eds.), Cambridge: Cambridge University Press

Garicano, Luis and Estaban Rossi-Hansberg. 2015. "Knowledge-Based Hierarchies: Using Organizations to Understand the Economy" Annual Review of Economics, 7(1): 1-30

Gennaioli, Nicola, Rafael La Porta, Florencio Lopez-de-Silvanes and Andrei Shleifer. 2013. "Human Capital and Regional Development" Quarterly Journal of Economics 128(1): 105-164

Gibbons, Robert and John Roberts. 2013. The Handbook of Organizational Economics. Princeton: Princeton University Press.

Gibbons, Robert and Rebecca Henderson. 2012. "Relational Contracts and Organizational Capabilities." Organizational Science, 23(5): 1350-1364.

Giorcelli, Michela. 2016. "The Long Term Effects of Management and Technology Transfer." Stanford mimeo.

Greenstone, Michael, Richard Hornbeck, and Enrico Moretti. 2010. "Identifying Agglomeration Spillovers: Evidence from Winners and Losers of Large Plant Openings." Journal of Political Economy, 118(3): 536-598.

Griliches, Zvi. 1957. "Hybrid corn: An exploration in the economics of technological change." Econometrica, 25, 501-522.

Griliches, Zvi. 1998. REDD and Productivity: The Econometric Evidence. Chicago: Chicago University Press.

Guner, Nezih and Gustavo Ventura. 2014. "Managers and Productivity Differences." ASU mimeo. Hall, Robert and Charles Jones. 1999. "Why Do Some Countries Produce so Much More Output per Worker than Others?" Quarterly Journal of Economics, 114(1): 83-116.

Helper, Susan and Rebecca Henderson. 2014. "Management Practices, Relational Contracts, and the Decline of General Motors." Journal of Economic Perspectives, 28(1):49-72.

Helpman, Elhanan, Marc Melitz, and Stephen Yeaple. 2004. "Export versus FDI with Heterogeneous Firms." American Economic Review, 94(1): 300-316.

Hopenhayn, Hugo. 1992. "Entry, Exit and Firm Dynamics in Long-Run Equilibrium." Econometrica, 60(5): 1127-50.

Hsieh, Chiang-Tai and Pete Klenow. 2009. "Misallocation and Manufacturing TFP in China and India." Quarterly Journal of Economics, 124(4): 1403-1448.

Huselid, Mark, 1995. "The Impact of Human Resource Management Practices on Turnover, Productivity and Corporate Financial Performance", Academy of Management Journal, 38: 635-672.

Ichniowski, Casey, Kathryn Shaw, and Giovanna Prennushi. 1997. "The Effects of Human Resource Management Practices on Productivity: A Study of Steel Finishing Lines." American Economic Review, 87(3): 291-313.

König, Michael, Jan Lorenz and Fabrizio Zilibotti. 2016. "Innovation vs. Imitation and the Evolution of Productivity Distributions." Theoretical Economics 11(3): 1053-1102. 
Lazear, Edward, Kathryn Shaw and Christopher Stanton. 2015. "The Value of Bosses" Journal of Labor Economics 33(4): 823-861.

Lemieux, Thomas, Bentley MacLeod and Daniel Parent. 2009. "Performance pay and wage inequality", Quarterly Journal of Economics, 124(1): 1-49.

Lucas, Robert. 1978. "On the Size Distribution of Business Firms." Bell Journal of Economics, 9(2): 508-523.

McKenzie, David and Christopher Woodruff. 2013. "What Are We Learning from Business Training and Entrepreneurship Evaluations around the Developing World?" World Bank Research Observer, July, 1-35

McKenzie, David and Christopher Woodruff. 2017. "Business Practices in Small Firms in Developing Countries" Management Science 63(9): 2967-2981.

Melitz, Marc. 2003. "The Impact of Trade on Intra-Industry Reallocations and Aggregate Productivity Growth." Econometrica, 71(6): 1695-1725.

Milgrom, Paul. 1988. "Employment Contracts, Influence Activities, and Efficient Organization Design." Journal of Political Economy, 96(1): 42-60.

OECD. 2016. "The Productivity-Inclusiveness Nexus". mimeo, Paris:OECD

Olley, Steve and Ariel Pakes. 1996. "The Dynamics of Productivity in the Telecommunications Industry", Econometrica, 64(6): 1263-1297.

Osterman, Paul, 1994. 'How Common Is Workplace Transformation and Who Adopts It?', Industrial and Labor Relations Review, 47(2): 173-188 .

Prescott, Edward and Michael Visscher. 1980. "Organization Capital." Journal of Political Economy, 88(3): 446-61.

Ramey, Valerie and Mathew Shapiro. 2001. "Displaced Capital: A Study of Aerospace Plant Closings." Journal of Political Economy, 109(5): 958-992.

Restuccia, Diego and Richard Rogerson. 2008. "Policy Distortions and Aggregate Productivity with Heterogeneous Establishments." Review of Economic Dynamics, 11(4): 707-720.

Stokey, Nancy, Robert Lucas and Edward Prescott. 1989. Recursive Methods in Economic Dynamics. Cambridge: Harvard University Press.

Syverson, Chad. 2011. "What Determines Productivity?" Journal of Economic Literature, 49(2): 326-365.

Woodward Joan. 1958. Management and Technology. Cambridge: Cambridge University Press.

Walker, Francis. 1887. "The Source of Business Profits." Quarterly Journal of Economics. 1(3): 265-288. 


\section{Figure 1: Average Management Scores by Country}

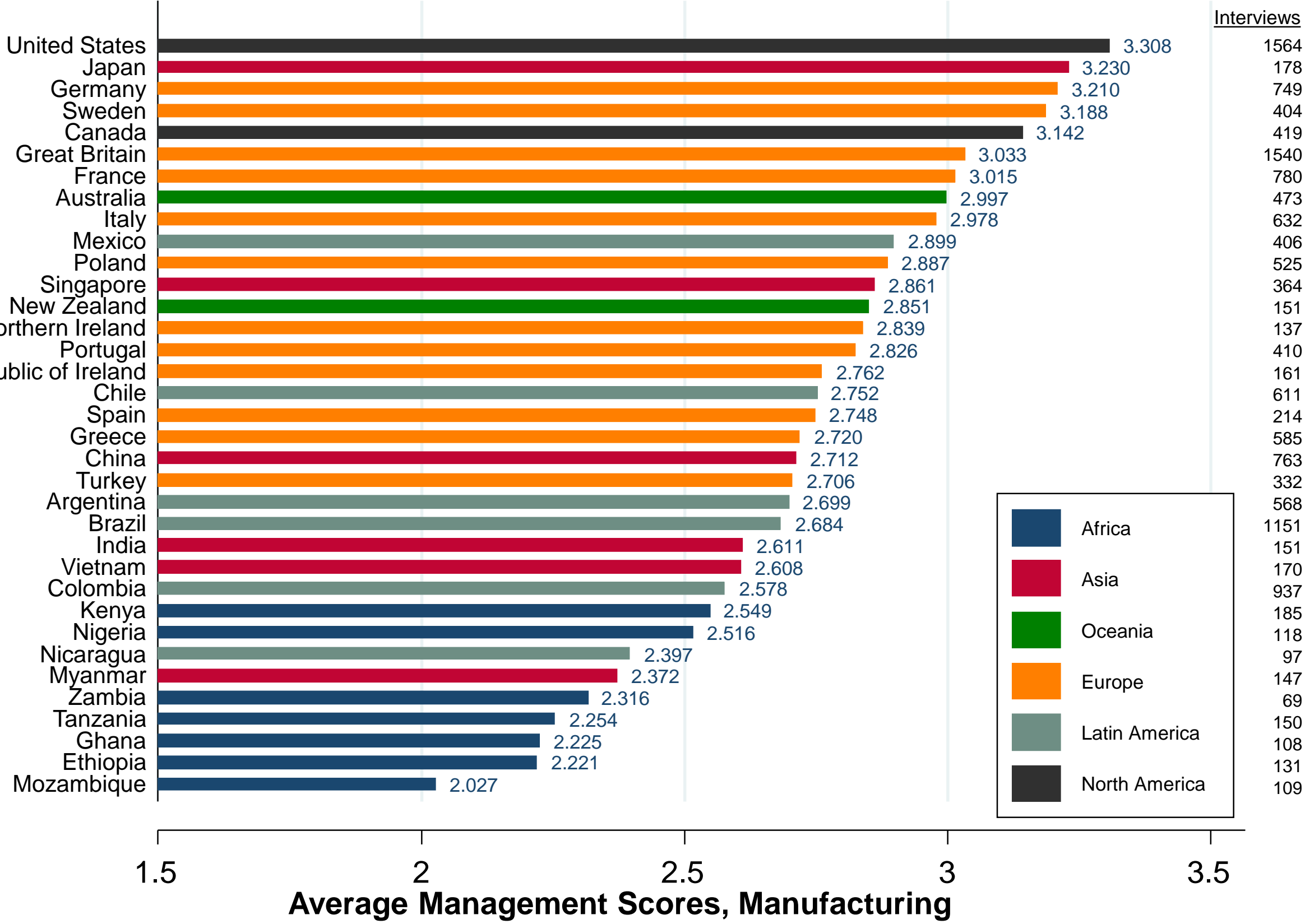

Note: Unweighted average management scores; \# interviews in right column (total =15,489); all waves pooled (2004-2014) 


\section{Figure 2: Management Practice Scores Across Firms}

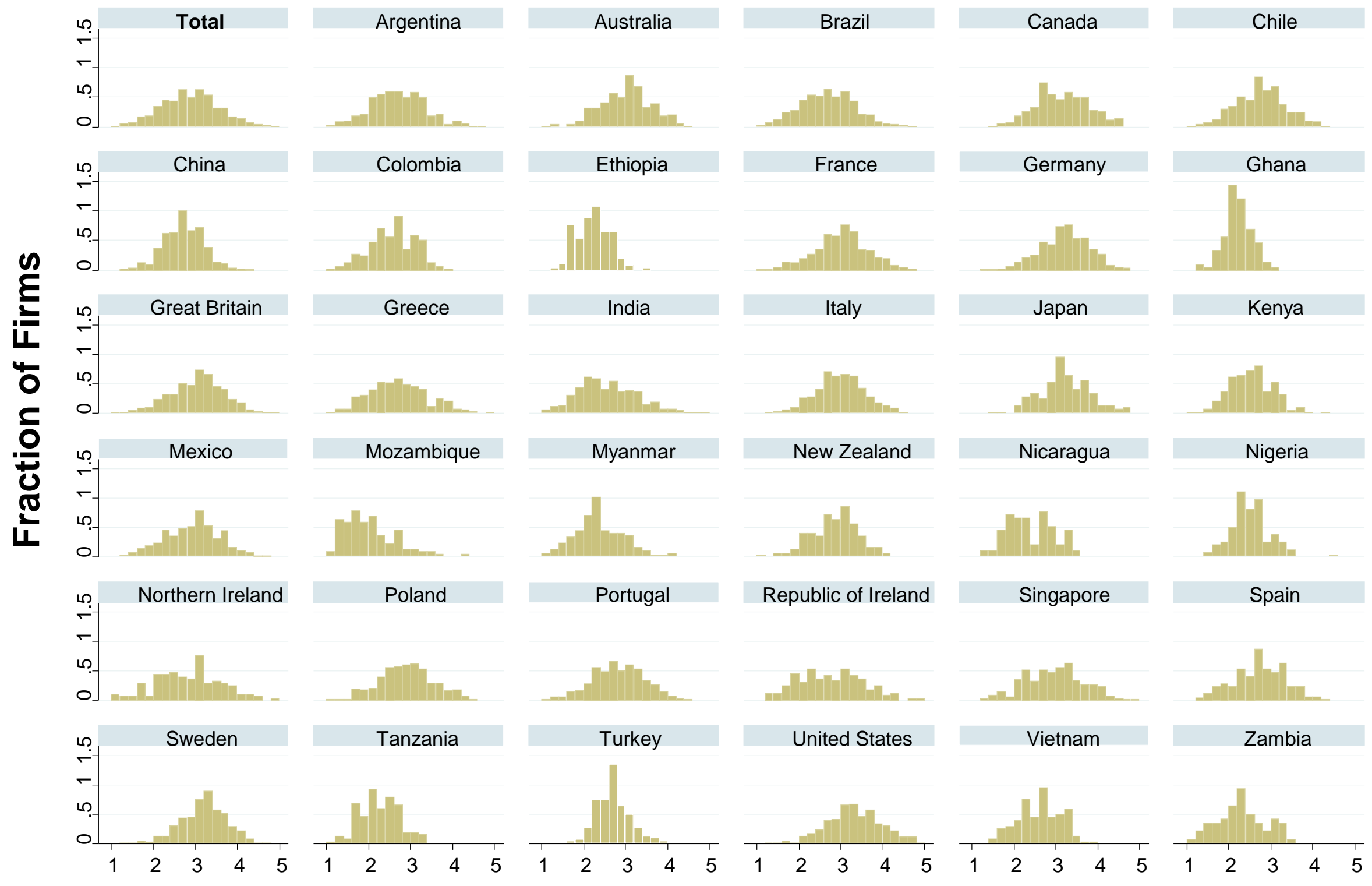

Firm level average management scores, $\mathbf{1}$ (worst practice) to 5 (best practice)

Note: Bars are the histogram of the actual density. 15,489 interviews. 


\section{Figure 3: Management Spreads: Data and Simulation}
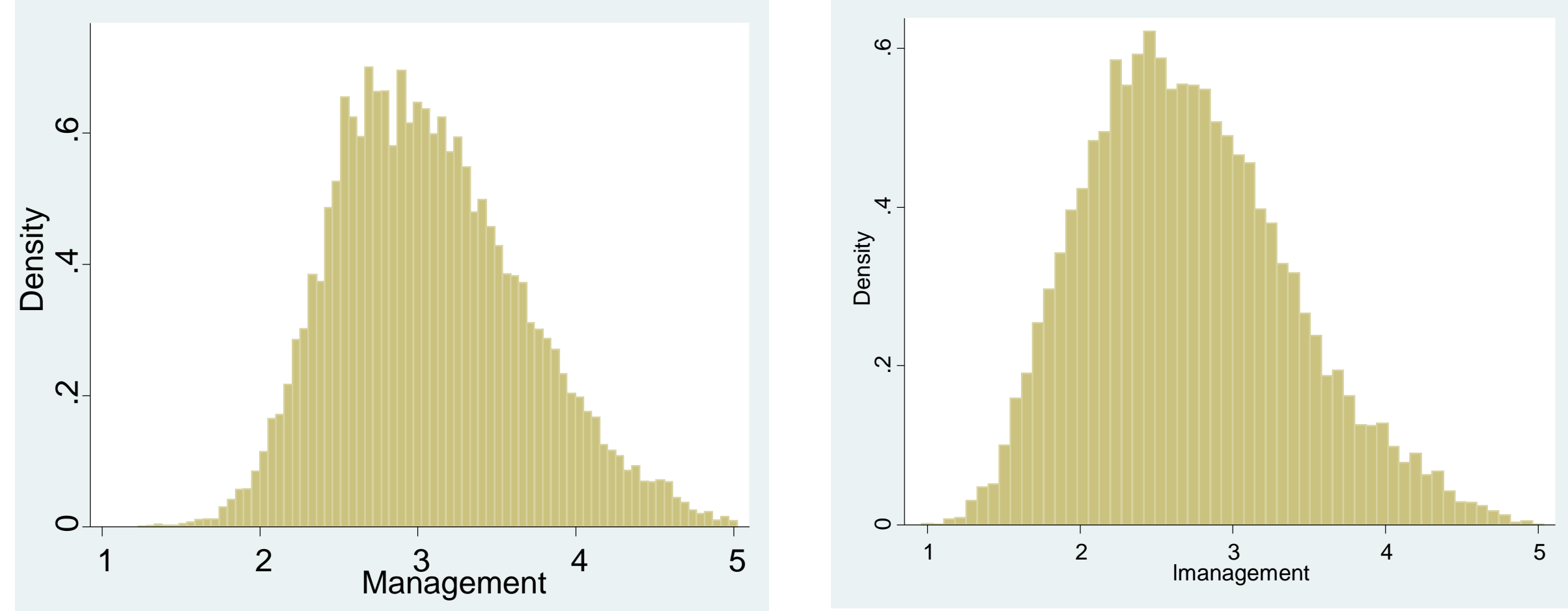

Notes: The left plot is the management distribution for our entire sample of 15,489 firm surveys. The right plot is the histogram for a simulation of 15,489 simulated firm-years, where management has been logged and scaled onto a 1 to 5 range. Replication file on http://web.stanford.edu/ nbloom/MAT.zip 


\section{Figure 4: Management and Competition - Simulations}

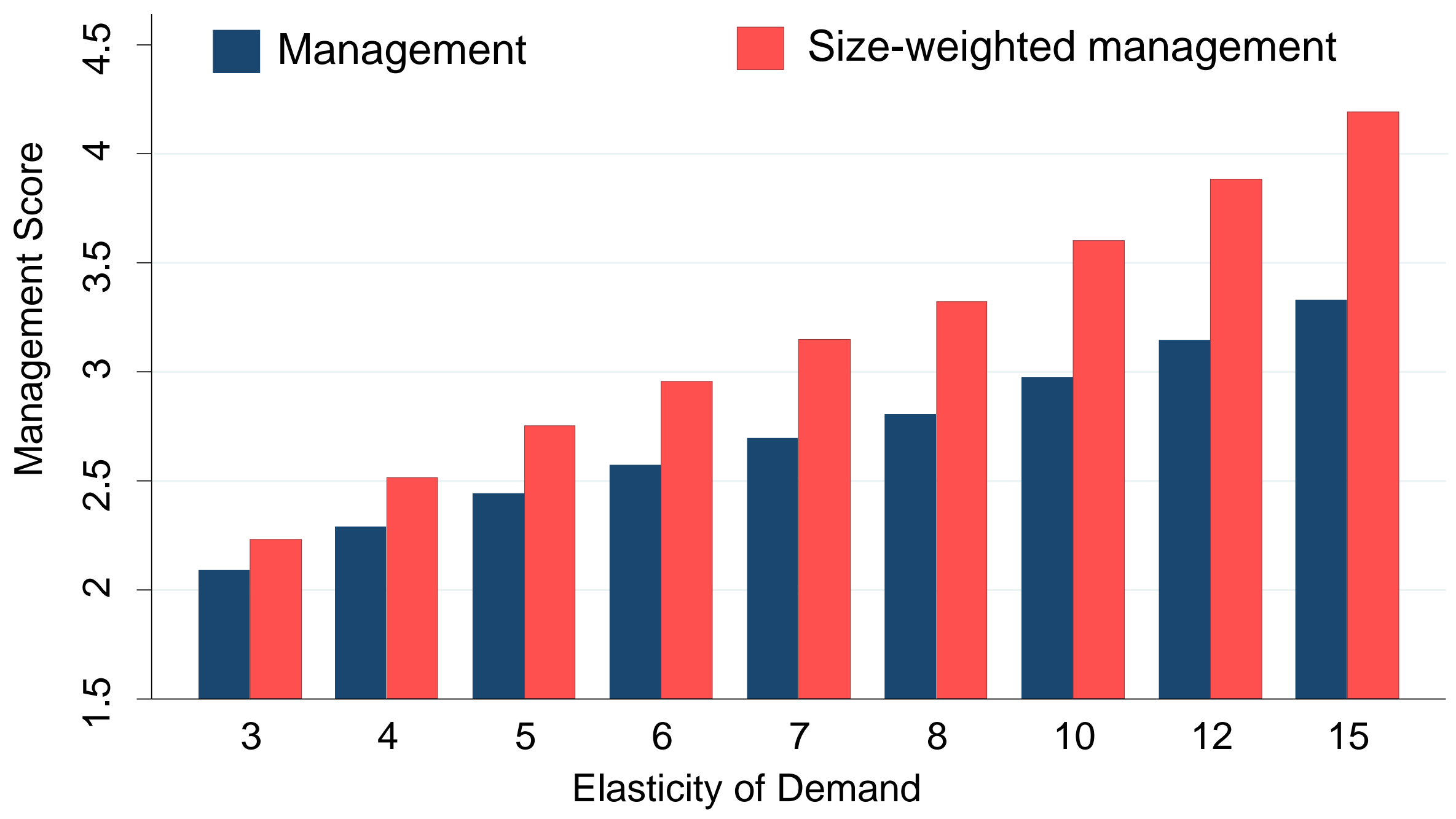

Notes: Results from using our estimated MAT model to simulate 5,000 firms per year in the steady state. Plots log(management) in the simulation data normalized onto a 1 to 5 scale, and log(sales). Competition is index by demand elasticity $(\rho=5)$ in baseline. Dark Blue bar is unweighted mean across firms, Light Red bar is weighted by firm size (employees). Replication file on http://web.stanford.edu/ nbloom/MAT.zip 


\section{Figure 5: Management and Firm Age - Simulations}

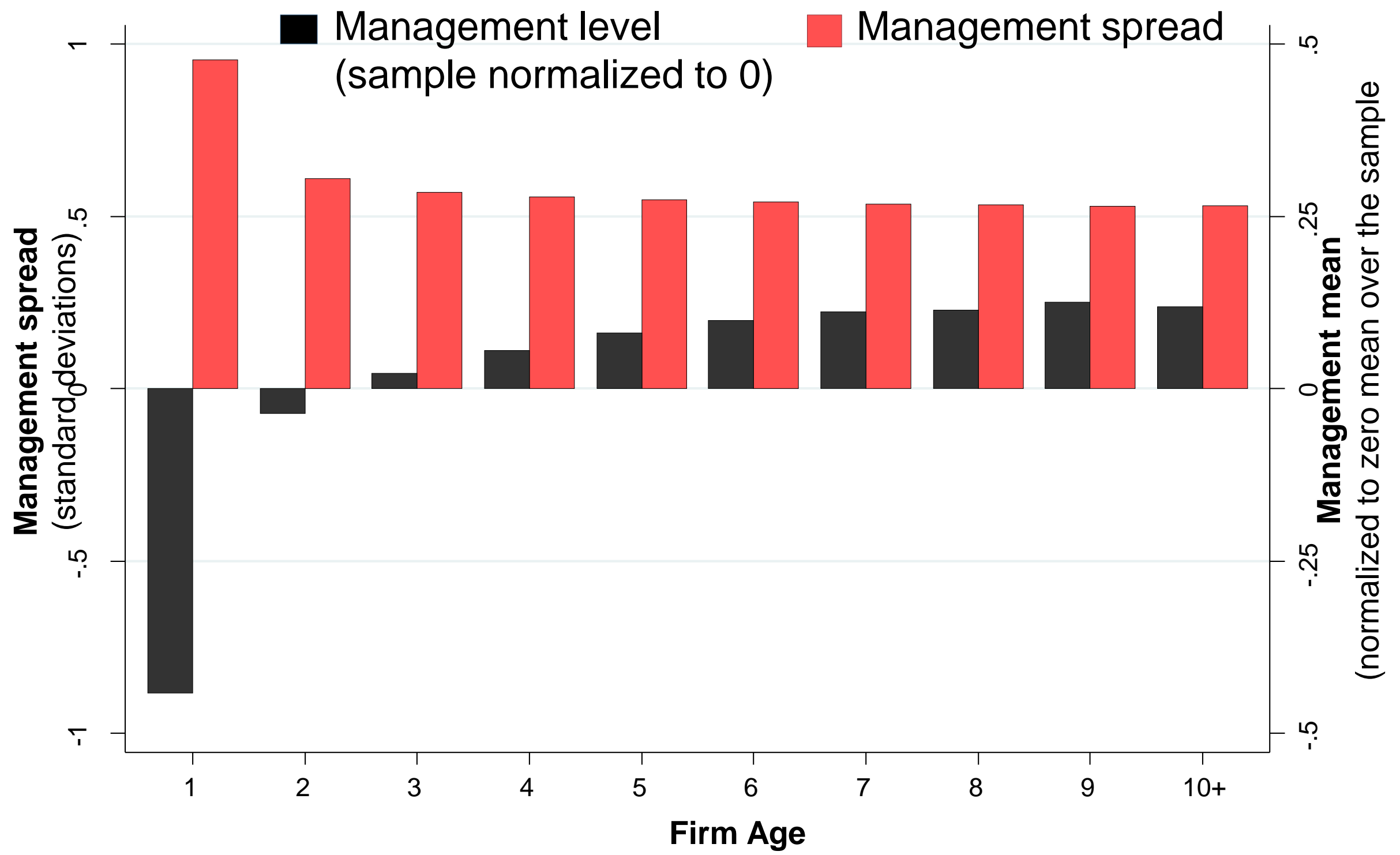

Notes: Plots In(management) scores weighted by age. Results from simulating 5,000 firms per year in the steady state taking the last 10 years of data and defining age based on the number of observed years. Management normalized to zero on the sample. Replication file on http://web.stanford.edu/ nbloom/MAT.zip 


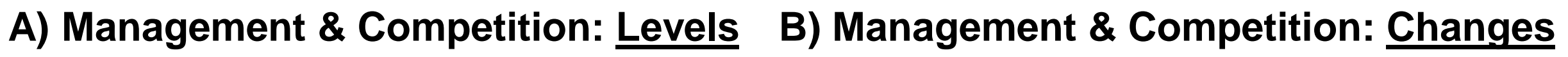
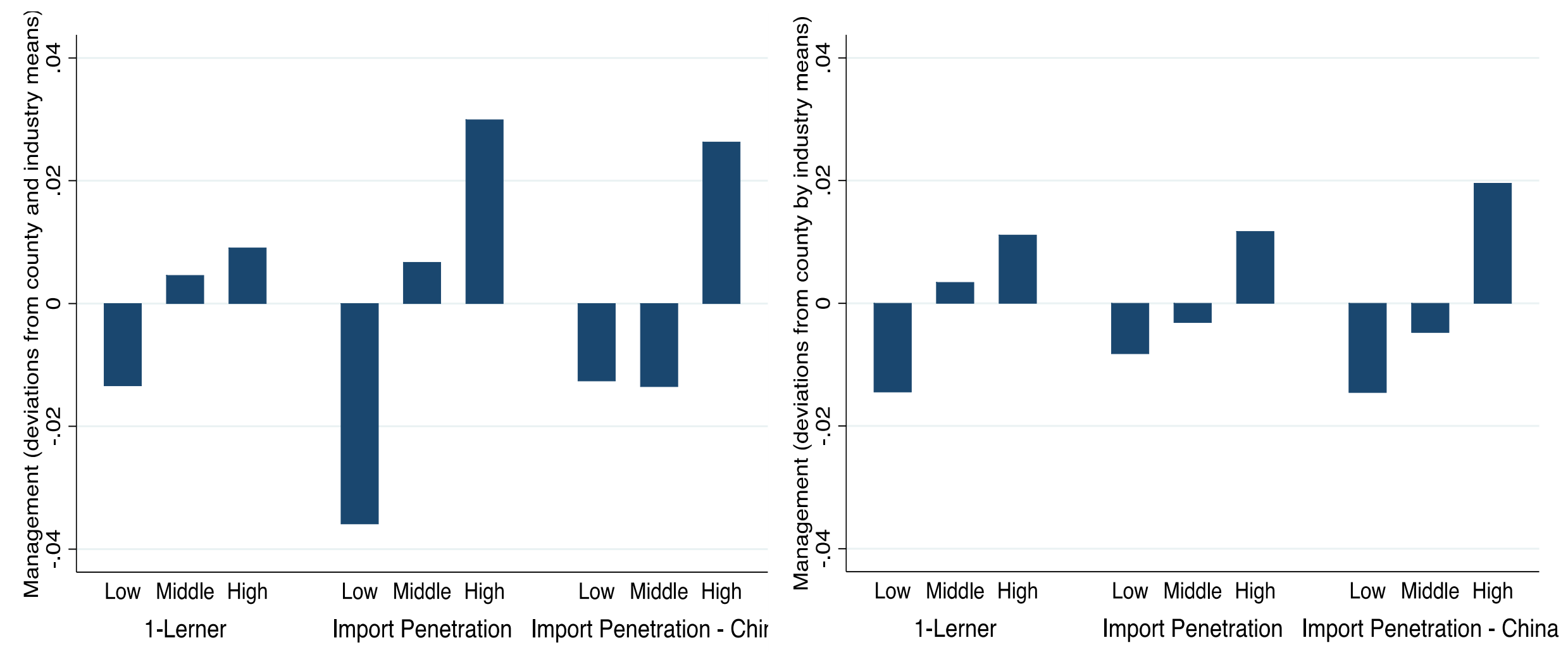

Notes: Competition proxies are 1-Lerner = median firm profits/sales, Imports = imports/apparent consumption, Imports China = imports from China/apparent consumption, all in industry by country cell. In "levels" panels control for linear country \& industry average. "Changes" are in deviations from time-specific country by industry dummies. 
Figure 8. Management and Age - Data

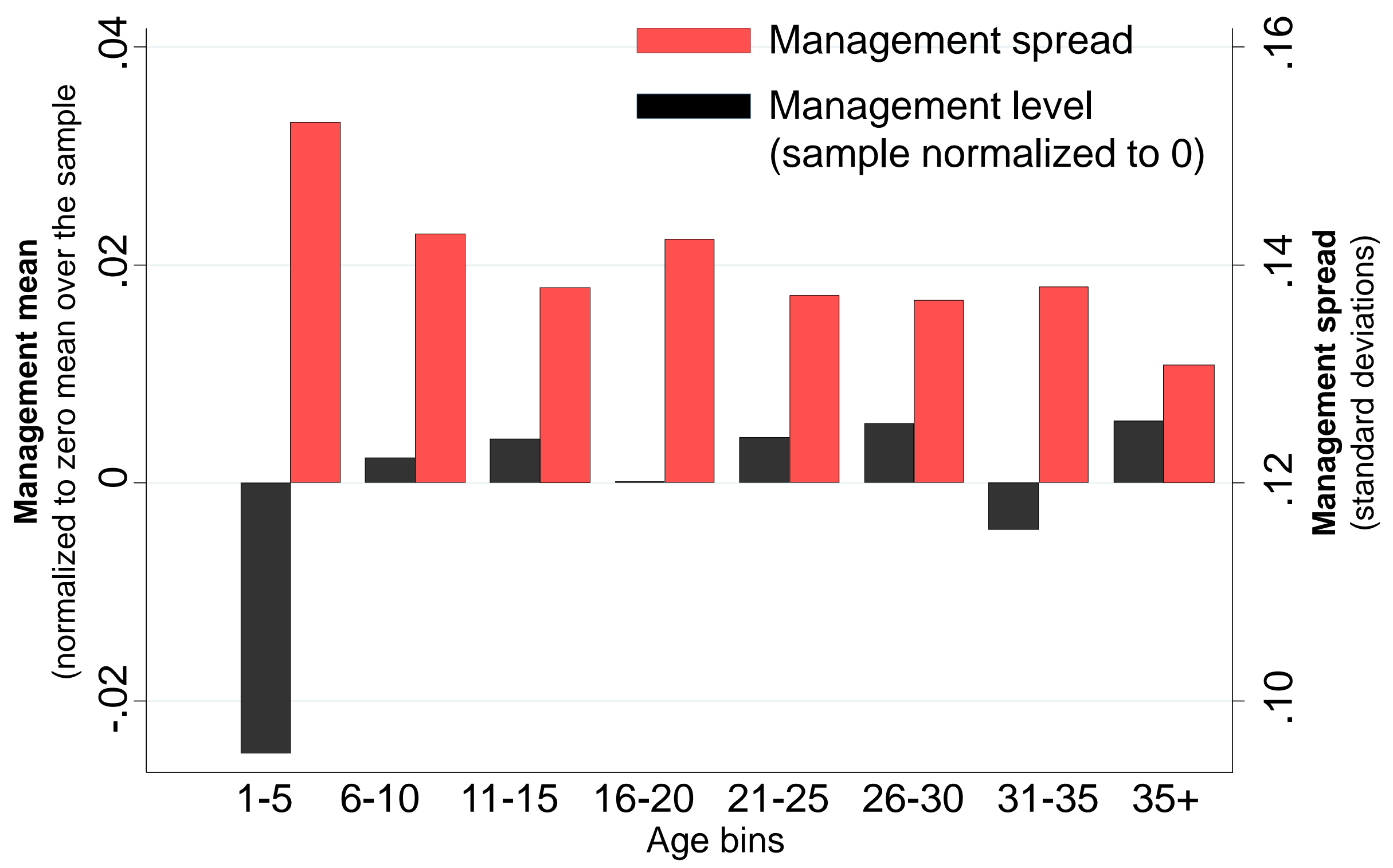

Notes: Data from 31,793 plants from the Management and Organizational Practices supplement to the 2010 Annual Survey of Manufacturing, run by the US Census. Mean management in deviation from the sample mean. Management score from 0 (no modern practices adopted) to 1 (all 16 modern management practices adopted). 


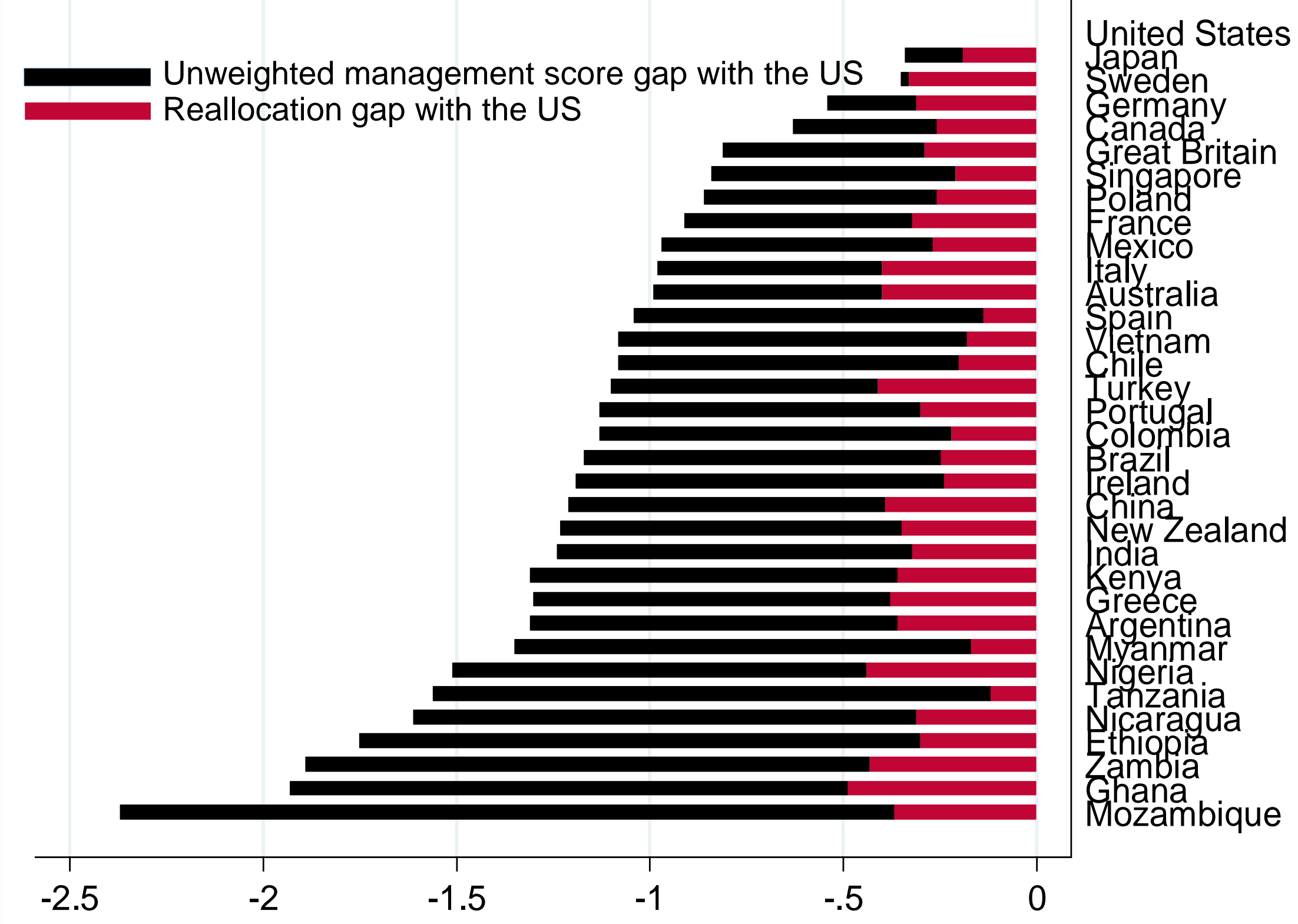

Notes: Share-weighted management score differences relative to the US (in terms of management score standard deviations). Length of bar shows total deficit, composed of the sum of the (i) the unweighted average management scores (black bar) and the Olley-Pakes reallocation effect (red bar). Domestic firms only with management scores corrected for sampling selection bias. 
TABLE 1: CALIBRATED PARAMETERS FROM THE LITERATURE

\begin{tabular}{|c|c|c|c|}
\hline Parameter & Symbol & value & Rationale \\
\hline Output-labor elasticity & $\beta$ & 0.6 & NIPA factor share. \\
\hline Output-management elasticity & $\gamma$ & 0.1 & Bloom et al (2013) \\
\hline Output-capital elasticity & $\alpha$ & 0.3 & Implied from Constant Returns \\
\hline Demand elasticity & $\rho$ & 5 & Bartelsman et al (2013) \\
\hline AR(1) parameter on $\ln (\mathbf{T F P})$ & $\rho_{A}$ & 0.885 & Cooper and Haltiwanger(2006) \\
\hline Standard deviation of $\ln (\mathrm{TFP})$ & $\sigma_{\mathrm{A}}$ & 0.453 & Cooper and Haltiwanger(2006)* \\
\hline Discount Factor & $\beta$ & $1 / 1.1$ & Standard $10 \%$ interest rate \\
\hline Capital depreciation rate & $\delta_{\mathrm{K}}$ & $10 \%$ & Standard accounting assumption \\
\hline Capital resale loss & $\phi_{\mathrm{K}}$ & $50 \%$ & Ramey and Shapiro (2001) \\
\hline
\end{tabular}

Notes: The production function in MAT is $Y_{i}=\tilde{A}_{i} K_{i}^{1-\beta-\gamma} L_{i}^{\beta} M_{i}^{\gamma}$ and the revenue function is $(P Y)_{i}=A_{i} K_{i}^{a} L_{i}^{b} M_{i}^{c}$ Fixed cost of production is normalized to 100 and mean of $\ln$ (TFP) is normalized to 1 .

* Assumes measurement error on measured TFP has the same variance as true TFP as estimated in Bloom et al (2013). 
TABLE 2: ESTIMATED PARAMETERS USING SIMULATED METHOD OF MOMENTS

\section{PANEL A: PARAMETER ESTIMATES FROM SMM}

\begin{tabular}{lll}
\hline \hline Parameter & Symbol & Value \\
\hline Depreciation rate of management & $\delta_{\mathrm{M}}$ & $0.119(0.053)$ \\
Adjustment cost parameter for management & $\gamma_{\mathrm{M}}$ & $0.212(0.062)$ \\
Adjustment cost parameter for capital & $\gamma_{\mathrm{K}}$ & $0.195(0.047)$ \\
\hline \hline
\end{tabular}

PANEL B: MOMENTS USED IN SMM ESTIMATES

\begin{tabular}{lcc}
\hline \hline Parameter & Simulated Value & Data Value \\
\hline Standard deviation of 5 year management growth & 0.554 \\
Standard deviation of 5 year sales growth & 0.929 \\
Standard deviation of 5 year capital growth & 0.870 \\
\hline \hline
\end{tabular}

Notes: These are the parameters we estimate using the model (see text). Calibrated parameters from Table 1. Estimation by SMM on the management- accounting panel dataset of up to 4907 firms. Standard errors generated by moment block-bootstrap and moment derivatives taken around the estimated parameter values. 
TABLE 3: PERFORMANCE REGRESSIONS

\begin{tabular}{|c|c|c|c|c|c|c|c|c|c|c|}
\hline & (1) & (2) & (3) & (4) & (5) & (6) & (7) & (8) & (9) & (10) \\
\hline $\begin{array}{l}\text { Dependent } \\
\text { variable }\end{array}$ & $\begin{array}{c}\text { Ln } \\
\text { (Value } \\
\text { Added) }\end{array}$ & $\begin{array}{c}\text { Ln } \\
\text { (Value } \\
\text { Added) }\end{array}$ & $\begin{array}{c}\text { Ln } \\
\text { (Value } \\
\text { Added) }\end{array}$ & $\begin{array}{c}\text { Ln } \\
\text { (Value } \\
\text { Added) }\end{array}$ & $\begin{array}{c}\text { Ln } \\
\text { (Value } \\
\text { Added) }\end{array}$ & $\begin{array}{c}\text { Ln } \\
\text { (Employees) }\end{array}$ & $\begin{array}{l}\text { Profitability } \\
\text { (ROCE, \%) }\end{array}$ & $\begin{array}{c}5 \text { year } \\
\text { Sales } \\
\text { growth }\end{array}$ & $\begin{array}{c}\text { Ln } \\
(\text { Tobin q) }\end{array}$ & $\begin{array}{c}\text { Survival } \\
(\%)\end{array}$ \\
\hline Method & OLS & OLS & OLS & $\begin{array}{c}\text { Fixed } \\
\text { Effects }\end{array}$ & $\begin{array}{l}\text { Olley } \\
\text { Pakes }\end{array}$ & OLS & OLS & OLS & OLS & OLS \\
\hline $\begin{array}{l}\text { Management } \\
\text { (z-score) }\end{array}$ & $\begin{array}{c}0.316 * * * \\
(0.017)\end{array}$ & $\begin{array}{c}0.148 * * * \\
(0.015)\end{array}$ & $\begin{array}{c}0.139 * * * \\
(0.018)\end{array}$ & $\begin{array}{c}0.028 * * \\
(0.013)\end{array}$ & $\begin{array}{c}0.102 * * * \\
(0.013)\end{array}$ & $\begin{array}{c}0.404 * * * \\
(0.014)\end{array}$ & $\begin{array}{c}0.989 * * * \\
(0.297)\end{array}$ & $\begin{array}{c}0.040 * * * \\
(0.013)\end{array}$ & $\begin{array}{l}0.028 * \\
(0.014)\end{array}$ & $\begin{array}{c}0.006 * * * \\
(0.002)\end{array}$ \\
\hline Ln(Labor) & $\begin{array}{c}0.938 * * * \\
(0.017)\end{array}$ & $\begin{array}{c}0.662 * * * \\
(0.026)\end{array}$ & $\begin{array}{c}0.669 * * * \\
(0.030)\end{array}$ & $\begin{array}{c}0.424 * * * \\
(0.058)\end{array}$ & $\begin{array}{c}0.593 * * * \\
(0.025)\end{array}$ & & & & & \\
\hline Ln(Capital) & & $\begin{array}{c}0.274 * * * \\
(0.019)\end{array}$ & $\begin{array}{c}0.260 * * * \\
(0.022)\end{array}$ & $\begin{array}{c}0.193 * * * \\
(0.041)\end{array}$ & $\begin{array}{c}0.403 * * * \\
(0.009) \\
\end{array}$ & & & & & \\
\hline $\begin{array}{l}\text { General } \\
\text { controls }\end{array}$ & No & Yes & Yes & Yes & Yes & Yes & Yes & Yes & Yes & Yes \\
\hline Observations & 11,465 & 11,465 & 9,334 & 9,334 & 8,701 & 25,947 & 13,255 & 12,046 & 6,628 & 7,726 \\
\hline
\end{tabular}

Notes: *** denotes significance at the $1 \%$ level, $* *$ denotes $5 \%$ significance and $*$ denotes $10 \%$ significance. All columns estimated by OLS (except column (5) which uses the uses the Olley-Pakes estimator). Standard errors in parentheses under coefficients (clustered by firm except in column (5) which is bootstrapped with 150 replications). "Fixed Effects" includes a full set of firm dummies. Columns (1) to (9) are run on the combined full management-accounting panel from 2004 to 2014 although number of observations differs due to missing values. Column (10) is run on the 2011 cross-section using firms surveyed up until 2010, with this cut-off defined to provide 4 years to measure exit (firms can take up to 4 years to show up as dead in accounting data). Columns (3) and (4) restrict to firms which were surveyed in at least two different years. Column (5) restricts to firms with positive lagged investment data (the proxy variable in Olley-Pakes). "Management" is the firm's normalized z-score of management (the z-score of the average zscores of the 18 management questions). "Profitability" is "Return on Capital Employed" (ROCE) and "5 year Sales growth" is the 5-year growth of sales defined as the difference of current and 5-year lagged logged sales. All columns include a full set of country, time and industry dummies. "Survival" is the probability of not exiting by 2011 , conditional on being alive at some point in the 2004-2010 period (sample mean of exit is $2.4 \%$ ). "Tobin's Q" is the stock-market equity and book value of debt value of the firm normalized by the book value of the firm, available for the publicly listed firms only. "General controls" comprises of firm age and the proportion of employees with college degrees and firm age, plus a set of survey noise controls (interviewer dummies, the seniority and tenure of the manager who responded, the duration of the interview, the day of week the interview was conducted and an indicator of the reliability of the information as coded by the interviewer). Column (10) omits noise controls because of collinearity due to low number of exits. 
TABLE 4: COMPETITION AND MANAGEMENT

\begin{tabular}{|c|c|c|c|c|c|c|}
\hline & $(1)$ & $(2)$ & $(3)$ & $(4)$ & $(5)$ & $(6)$ \\
\hline $\begin{array}{l}\text { Dependent Variable: Management (z-scored) } \\
\text { (1-Lerner) }\end{array}$ & $\begin{array}{l}0.990 * * * \\
(0.366)\end{array}$ & $\begin{array}{l}1.751 * * * \\
(0.443)\end{array}$ & & & & \\
\hline Import Penetration & & & $\begin{array}{l}0.398 * * \\
(0.170)\end{array}$ & $\begin{array}{l}0.830 * * \\
(0.327)\end{array}$ & & \\
\hline Import Penetration - from China only & & & & & $\begin{array}{l}2.090 * * \\
(0.972)\end{array}$ & $\begin{array}{l}2.204^{*} \\
(1.137) \\
\end{array}$ \\
\hline Observations & 8,630 & 8,630 & 8,630 & 8,630 & 8,630 & 8,630 \\
\hline Size- weight the regressions? & No & Yes & No & Yes & No & Yes \\
\hline
\end{tabular}

Notes: ** indicates significance at $5 \%$ level and $*$ at the $10 \%$. The dependent variable in all columns is the $\mathrm{z}$-score of the average $\mathrm{z}$-scores of the 18 management questions. OLS estimates with standard errors in parentheses below coefficients. Standard errors are clustered at the industry by country by period cell in all columns. "Lerner" is the median gross price-cost margin across all firms (from the ORBIS population) in the firm's three digit SIC industry by country by period cell; "Import penetration" is the value of all imports divided by apparent consumption (total production + imports - exports) in the plant's ISIC Rev3 industry by country by period cell. "Import penetration - from China only" is the value of all imports originating from China divided by apparent consumption in the plant's ISIC Rev3 industry by country by period cell. All columns include only firms located in OECD countries and include all data collected across 2004-2014 survey waves. Industry is defined at the 3 digit SIC level in columns (1)-(2), and at the ISIC Rev3 level in columns (3)-(6). All columns include $\ln$ (firm employment) and $\ln$ (plant employment), plus a full set of country by industry dummies and general controls (firm age and the proportion of employees with college degrees (from the survey), a set of survey noise controls which are interviewer dummies, the seniority and tenure of the manager who responded, the duration of the interviews and an indicator of the reliability of the information as coded by the interviewer). Columns (1) and (2) include a variable measuring the $\log$ of the number of firms used to build the Lerner index in the country-industry-period cell. Columns (3)-(6) include the variable measuring apparent consumption in the country-industry-period cell (the denominator of the import penetration variable) in levels. Employment weights are defined with respect to total employment in the industry ( 3 digit SIC) by country cell. 
TABLE 5: REALLOCATION TOWARDS BETTER MANAGED FIRMS

\begin{tabular}{|c|c|c|c|c|c|c|}
\hline & $(1)$ & $(2)$ & $(3)$ & $(4)$ & $(5)$ & $(6)$ \\
\hline Dep. Variable: & Employees & Employees & Employees & Employees & Employees & Employees \\
\hline $\begin{array}{l}\text { Management (M) } \\
\text { (US is the omitted base) }\end{array}$ & $\begin{array}{c}182.6 * * * \\
(20.8)\end{array}$ & $\begin{array}{c}268.4 * * * \\
(40.1)\end{array}$ & $\begin{array}{l}294.83 * * * \\
(77.22)\end{array}$ & $\begin{array}{l}285.09 * * * \\
(45.53)\end{array}$ & $\begin{array}{c}463.23 * * * \\
(105.09)\end{array}$ & $\begin{array}{l}289.397 * * * \\
(71.538)\end{array}$ \\
\hline Management*Employment & & & $-56.73 *$ & & $-59.21 *$ & \\
\hline Protection (country level) & & & $(30.46)$ & & $(30.66)$ & \\
\hline Management $*$ Trade costs & & & & $-0.10 * * *$ & $-0.16^{* * *}$ & \\
\hline (country level) & & & & $(0.03)$ & $(0.05)$ & \\
\hline $\begin{array}{l}\text { Management } * \text { Tariff Levels } \\
\text { (country*industry) }\end{array}$ & & & & & & $\begin{array}{l}-45.141 * \\
(24.653)\end{array}$ \\
\hline MNG*Africa & & $\begin{array}{c}-144.6^{* * *} \\
(52.1)\end{array}$ & & & & \\
\hline MNG*Americas & & $\begin{array}{c}-96.3^{* *} \\
(43.9)\end{array}$ & & & & \\
\hline MNG*(Other EU) & & $\begin{array}{l}-46.6 \\
(58.5)\end{array}$ & & & & \\
\hline MNG*(South EU) & & $\begin{array}{c}-199.5^{* * *} \\
(46.1)\end{array}$ & & & & \\
\hline MNG*Asia & & $\begin{array}{l}-64.3 \\
(52.3)\end{array}$ & & & & \\
\hline Observations & 8,991 & 8,991 & 7,272 & 8,918 & 7,272 & 8,087 \\
\hline
\end{tabular}


TABLE 6: MANAGEMENT BY DESIGN - STYLES DIFFER DEPENDING ON ENVIRONMENT

\begin{tabular}{|c|c|c|c|c|c|c|c|c|c|}
\hline & $\begin{array}{c}(1) \\
\text { People } \\
\text { Management } \\
(\mathbf{P}) \\
\end{array}$ & $\begin{array}{c}(2) \\
\text { Monitoring } \\
\text { \& Targets } \\
\text { (MT) } \\
\end{array}$ & $\begin{array}{c}(3) \\
\text { Relative } \\
\text { People } \\
\text { (P-MT) } \\
\end{array}$ & $\begin{array}{c}(4) \\
\text { People } \\
\text { Management } \\
(\mathbf{P}) \\
\end{array}$ & $\begin{array}{c}(5) \\
\text { Monitoring } \\
\text { \&Targets } \\
\text { (MT) } \\
\end{array}$ & $\begin{array}{c}\text { (6) } \\
\text { Relative } \\
\text { People } \\
\text { (P-MT) } \\
\end{array}$ & $\begin{array}{c}(7) \\
\text { People } \\
\text { Management } \\
\text { (P) } \\
\end{array}$ & $\begin{array}{c}(8) \\
\text { Monitoring } \\
\text { \&Targets } \\
(\text { MT) } \\
\end{array}$ & $\begin{array}{c}(9) \\
\text { Relative } \\
\text { People } \\
\text { (P-MT) } \\
\end{array}$ \\
\hline \multicolumn{10}{|c|}{ Panel A: Using US Four digit industry (NBER, NSF) } \\
\hline $\ln (\mathbf{K} / \mathbf{L})$ & $\begin{array}{c}0.018 \\
(0.015)\end{array}$ & $\begin{array}{c}0.107 * * * \\
(0.016)\end{array}$ & $\begin{array}{c}-0.118 * * * \\
(0.018)\end{array}$ & & & & $\begin{array}{l}-0.000 \\
(0.014)\end{array}$ & $\begin{array}{c}0.096^{* * *} \\
(0.016)\end{array}$ & $\begin{array}{c}-0.125^{* * * *} \\
(0.019)\end{array}$ \\
\hline R\&D Intensity & & & & $\begin{array}{c}0.136^{* *} \\
(0.064)\end{array}$ & $\begin{array}{c}0.041 \\
(0.087)\end{array}$ & $\begin{array}{c}0.114 \\
(0.089)\end{array}$ & $\begin{array}{c}0.031 \\
(0.062)\end{array}$ & $\begin{array}{c}-0.125^{*} \\
(0.072)\end{array}$ & $\begin{array}{c}0.201 * * * \\
(0.074)\end{array}$ \\
\hline $\ln (\%$ degree $)$ & & & & & & & $\begin{array}{c}0.139 * * * \\
(0.008) \\
\end{array}$ & $\begin{array}{c}0.123 * * * \\
(0.007) \\
\end{array}$ & $\begin{array}{c}0.011 \\
(0.010) \\
\end{array}$ \\
\hline Observations & 13,681 & 13,681 & 13,681 & 13,681 & 13,681 & 13,681 & 13,681 & 13,681 & 13,681 \\
\hline \multicolumn{10}{|c|}{ Panel B: Two-Digit industry by county specific value (KLEMS, OECD) } \\
\hline $\ln (\mathbf{K} / \mathbf{L})$ & $\begin{array}{l}-0.044 \\
(0.040)\end{array}$ & $\begin{array}{c}0.039 \\
(0.032)\end{array}$ & $\begin{array}{c}-0.104 * * \\
(0.040)\end{array}$ & & & & $\begin{array}{l}-0.062 \\
(0.040)\end{array}$ & $\begin{array}{c}0.038 \\
(0.034)\end{array}$ & $\begin{array}{c}-0.126 * * * * \\
(0.037)\end{array}$ \\
\hline R\&D Intensity & & & & $\begin{array}{c}0.496 \\
(0.358)\end{array}$ & $\begin{array}{c}0.100 \\
(0.260)\end{array}$ & $\begin{array}{l}0.476^{*} \\
(0.249)\end{array}$ & $\begin{array}{c}0.584 \\
(0.413)\end{array}$ & $\begin{array}{l}-0.004 \\
(0.254)\end{array}$ & $\begin{array}{c}0.721^{* *} \\
(0.306)\end{array}$ \\
\hline $\ln (\%$ degree $)$ & & & & & & & $\begin{array}{c}0.132 * * * \\
(0.015) \\
\end{array}$ & $\begin{array}{c}0.071 * * * \\
(0.012) \\
\end{array}$ & $\begin{array}{c}0.070 * * * \\
(0.019) \\
\end{array}$ \\
\hline Observations & 4,855 & 4,855 & 4,855 & 4,855 & 4,855 & 4,855 & 4,855 & 4,855 & 4,855 \\
\hline
\end{tabular}

Notes: $* * *$ denotes $1 \%$ significant, $* *$ denotes $5 \%$ significance and * denotes $10 \%$ significance. All dependent variables are z-scores of average $\mathrm{z}$-scores of the underlying questions. "People management" is the index built using all management questions between 13 to 18 and "Monitoring and targets" are all the remaining questions. All columns estimated by OLS with standard errors in parentheses under coefficients. All columns control for two-digit SIC industry dummies, country and year dummies, ln(firm employment) and $\ln$ (plant employment), plus a full set of general controls (firm age and the proportion of employees with college degrees (from the survey), plus a set of survey noise controls which are interviewer dummies, the seniority and tenure of the manager who responded, the duration of the interviews and an indicator of the reliability of the information as coded by the interviewer). In Panel A the capital-labor ratio is taken from the NBER Bartelsman-Grey dataset and R\&D intensity is business R\&D divided by employment from NSF. Both capital-labor and R\&D intensity are at the four digit level for the US and used across all countries (so no country-specific variation). In Panel B the capital-labor ratio is measured at the two digit by country level from the EU KLEMs dataset and R\&D/Value added is from the OECD STAN/ANBERD. EU-KLEMS is only available for a restricted set of countries (Australia, Germany, Italy, Japan, Sweden, UK and US) hence the smaller sample size. Standard errors are clustered at the four digit level in Panel A and two-digit industry by country level in Panel B 
TABLE 7: DECOMPOSITION OF CROSS COUNTRY TFP AND MANAGEMENT

\begin{tabular}{|c|c|c|c|c|c|c|c|}
\hline Country & $\begin{array}{c}\text { Weighted } \\
\text { Manage } \\
\text { ment }\end{array}$ & $\begin{array}{c}\text { Un- } \\
\text { weighted } \\
\text { Manage } \\
\text { ment } \\
\text { (2) }\end{array}$ & $\begin{array}{c}\text { OP } \\
\text { Covar- } \\
\text { iance } \\
\\
(3)\end{array}$ & $\begin{array}{l}\text { Mng. } \\
\text { Gap vs. } \\
\text { US }\end{array}$ & $\begin{array}{l}\text { Reallocat } \\
\text { ion \% of } \\
\text { Mng Gap } \\
(5)\end{array}$ & $\begin{array}{c}\text { TFP } \\
\text { Index } \\
\text { relative } \\
\text { to US } \\
(6)\end{array}$ & $\begin{array}{r}\% \text { TFP } \\
\text { Gap due } \\
\text { to Man- } \\
\text { agement } \\
(7)\end{array}$ \\
\hline US & 0.90 & 0.40 & 0.50 & 0 & & 1 & \\
\hline Japan & 0.57 & 0.26 & 0.31 & -0.33 & 56.64 & 0.71 & 9.71 \\
\hline Sweden & 0.55 & 0.38 & 0.17 & -0.35 & 93.39 & 0.92 & 43.49 \\
\hline Germany & 0.36 & 0.18 & 0.19 & -0.54 & 57.91 & 0.83 & 28.72 \\
\hline Canada & 0.27 & 0.04 & 0.24 & -0.63 & 41.92 & 0.88 & 48.64 \\
\hline UK & 0.10 & -0.11 & 0.21 & -0.81 & 35.88 & 0.86 & 55.34 \\
\hline Singapore & 0.07 & -0.23 & 0.29 & -0.84 & 24.69 & & \\
\hline Poland & 0.04 & -0.20 & 0.23 & -0.86 & 30.69 & 0.80 & 39.26 \\
\hline France & -0.01 & -0.19 & 0.18 & -0.91 & 35.29 & 0.84 & 52.52 \\
\hline Mexico & -0.07 & -0.30 & 0.23 & -0.97 & 28.21 & 0.73 & 30.20 \\
\hline Australia & -0.08 & -0.18 & 0.10 & -0.98 & 40.24 & 0.83 & 51.56 \\
\hline Italy & -0.08 & -0.18 & 0.10 & -0.98 & 41.05 & 0.82 & 48.90 \\
\hline Spain & -0.14 & -0.50 & 0.36 & -1.04 & 13.19 & 0.76 & 39.03 \\
\hline Vietnam & -0.18 & -0.50 & 0.32 & -1.08 & 16.42 & & \\
\hline Chile & -0.19 & -0.48 & 0.29 & -1.09 & 18.81 & 0.69 & 29.48 \\
\hline Turkey & -0.20 & -0.29 & 0.09 & -1.10 & 36.92 & & \\
\hline Portugal & -0.22 & -0.43 & 0.20 & -1.13 & 26.27 & 0.66 & 27.41 \\
\hline Colombia & -0.23 & -0.51 & 0.28 & -1.13 & 19.28 & 0.52 & 17.21 \\
\hline Brazil & -0.26 & -0.51 & 0.25 & -1.16 & 21.20 & 0.45 & 14.63 \\
\hline Ireland & -0.29 & -0.55 & 0.26 & -1.19 & 20.33 & & \\
\hline China & -0.31 & -0.41 & 0.11 & -1.21 & 32.49 & 0.41 & 13.44 \\
\hline $\mathrm{NZ}$ & -0.33 & -0.48 & 0.15 & -1.23 & 28.44 & 0.79 & 51.00 \\
\hline India & -0.34 & -0.52 & 0.17 & -1.25 & 26.07 & 0.48 & 17.20 \\
\hline Greece & -0.40 & -0.52 & 0.12 & -1.30 & 29.09 & 0.25 & 37.48 \\
\hline Kenya & -0.40 & -0.55 & 0.14 & -1.30 & 27.26 & 0.70 & 9.32 \\
\hline Argentina & -0.41 & -0.55 & 0.14 & -1.31 & 27.74 & 0.68 & 34.84 \\
\hline Myanmar & -0.45 & -0.78 & 0.33 & -1.35 & 12.58 & & \\
\hline Nigeria & -0.61 & -0.67 & 0.06 & -1.51 & 28.85 & & \\
\hline Tanzania & -0.67 & -1.04 & 0.37 & -1.57 & 7.96 & 0.26 & 11.74 \\
\hline Nicaragua & -0.71 & -0.89 & 0.19 & -1.61 & 19.44 & & \\
\hline Ethiopia & -0.85 & -1.05 & 0.20 & -1.75 & 17.09 & & \\
\hline Zambia & -0.99 & -1.05 & 0.06 & -1.89 & 23.00 & 0.05 & 6.22 \\
\hline Ghana & -1.03 & -1.04 & 0.01 & -1.94 & 25.49 & 0.14 & 9.69 \\
\hline Mzmbique & -1.46 & -1.60 & 0.13 & -2.36 & 15.47 & 0.33 & 21.40 \\
\hline Average & & & & -1.14 & 29.68 & 0.62 & 29.94 \\
\hline
\end{tabular}

Notes: Colum (1) is employment share weighted management z-score. Column (2) is the unweighted score and Column (3) is the management-employment covariance. Column (4) is the weighted management score in column (1) relative to US . Column (5) is the proportion of relative weighted management score in column (1) due to reallocation. The country's TFP relative to the US in column (6) is from Penn World Tables version 8.1. (Feenstra et al, 2015) available at http://www.rug.nl/research/ggdc/data/pwt/v81/the_next_generation_of_the_penn_world_table.pdf. Column (7) is the fraction of the TFP gap with the US in column (6) that is due to the weighted relative management score in column (1). We assume a one standard deviation increase in the management score causes a 10\% increase in TFP (using Table 3 and Bloom et al, 2013). All scores are adjusted for nonrandom selection into the management survey (see text). Only domestic firms used in these calculations (i.e. multinationals and their subsidiaries are dropped). 
TABLE 8: ROBUSTNESS OF DECOMPOSITIONS

\begin{tabular}{|c|c|c|c|c|c|c|}
\hline & (1) & (2) & (3) & (4) & (5) & (6) \\
\hline & \multicolumn{3}{|c|}{$\begin{array}{l}\text { Relative to US size-weighted } \\
\text { Management Score }\end{array}$} & \multicolumn{3}{|c|}{$\begin{array}{c}\text { Share of TFP gap with US accounted for } \\
\text { by size-weighted management }\end{array}$} \\
\hline & Countries & Mean & $\begin{array}{l}\text { Correlation with } \\
\text { baseline }\end{array}$ & Countries & Mean & $\begin{array}{l}\text { Correlation } \\
\text { with baseline }\end{array}$ \\
\hline 1. $\quad$ Baseline & 33 & -1.14 & 1 & 25 & 29.90 & 1 \\
\hline 2. Drop pre-2006 data & 33 & -1.22 & 0.998 & 25 & 33.10 & 0.992 \\
\hline 3. Drop panel firms after first year & 33 & -1.17 & 0.995 & 25 & 31.55 & 0.991 \\
\hline 4. Just size in selection equation & 33 & -0.99 & 0.996 & 25 & 24.80 & 0.985 \\
\hline 5. No Selection Correction & 33 & -0.86 & 0.984 & 25 & 19.97 & 0.873 \\
\hline 6. Include multi-nationals & 33 & -1.02 & 0.854 & 25 & 24.43 & 0.888 \\
\hline $\begin{array}{l}\text { 7. Weighted inputs as size } \\
\text { measure }\end{array}$ & 33 & -0.98 & 0.990 & 25 & 34.48 & 0.960 \\
\hline 8. Include firms outside 50,5000 & 13 & -0.86 & 1 & 12 & 41.16 & 1 \\
\hline 9. Include firms outside 50,5000 & 13 & -1.08 & 0.925 & 12 & 49.98 & 0.968 \\
\hline
\end{tabular}

Notes: This Table shows key statistics for alternative ways of dealing with potential sample selection concerns. The baseline in row 1 summarizes results in Table 7 where we correct for country-specific sample selection (modelled from a first stage probit of whether an eligible firm responded as a function of ln(employment size), whether the firm was publicly listed, and industry dummies). We then weight observations by the inverse of the probability of being in the sample. Row 2 drops all data before 2006 . Row 3 drops all observations in the panel after the first year the firm is drawn in the sample. Row 4 uses only $\ln ($ employment) in the probit for sample selection. Row 5 uses the raw data, i.e. does not correct for selection. Row 6 includes multinationals (the baseline results only use domestic firms) and includes a foreign multinational dummy in the selection equation. Row 7 uses weighted inputs (capital and labor) as a size measure rather than just labor. Our sampling frame uses firms with between 50 and 5,000 employees. For a sub-sample of countries we know the fraction of employment this covers differs across countries (see Appendix B for details) and can use this to impute management in the "missing" part of the size distribution. We show the results of this in rows 8 and 9 . Since this correction can only be done for the sub-sample of countries where we know the full firm size distribution for manufacturing, row 8 shows what the baseline results look like for this sub-sample of countries and row 9 presents the corrected results. "Correlation with baseline" is the correlation of the relevant (country level) variable with the baseline values in row 1 . The correlation with size weighted management is in column (3) and the correlation of the fraction of country TFP accounted for by management is in column (6). 
TABLE 9: TFP SPREAD ACCOUNTED FOR BY MANAGEMENT PRACTICES

\begin{tabular}{|c|c|c|c|c|c|}
\hline & & (1) & $(2)$ & (3) & $(4)$ \\
\hline Country & Source & $\begin{array}{c}\text { Ln(TFP) } \\
90-10\end{array}$ & $\begin{array}{c}\text { Management } \\
90-10\end{array}$ & $\begin{array}{c}\text { Implied TFP } \\
\text { change }\end{array}$ & $\begin{array}{c}\% \text { TFP 90-10 } \\
\text { accounted for by } \\
\text { Management }\end{array}$ \\
\hline Australia & OECD & 1.93 & 2.68 & 0.27 & $14 \%$ \\
\hline Chile & OECD & 2.97 & 2.77 & 0.28 & $9 \%$ \\
\hline France & OECD & 1.42 & 2.72 & 0.27 & $19 \%$ \\
\hline Italy & OECD & 1.57 & 2.56 & 0.26 & $16 \%$ \\
\hline Japan & OECD & 1.15 & 2.48 & 0.25 & $22 \%$ \\
\hline New Zealand & OECD & 1.93 & 2.58 & 0.26 & $13 \%$ \\
\hline Sweden & OECD & 1.44 & 2.51 & 0.25 & $17 \%$ \\
\hline UK & Disney, Haskel and Heden (2000) & 0.91 & 2.61 & 0.26 & $29 \%$ \\
\hline US & Syverson $(2004)$ & 0.90 & 2.55 & 0.26 & $28 \%$ \\
\hline Average & & & & & $19 \%$ \\
\hline
\end{tabular}

Notes: Column (1) reports the 90-10 spread in $\ln (\mathrm{TFP})$ in manufacturing. Column (2) reports the 90-10 spread in the standardized management score within each country. We assume that a one standard deviation increase in the management score causes a 10\% increase in TFP (using Table 3 and Bloom et al, 2013). Column (3) reports the implied effect on $\ln$ (TFP) of an increase in the management score equivalent to the 90-10 management spread. Column (4) reports the fraction of the 90-10 ln(TFP) spread accounted for by a 90-10 increase in the management score. The data on ln(TFP) for Australia, Chile, France, Italy, Japan, New Zealand and Sweden is drawn from OECD (2016). The data for the UK is drawn from Disney, Haskel and Heden (2000). The data for the US is drawn from Syverson (2004). As noted in Section 1 these are all revenue based measured of TFP ("TFPR"). 


\section{APPENDICES INTENDED FOR ONLINE PUBLICATION ONLY}

\section{A APPENDIX: DATA}

We overview the datasets in this Appendix. More information on an earlier version of the WMS dataset can be found in Bloom, Sadun and Van Reenen (2012b) and Bloom and Van Reenen (2007). More information on the management survey in general (including datasets, methods and an online benchmarking tool) is available on http://worldmanagementsurvey.org/. Details on the MOPS data is in Bloom et al (2017).

\section{A.1 Firm-level Accounting Databases}

\section{Manufacturing firm sampling frame}

For the WMS we focus on medium sized manufacturing firms, so to conduct our surveys we would ideally draw a sampling frame from a business registry of firms. Unfortunately, the names of these firms in administrative data from business registers (where it exists) are usually confidential. Three exceptions were Chile, Colombia and Singapore. In Chile we worked directly with the government, so it was possible to use the confidential business register data to phone firms - the Industrial Annual Survey Sample of Firms (Encuesta Nacional Industrial Annual - ENIA), which covers all manufacturing firms with more than 10 employees. We used a similar model in Colombia, working with the Business Ministry and World Bank. In Singapore the Ministry of Trade and Industry ran the survey (with our training) using their population business register. ${ }^{47}$

For other countries we use publicly available data sources. ${ }^{48}$ Our main sampling frame was based on various accounting databases supplied by Bureau van Dijk (BVD), a private sector organization that seeks to compile accounting information on companies from all over the world. BVD ORBIS has names, industry, addresses, status (e.g. active or bankrupt), and accounting information such as employment and sales. ORBIS is constructed from a range of sources, primarily the national registries of companies (such as Companies House in the U.K.). The full sources for the sampling frame are listed in column (3) of Table A2. ${ }^{49}$ In some countries we were concerned about incomplete coverage by ORBIS so we supplemented it with other sources. We also used Dun \& Bradstreet for Australia and New Zealand. In India we use CMIE Firstsource 2005. ${ }^{50}$ Low income countries pose

\footnotetext{
${ }^{47}$ Unlike in Chile and Colombia, we were not able to obtain the characteristics of the non-responders in the sampling frame from the Singaporean government due to confidentiality reasons.

${ }^{48}$ There is usually a fee to be paid for access to the data compiled in an easy to use form, but the names and addresses of the firms are given in this data (unlike administrative government data where names are not revealed) as they are in the public domain.

${ }^{49}$ The firm-level databases underlying ORBIS are sometimes packaged under different names in different regions of the world by BVD (for a given country, the same firms are covered but sometimes with more fields of data). For example, in Europe the firm database is called AMADEUS (France, Germany, Greece, Great Britain, Italy, Ireland, Northern Ireland, Poland, Portugal, Spain, Sweden and Turkey); in North America it is called ICARUS (U.S. and Canada) and in parts of Asia it is called ORIANA (China, Japan). Other countries where we simply used ORBIS include Argentina, Brazil, Mexico and Viet Nam. In Table A2 we simply refer to all of these as ORBIS as this is the same overall list of firms.

${ }^{50} \mathrm{CMIE}$ is constructed from the Registry of Companies in India. Icarus is constructed from the Dun \& Bradstreet
} 
a particular challenge, as there is generally no well maintained business register to draw upon. We used a larger variety of data sources to construct sampling frames for these countries complementing ORBIS with country specific "enterprise maps" put together by researchers such as John Sutton at the London School of Economics' International Growth Centre (IGC), who worked with local consultants. For full details on the African sampling frame, see Lemos and Scur (2015). Briefly, in addition to ORBIS and the enterprise maps in Ethiopia (Sutton and Kellow, 2010), we also used trade directories and the online yellow pages; in Ghana we supplemented Sutton and Kpentey (2012) with the Ghana Free Zones Board and Business Ghana Directory; in Kenya we supplemented ORBIS with the Kenya Association of Manufacturers; in Mozambique we supplemented Sutton, Pimpao, Simione, Zhang and Zita (2014) with the Ministry of Commerce's database and FACIM; in Nigeria we supplemented ORBIS with VConnect; in Tanzania we supplemented Sutton and Olomi (2012) with the Ministry of Trade database; in Zambia we supplemented Sutton and Langmead (2013) with the Zambia Association of Manufacturers. In Myanmar we supplemented the PEDL Enterprise Map with industry directories and lists of manufacturers provided by the Myanmar Industry Association (see Tanaka, 2015) and in Nicaragua we used business directories and an IADB database.

These databases all provide sufficient information on companies to conduct a stratified telephone survey (company name, address, and a size indicator). They also typically have some accounting information on employment, sales, and capital. We did not insist on having accounting information to form the sampling frame, however.

\section{Representativeness of the sampling frame}

How representative are our sampling frames of the underlying population of manufacturing firms? For most of the countries we have evidence that the data is reasonably comprehensive. For example, when comparing aggregate employment in the ORBIS populations to those from census data, we usually find a reasonably close match (e.g. Kalemli-Ozcan et al, 2015; Bloom, Draca and Van Reenen, 2016).

In Bloom, Sadun and Van Reenen (2012b) we analyze this in more detail. For example, we compare the number of employees for different size bands from our sampling frame with the figures for the corresponding manufacturing populations obtained from national census data from each of the countries where this is available. There are several reasons for a mismatch between Census data and firm level accounts. ${ }^{51}$ Despite these potential differences, our sampling frame appears to cover

database, which is a private database of over 5 million US trading locations built up from credit records, business telephone directories and direct research. Oriana is constructed from Huaxia credit in China and Teikoku Database in Japan, covering all public and all private firms with one of the following: 150 or more employees, 10 million US\$ of sales, or 20 million US\$ of assets.

${ }^{51}$ First, even though we only use unconsolidated firm accounts, employment may include some jobs in overseas branches. Second, the time of when employment is recorded in a census year will differ from that recorded in firm accounts. Third, the precise definition of "enterprise" in the census may not correspond to the "firm" in company accounts. Fourth, we keep firms whose primary industry is manufacturing whereas census data includes only 
near to the population of all firms for most countries. ${ }^{52}$

Mismatch between the true population and our sampling frame could be a problem if our sampling frame was non-randomly omitting firms - for example under-representing smaller firms - because it would bias our cross-country comparisons. We tried several approaches to address this. First, in almost all the regression tables we include country fixed effects to control for any differences across countries in sample selection bias. Hence, our key results are identified by within country variation. Second, we ran experiments where we dropped problematic countries (e.g. Portugal and Sweden) from the analysis to show that the results are robust.

It is harder to make such comparisons between our sampling frame and the full population of firms in some of the poorer countries as there is no reliable employment aggregate numbers to compare to. The enterprise maps by Sutton and others that we draw our sampling frames from are probably the most reliable sources. Given this, we should interpret some of the results from the African countries with more caution than those of the other nations.

\section{Medium sized manufacturing firms vs. all manufacturing firms}

A further concern that is that even if our sampling frame is fully comprehensive, the proportion of employment covered by medium sized firms differs systematically across countries. Using Census sources on firm populations, Table A3 shows the employment distribution for the countries where it is available. Firms employing between 50 and 5,000 workers account for about half of all manufacturing workers in most countries, although the proportion was larger in some countries such as Ireland $(72 \%)$ and Poland $(71 \%)$. The proportion employed by very large firms with over 5,000 workers varies more between nations. The patterns are broadly consistent with our MAT model. In countries where competition is strong and reallocation easier, there is a larger fraction of jobs in very large firms (e.g. $34.7 \%$ in the U.S.) and a small fraction in small firms with under 50 employees (e.g. 16.2\% in the U.S.). Germany, also a high productivity and high management score country, looks similar to the U.S. (34.9\% in large firms vs. $16.5 \%$ in small firms). By contrast, in countries like Italy and Greece, only $6.4 \%$ and $6.2 \%$ of employees respectively are in these large firms compared to $45.1 \%$ and $41.3 \%$ in small firms. In Appendix B we provide some corrections to our cross country decompositions to deal with the fact that we are missing management scores in the very large firms in some countries (e.g. the U.S. and Germany) compared to other countries, like those in southern Europe. As expected, these corrections strengthen our overall findings as

plants whose primary industry code is manufacturing. Fifth, there may be duplication of employment in accounting databases due to the treatment of consolidated accounts. Finally, reporting of employment is not mandatory for the accounts of all firms in all countries. This was particularly a problem for Indian and Japanese firms, so for these countries we imputed the missing employment numbers based on a regression of sales on employment for firms where we had both variables.

${ }^{52}$ In two countries the coverage from accounting databases underestimates the aggregate: the Swedish data covers only $62 \%$ of Census data and the Portuguese accounting database covers $72 \%$. This is due to incomplete coverage in ORBIS of these smaller nations. 
the "corrected" relative average management scores for the U.S. and Germany rise compared to southern Europe.

A caveat to Table A3 is that total employment in firms with over 5,000 workers is not disclosed in all countries (because of concerns it would reveal individual firm's identities). In the U.S. and Japan we have the exact Census numbers from public use tables and in the U.K. we had access to confidential Census micro-data to do this ourselves. In the other countries we used accounting data from ORBIS and other sources to estimate employment for the very large firms. Since these firms are so large, data is relatively plentiful as they are almost all publicly listed and so followed closely by market analysts. ${ }^{53}$

\section{A.2 The World Management Survey}

In every country the sampling frame for the management survey was all firms with a manufacturing primary industry code and that employed between 50 and 5,000 workers ${ }^{54}$ on average over the most recent three years of data prior to the survey. ${ }^{55}$ Interviewers were each given a randomly selected list of firms from the sampling frame. The size of this sampling frame by country is shown in column (5) of Table A2 for the first year that we interviewed a firm. We have conducted the surveys over multiple years as noted in column (6). The five major waves were in 2004, 2006, 2009/10, 2013 and $2014^{56}$, although we had smaller scale surveys in some of the intervening years (e.g. China in 2007; Brazil, Canada and Ireland ${ }^{57}$ in 2008).

In the first survey in 2004 we covered 732 firms in France, Germany, the U.K. and the U.S. ${ }^{58}$ In 2006 we covered eight countries (China, Greece, India, Italy, Japan, Poland, Portugal and Sweden) as well as the four core countries. In addition to the new countries and a refreshment sample of the four 2004 countries we also re-contacted all firms from 2004 to form a short panel. In

\footnotetext{
${ }^{53}$ Corrections have to be made to estimate the number of domestic employees (which is the Census concept) if this is not revealed directly by the firms. To do this we ran country specific regressions of the proportion of domestic over total global employment on a polynomial of total employment, industry dummies, and multinational status. Then we used this to impute the number of domestic workers for the firms who did not disclose domestic employment.

${ }^{54}$ In Japan and China we used all manufacturing firms with 150 to 5000 employees since Oriana only samples firms with over 150 employees. Note that the Oriana database does include firms with less than 150 employees if they meet the sales or assets criteria, but we excluded this to avoid using a selected sample. We checked the results by conditioning on common size bands (above 150 in all countries) to ensure that the results were robust.

${ }^{55}$ In the U.S. only the most recent year of employment is provided. In India, employment is not reported for private firms, so for these companies we used forecast employment, predicted from their total assets (which are reported) using the coefficients from regressing $\ln$ (employees) on $\ln$ (assets) for public firms.

${ }^{56}$ Major waves were started in early summer, but sometimes stretched throughout the year. In 2009 , the wave stretched through to the following February. We kept information on when the interview took place to control for any seasonal influences (a noise control).

${ }^{57}$ We split out Northern Ireland from the rest of the U.K. in Table A2 as we did an additional wave specifically of Northern Irish firms in 2008. Some of the Northern Irish firms were also surveyed in 2004, 2006 and 2010 as part of the general U.K. waves, but only a smaller number as the region is only a small part of the U.K..

${ }^{58}$ This sample was drawn from the BVD Amadeus dataset for Europe and the Compustat dataset for the U.S. Only companies with accounting data were selected. So, for the U.K. and France, this sampling frame was very similar to the 2006 sampling frame. For Germany it is more heavily skewed towards publicly quoted firms since smaller privately held firms report little balance sheet information. For the U.S. it comprised only publicly quoted firms. As a robustness test we drop the firms that were resurveyed from 2004.
} 
2009/10 we again resurveyed all firms interviewed 2006 including the original 2004 firms (if they were still alive). For budgetary reasons we did not do a refreshment sample in this wave although we did add New Zealand and Australia. In 2013 we mainly surveyed low income countries in Africa (Ethiopia, Ghana, Mozambique, Nigeria, Tanzania and Zambia) and Latin America (Colombia and Nicaragua) for the first time. But we also followed Argentina, Mexico and Brazil in the panel and surveyed Spain and Turkey for the first time. In 2014 we included new countries (Kenya, Myanmar and Vietnam) and performed refreshment samples of the U.S. and the main EU countries (France. Germany, Greece, Italy, Portugal and the U.K.). This included attempting to re-survey all the panel firms from the these EU countries and the U.S. that we had from earlier waves.

\section{The Survey response rate}

Column (4) of Table A2 shows the response rates by country. Of the firms we contacted $41 \%$ took part in the survey, a high success rate given the voluntary nature of participation. Of the remaining firms, $16 \%$ refused to be surveyed, while the remaining $43 \%$ were in the process of being scheduled when the survey ended.

There are clear differences by country, with the response rate being lowest in Japan and highest in Nigeria. Table A4 analyzes the probability of being interviewed. ${ }^{59}$ All columns condition on country dummies, industry dummies and time dummies (for year of interview and year the accounting data is taken from if different). The first column simply includes employment as a measure of size. The size variable is significant suggesting that there was a tendency for large firms to respond more frequently, although the coefficient is not large: a doubling of firm size is associated with only a $6 \%$ higher probability of response.

In column (2) of Table A4 we add in labor productivity and reassuringly find that firms with higher revenues per employee are not significantly more likely to agree to be interviewed than others. Column (3) includes the return on capital employed (ROCE) as an alternative performance measure which is also insignificant. These are important results as they suggest we are not interviewing particularly high or low performing firms. In columns (4), (5) and (6) we find that multinational status, firm age, and capital are also all insignificant in the selection equations.

In summary, within a country, industry, and year, respondents were not significantly more productive, profitable, or capital intensive than non responders. Respondents did tend to be slightly larger, but were not more likely to be older or multinationals. Since all regressions include size, country, industry, and time dummies, this potential source of bias is controlled for.

One concern, however, is that when we make cross country comparisons these selection effects could create biases. Hence in our decomposition analysis we re-weight the data to allow for country

\footnotetext{
${ }^{59}$ The responders sample implicit in Table A 4 is smaller than the total number of observations in Figure 1 for three reasons. First, we look only at the first time we contact a firm: this is because firms that appear in the panel are likely to be better managed and more productive (since they survived longer). Second, we conduct the analysis at the levels of the firm's accounts and there may be multiple plants analyzed for the same firm in the same year. Third, we do not include Singapore because (as noted above) we do not have access to the non-responders.
} 
specific sampling bias (see Appendix B and main text). Specifically, we ran probits of whether a firm responded compared to others in the sampling frame where the right hand side variables are employment, firm age, industry dummies and time dummies. We then calculated the probability of sample response and used the inverse of the sampling probability as weights (winsorizing the top and bottom percentiles).

\section{Management - Accounting panel dataset}

As described above, we have a panel element to the database. This is built by combining the management survey waves with the accounting panel data, and then interpolating (but never extrapolating) the management and accounting data to fill in the missing years. For example, if we measure management practices every three years, we linearly interpolate the data in the intervening years. This helps to increase the sample sizes for the five year difference moment since we do not need to have exactly five years between survey waves (for example, without interpolating, if we survey firms every three years we can never generate a five year difference). But, to confirm our results are not dependent on interpolating, we checked we can successfully replicate Table 3 using non-interpolated data finding very similar results. We also have about $5 \%$ of firm-years with multiple survey values, for which we take the average value of all continuous variables (including all the overall management score) and the value from the chronologically first survey for the discrete values (e.g. "plant county of location", "ownership type" etc). ${ }^{60}$ All regression standard errors are clustered by firm so that the standard-errors are appropriately corrected for any potential serial correlation in the errors induced by interpolation.

The sample size in the regressions depend on the number of non-missing variables (and specific regressions will drop observations that are effectively redundant if they are absorbed by the controls). In terms of sample size for the overall panel, we have 15,003 firm-year observations between 2004 and 2014 inclusive for the non-interpolated data and 25,953 observations for the interpolated data. Only a sub-set of these observations have non-missing values on the elements for the production functions. In addition, we condition on having a minimum number of 20 firm-year observations per country in the regressions. This leaves us with 15,001 observations in the panel distributed over 18 countries -Argentina, Australia, Brazil, Chile, China, France, Germany, Greece, Ireland, Italy, Japan, Mexico, Poland, Portugal, Spain, Sweden, the UK and US.

\section{Firm-level variables}

We have firm accounting data on sales, employment, capital, materials, profits, shareholder equity, long-term debt, market values (for quoted firms), and payroll (the wage bill). Value added is

\footnotetext{
${ }^{60}$ For example, the coefficients (standard errors) on management for columns (1) to (4) from Table 3 with noninterpolated data are $0.274(0.017), 0.142(0.015), 0.123(0.016)$ and $0.038(0.014)$ respectively.
} 
calculated as sales minus materials. ${ }^{61}$ We also collected information on whether the firm was part of a multinational enterprise during the survey interview. We supplemented and verified this information through BVD, web searches, and direct telephone inquiries to the firms. We also collected specific questions on the multinational status of the firm (whether it owned plants abroad and the country where the parent company is headquartered) to be able to distinguish domestic multinationals from foreign multinationals.

We collected many variables through our survey, including information on plant and firm employment, the fraction of employees with a degree, organizational structure, how many competitors managers thought they faced, etc.

Management practices were scored following the methodology of Bloom and Van Reenen (2007), with practices grouped into four areas: operations (three practices), monitoring (five practices), targets (five practices), and incentives (five practices). The shop-floor operations section focuses on the introduction of lean manufacturing techniques, the documentation of processes improvements, and the rationale behind introductions of improvements. The monitoring section focuses on the tracking of performance of individuals, reviewing performance, and consequence management. ${ }^{62}$ The targets section examines the type of targets, the realism of the targets, the transparency of targets, and the range and interconnection of targets. Finally, the incentives/people management section includes promotion criteria, pay and bonuses, and fixing or firing bad performers, where best practice is deemed the approach that gives strong rewards for those with both ability and effort. Our management measure averages the z-scores of all 18 dimensions and then z-scores this average again.

\section{Industry level variables}

Our basic industry code is the U.S. SIC (1997) three digit level - which is our common industry definition in all countries except otherwise noted. We allocate each firm to its main three digit sector (based on sales), covering 135 unique three-digit industries. There are at least ten sampled firms in each industry for $97 \%$ of the sample.

The "Lerner index of competition" is constructed, as in Aghion et al (2005), as the cross-firm median of (1-profit/sales) in a country-industry-time period cell. Profits are defined as EBIT (earnings before interest and taxation) to include the costs of labor, materials, and capital, but exclude any financing or tax costs. The source of accounting data used to build the index is ORBIS population data for all countries (i.e. we do not condition on having any management data). We first build the median Lerner index for every country-industry-year cell. ${ }^{63}$ We then average the

\footnotetext{
${ }^{61}$ Some firms report "costs of good sold" and not materials. In this case we estimate materials as costs of goods sold minus the wage bill. For observations which still had missing values for materials we assumed that the fraction of materials in sales was equal to the industry-year average.

${ }^{62}$ Since the operations and monitoring concepts overlap we often group them together as "monitoring".

${ }^{63}$ To reduce the influence of outliers, we drop observations below the 1 th and above the 99th percentile of the Lerner index.
} 
yearly values over three three-years sub-periods: period 1, including years between 2004 and 2006; period 2, including years between 2008 and 2010; and period 3, including 2012 and 2013 data (2013 being the last year for which we have full ORBIS extractions). This timing roughly corresponds to pre-crisis, crisis and post-crisis periods. These time varying measures of the Lerner index are matched to the management interviews according to the year in which these were conducted (20042006 for period 1; 2008-2010 for period 2; and 2012-2014 for period 3).

The variable "Import penetration" is built using data drawn from the World Input-Output Database (WIOD). Import penetration is built as the share of imports over apparent consumption (total production minus exports plus imports). This measure is built at the country by industry by year level and then, similarly to the Lerner index, averaged across sub-periods. Since the last available year for the WIOD is 2011, we use only two sub-periods, 2004-2006 (matched with management data collected between 2004-2006) and 2008-2010 (matched with management data collected between 2008-2014). The industry classification is ISIC, Rev 3.

The variable "Import penetration from China" is built exactly as the "Import Penetration" variable, except that it includes only imports originating from China in the numerator.

Tariff data was kindly supplied by Feenstra and Romalis (2015) and is at the country by industry (SITC, Rev 4) by year (2000-2006) level. Since we have limited time series variation, we collapse the data to the country by industry level.

\section{Country level variables}

We take country level measures of GDP per capita and TFP from the latest Penn World Tables (Timmer et al, 2015). The OECD "Difficulty of Hiring" index (ranging from 1 to 100) is the variable EPRC_V2 (available for all years in the interval 1998-2013), and is drawn from their indicators of employment protection. These are synthetic indicators of the strictness of regulation on dismissals and the use of temporary contracts, compiled from 21 items covering three different aspects of employment protection regulations as they were in force on January 1st of each year. We also employ the variable "Cost to export (US\$ per container)" drawn from the World Bank "Doing Business" dataset (2015) which reflects the cost of obtaining export licenses and average container costs.

\section{A.3 Management and Organizational Practices Survey (MOPS)}

MOPS was jointly funded by the U.S. Census Bureau and the National Science Foundation as a supplement to the Annual Survey of Manufactures (ASM). The original design was based on the same concepts as the WMS and was adapted to the U.S. through several months of development and cognitive testing by the Census Bureau. It was sent by mail and electronically to the ASM respondent for each establishment, which was typically the accounting, establishment, or human-resource manager. Most respondents (58.4\%) completed the survey electronically, with the 
remainder completing the survey by paper $(41.6 \%)$. Non-respondents were given up to three followup telephone calls if no response had been received within three months. The survey comprised 36 multiple choice questions about the establishment, taking about 20 to 30 minutes to complete. The survey included 16 questions on management practices covering (like WMS) monitoring, targets and incentives.

The monitoring section asked firms about their collection and use of information to monitor and improve the production process. For example, firms were asked how frequently performance indicators were tracked at the establishment, with options ranging from "never" to "hourly or more frequently". The targets section asked about the design, integration, and realism of production targets. For example, firms were asked what the time-frame of production targets was, ranging from "no production targets" to "combination of short-term and long-term production targets". Finally, the incentives section asked about non-managerial and managerial bonus, promotion and reassignment/dismissal practices. For example, it asked how managers were promoted at the establishment, with answers ranging from "mainly on factors other than performance and ability, for example tenure or family connections" to "solely on performance and ability". The full questionnaire is available on http://bhs.econ.census.gov/bhs/mops/form.html.

In our analysis, we aggregate the results from these 16 check box questions into a single measure of structured management. The structured management score is the unweighted average of the score for each of the 16 questions, where each question is first normalized to be on a $0-1$ scale. Thus the summary measure is scaled from 0 to 1, with 0 representing an establishment that selected the bottom category (little structure around performance monitoring, targets, and incentives) on all 16 management dimensions, and a 1 representing an establishment that selected the top category (an explicit focus on performance monitoring, detailed targets, and strong performance incentives) on all 16 dimensions. As with WMS, we asked a range of questions about the characteristics of the workers, firms, and collected variables that we used to approximate for interview noise (interviewee, interview and interviewer characteristics).

The MOPS survey was sent to all ASM establishments in the ASM mail-out sample. 37,177 filled surveys were received, implying a response rate of $78 \%$, which is extremely high for firm surveys. We further restricted the sample for establishments with at least 11 non-missing responses to management questions and also have positive value added, positive employment and positive imputed capital in the ASM. In addition to our management data we use establishment level data on sales, value-added and labor inputs from the ASM. The mean establishment size is 167 employees and the median is 80 . The average establishment in our sample has been in operation for 22 years, $44 \%$ of managers and $9 \%$ of non-managers have college degrees, $13 \%$ of their workers are in unions, $42 \%$ export and $69 \%$ are part of larger multi-plant firms.

More details on the MOPs survey are contained in Bloom et al (2017). 


\section{B APPENDIX: FURTHER RESULTS}

\section{B.1 Alternative Methods of estimating the productivity equation}

We considered a large number of alternative approaches to estimating the productivity regression, some of which are contained in Table A5. First, in column (1) we consider a standard "Solow Residual" approach deducting $\ln$ (labor) and $\ln$ (capital) from $\ln$ (value added) using three-digit industryspecific shares in nominal value added as weights for the factor inputs. A regression of this TFP measure on management has a highly significant coefficient of 0.080 .

The next three columns embody alternative popular econometric approaches to estimating production functions Column (2) reports the Blundell and Bond (2000) system GMM approach for our standard specification of column (2) in Table 3. Here, we treat all factor inputs as endogenous and use lags as instruments (lagged levels in the difference equations and lagged differences in the levels equation). The unrestricted specification includes a lagged dependent variable and lags of the factor inputs (see Appendix C.1 below). The common factor (COMFAC) restrictions are imposed by minimum distance and the structural coefficients presented in the table. The management coefficient is about $0.05 .{ }^{64}$ Column (3) presents the Levinsohn and Petrin (2003) approach where we use materials (rather than investment) as the proxy variable. Column (4) reports the Olley-Pakes approach (as in column (5) of Table 3) except we use the Ackerberg, Caves and Frazer (2015) correction. The range of the estimates of the management coefficient is significant and positive throughout and in magnitude lies within the range of those in Table 3 with Blundell-Bond giving the lowest estimates and Levinsohn-Petrin the highest.

In columns (5) through (10) of Table A5 we repeat the specifications in Table 3 except we implement output based production functions instead of value added based version. Hence we also include material inputs on the right hand side. Column (5) has the whole sample, column (6) conditions on firms surveyed in at least two years, column (7) presents firm fixed effects and column (8) has the Blundell-Bond results. As expected, the factor input coefficients tend to be smaller in magnitude than their counterparts for the value added function, but all remain significant.

The last four columns again present results with sales as the dependent variable, but drop materials from the right hand side. Although the magnitude of the coefficient on management varies with the different estimation approaches, it is positive and significant in every specification. We also considered a wide variety of other approaches to production function estimation, for example using the wage bill instead of employment as a measure of labor services (as in Hsieh and Klenow, 2009). The significance of management remained in all of these experiments.

\footnotetext{
${ }^{64}$ Note that this is the econometric specification closest to the theoretical model-lags are legitimate instruments under the quadratic adjustment model we have assumed (Bond and Soderbom, 2005). We generalize the theory model slightly as we (implicitly) also allow labor to also have adjustment costs alongside capital and management. Interestingly, the sum of the coefficients on the factor inputs is 0.8, lower than the OLS levels and Olley-Pakes estimates in Table 3. This is consistent with the calibrated parameter values from Table 1 which has constant returns in production but CES monopolistic competition with a demand elasticity of 5 which means the coefficients in the revenue function should be $20 \%$ smaller than the output elasticities in the production function.
} 


\section{B.2 The contribution of management to cross country TFP gaps: Robustness}

In Section 5 we decomposed share-weighted management into reallocation and unweighted average components and use this to estimate the contribution to cross country TFP. In doing that, we made a variety of assumptions that we now relax to see if they materially alter our results. Recall that (i) the sample we used in the analysis is a sub-sample of that underlying Figure 1 as we drop multinationals because it is unclear what the appropriate measure of size is for such firms (we also show robustness to including multinationals); and (ii) we weight the management data according to a firm's country-specific employment share and adjust for non-random selection through sampling weights.

\section{B.2.1 Differential response rates to the survey}

There are several potential sources of sample selection, the most obvious one being that the firms who responded from the sampling frame were non-random in some dimension. Appendix A examined the overall evidence on sampling bias and argued that these were relatively small. Nevertheless, the baseline results in Table 7 control for this by calculating (country-specific) weights for the sample response probabilities. We do this by running country-specific probit models where the control variables are $\ln ($ employment size), firm age, a dummy for whether the firm was publicly listed and industry dummies. We chose these controls because they are available for responders and nonresponders, and there was some evidence from Appendix A that larger firms were more likely to respond. We then calculated the weights as the inverse of the probability of response.

We experimented with an alternative first stage probit to look into sample response bias, based on just using employment rather than the larger set of controls. The results are summarized in Table 8. Row 1 presents a summary of the baseline results that we use in Table 7 . Row 2 shows what happens when we drop pre-2006 data. This is motivated by the fact that 2004 was our first (and smallest) survey wave. The fraction of the TFP gap accounted for by management rises to $33 \%$ (from 30\%). We also show in column (6) that the correlation of this fraction explained with the baseline in row 1 is very high (0.992) and the correlation of the gaps in management with the baseline of Row 1 are also very high (0.998 in column (3)). Row 3 drops all observations which are in the panel part of the dataset except the first year. The motivation for doing this is that firms who have been in the panel for one year are more likely to respond in subsequent years than a randomly chosen firm. Since we attempt to re-sample panel firms in subsequent years this could potentially generate a bias. In the baseline results of Row 1 we down-weight these firms appropriately using estimate from the probits. Row 3 shows that our results are robust to just dropping them from the sample (32\% of TFP accounted for). We also looked at the sensitivity of the first stage probit to the controls by dropping all covariates except size (row 4) and not using any sample weights (row 5). Not using any selection correction generates the smallest fraction of the TFP explained in Table $8(20 \%)$. 
In Table 7, we dropped multinationals because of the difficulty of measuring group size appropriately for such companies. To check the robustness of these results, we included them in row 6 , but also included multinational status into the selection equation used to calculate the sample response rate weights (multinationals were slightly more likely to participate in the survey). We account for a bit less of the average TFP gap ( $24 \%$ compared to $30 \%$ in the baseline) and the cross country correlation remains reasonably high $(0.89)$.

We have focused on employment as our key measure of size as it is simple, a volume indicator which is straightforward to measure across countries. An alternative way to measure size is to look at a measure of weighted inputs, so we follow Bartelsman et al (2013) and construct a measure using capital stock information from Orbis where our composite input measure was $\exp [0.7 * \ln ($ labor $)+$ $0.3^{*} \ln ($ capital)]. The results are in row 7 of Table 8 and are again are similar to the baseline, although with slightly more of TFP accounted for by management (34.5\%).

\section{B.2.2 Sampling biases associated with dropping very small and very large firms}

Our management surveys focus on medium sized firms defined as those with over 50 and under 5000 employees. This was in order to compare firms of a broadly similar size. However, it could potentially cause bias in our comparisons of management levels across countries as the size distribution is different across nations (e.g. Garicano, Lelarge and Van Reenen, 2013, and Table A3). Obviously we do not know the exact distribution of management scores in these very large and very small firms, but we can estimate with additional assumptions what the potential biases could be.

From the census manufacturing population databases of firm demographics, in most countries we know the number of firms above and below 50 employees, and the total number of workers employed across firms of different sizes (see Table A3). We need to then make an assumption about the relationship between firm size and management for the very large and very small firms, which we extrapolate off the size-management relationship over the part of the distribution that we observe (50 to 5,000 employees). We checked that the extrapolated size-management relationship holds for firms below 50 and above 5,000 using the MOPs dataset which asks management questions to firms from all parts of the U.S. size distribution. ${ }^{65}$

We then use this information to estimate the weighted average management score across the entire distribution. Our preferred method exploits the fact that the firm size distribution in each country follows a power law (Axtell, 2001). Using results from this literature we can approximate the employment weighted mean management score in the sub-population under 50 workers and the sub-population with over 5,000 workers. ${ }^{66}$ We then use the information in Table A3 to calculate

\footnotetext{
${ }^{65}$ The coefficient on $\ln ($ employment size) in the management regression is 0.25 . We considered imposing a common constant on each country $(-1.46)$ or adjusting this to be consistent with the country-mean management score in the 50 to 5,000 range. Both methods lead to similar results.

${ }^{66}$ First, we consider the approximation in Johnson et al (1994) showing that the number of employees in each size
} 
the mean management score across the entire size distribution. Results of this exercise are in rows 8 and 9 of Table 8 . We first reproduce the baseline results on the smaller sample of countries in row 8 of Table 8 . In this sub-sample of 14 countries (13 differences as the U.S. is the base) we account for a higher fraction of TFP (41\%) since these are OECD countries. We then implement the size correction. The correlation between our baseline management scores and the new "size corrected" management scores is very high (0.925), as is the correlation of the fraction of TFP explained (0.968). If anything, we account for an even higher fraction of the TFP gap (just under $50 \%$ ) when making this correction.

\section{B.2.3 Manufacturing TFP vs. Whole Economy TFP}

The management scores are derived from manufacturing firms, but the decompositions in Table 7 use economy wide TFP. This is purely due to data restrictions - there are few countries in the world for which it is possible to construct reliable measures of manufacturing TFP that are comparable across countries. Our assumption is that countries with high economy wide TFP also have high manufacturing TFP. To test whether this might bias our results, we draw on estimates of manufacturing specific TFP levels (Citino, Haskel and Van Reenen, 2016). This is based primarily on the KLEMs data and constructs TFP in the same way as the Penn World Tables, correcting for capital services and skills. There are only seven countries that overlap between the two exercises where data is sufficiently rich: Australia, Germany, Italy, Spain, Sweden, the U.K. and U.S. The correlation of manufacturing TFP (relative to the U.S.) for these countries with economy TFP is reassuringly high: 0.938 . The average proportion of the TFP gap accounted for by management is $35 \%$, similar to the overall mean (but smaller than the proportion for just the seven countries in the baseline which is $43 \%) .{ }^{67}$

\section{CALIBRATION AND SIMULATION}

\section{C.1 Calibration Values}

The calibration values in Table 1 are conventional, but the presence of management in the production function generates some additional considerations. Conventional measures of the autocorrelation coefficient on TFPR $\left(\rho_{A}\right)$ assume that we have measured all factor inputs, but since

\footnotetext{
"bin" is equal when the bins are logarithmically sized if firm size is distributed according to Zipf's Law (which is approximately true in the data). We predict management in each bin and then employment weight the bin to obtain mean management for the below 50 and above 5,000 firms. We also considered the continuous version of the power law which lead to similar results.

${ }^{67}$ We performed a similar exercise for the market sector (i.e. dropping health, education and public administration). For this sample we do not have Australia, but we do can add France. Again the correlation of TFP between this sector (market sector) and total economy is high at 0.844 . We could account for $43.6 \%$ of the cross country TFP gaps, very similar to the fraction for these seven countries in Table 7 (44.7\%).
} 
managerial capital is a missing variable, it will implicitly show up in estimated TFPR. For example, consider the value added production function in Section $2,(P Y)_{i}=A_{i} K_{i}^{a} L_{i}^{b} M_{i}^{c}$. TFPR will be $\ln A_{i}=\ln (P Y)_{i}-a \ln K_{i}-b \ln L_{i}-c \ln M_{i}$. A standard way to measure TFP is replace the parameters with cost shares. This has the problem that management shows up in the residual so we actually have $\ln A_{i}+c \ln M_{i}$. This implies that we probably overestimate the auto-correlation of "true TFPR" by using existing measures as $M$ and $A$ will co-vary together. We can assess this by examining how our estimates of TFPR in the data compare with those from conventional measures. We find that the estimated coefficient is, in fact, not much less than the calibrated value from Cooper and Haltiwanger (2006) of 0.885. For example, using the productivity equation of column (2) in Table 3, we can calculate the (net-of-management) TFPR residual and then estimate an $\mathrm{AR}(1)$ regression which generates $\hat{\rho_{A}}=0.867$ (standard error $=0.009$; observations $=7,463$ ). This is close to the 0.871 if we do not control for management in our data. The similarity reflects the fact that management capital is a relatively small share of total value added.

An alternative approach is to use the implied values in the dynamic version of the revenue function. Under the assumptions in our model we can write $\ln (P Y)_{i t}=\rho_{A} \ln (P Y)_{i t}+a \ln K_{i t}-a \rho_{A} \ln K_{i t}+$ $b \ln L_{i t}-b a \rho_{A} \ln L_{i t}+c \ln M_{i t}-c \rho_{A} \ln M_{i t}+e_{i t}$ where $e_{i t}=\ln A_{0}+\rho_{A} \varepsilon_{i t}$ which is serially uncorrelated. This is the same specification as Cooper and Haltiwanger (2006) and Blundell and Bond (2000) and, like them, we estimate the equation by system GMM and impose the common factor restrictions (COMFAC) to recover the structural parameters (see Table A5 column (2)). Our estimate of $\left(\rho_{A}\right)$ is 0.854 (standard error $=0.013$ ) which is again, very close to the calibrated value used in Table 1.68

As noted in the text we use labor's factor share in GDP to guide the calibration of the output elasticities. It seems reasonable to assume that the cost of managerial capital shows up as payments to labor (e.g. executive time and consultancy wages). Recall that our structural model implies that the total labor share in GDP is $(\beta+\gamma)(\rho-1) / \rho$. From the US NIPA this is currently about $56 \%$ (see Autor et al, 2017, Table 1). Hence, given the other calibrated assumptions on the demand elasticity (Bartelsman et al, 2013; $\rho=5$ ) and output elasticity of management (Bloom et al, 2013; $\gamma=0.1$ ) we can then derive the output elasticity of labor as $\beta=-\gamma+0.56 \rho /(\rho-1)=-0.1+(0.56 * 5) /(5-1)=$ 0.60. Consequently, from our assumption of constant returns to scale in production we also have the output-elasticity of non-managerial capital as $\alpha=1-\beta-\gamma=1-0.6-0.1=0.1$.

\section{C.2 Details of Simulated Method of Moments (SMM) Approach}

SMM starts by selecting an arbitrary starting value of the parameter vector to be estimated $(\theta)$. The dynamic program is then solved and the policy functions are generated. These policy functions are used to create a simulated data panel of size $(\mu N, T)$, where $\mu$ is a strictly positive integer, $N$

\footnotetext{
${ }^{68} \mathrm{~A}$ similar exercise for the standard deviation of $\operatorname{TFPR}\left(\sigma_{A}\right)$ generates a value of 0.62 which is higher than the calibrated value of 0.453 in Cooper and Haltiwanger (2006). In our view, these higher order moments are better estimated from near population Census data, so we prefer to use these external measures than our more specific sample.
} 
is the number of firms in the actual data, and $T$ is the time dimension of the actual data. The simulated moments $\Psi^{S}(\theta)$ are calculated on the simulated data panel, along with an associated criterion function $\Gamma(\theta)$, where $\Gamma(\theta)=\left[\Psi^{A}-\Psi^{S}(\theta)\right]^{\prime} W\left[\Psi^{A}-\Psi^{S}(\theta)\right]$, which is a weighted distance ${ }^{69}$ between the simulated moments $\Psi^{S}(\theta)$ and the actual moments $\Psi^{A}$.

$$
\widehat{\theta}=\arg \min _{\theta \in \Theta}\left[\Psi^{A}-\Psi^{S}(\theta)\right]^{\prime} W\left[\Psi^{A}-\Psi^{S}(\theta)\right]
$$

A second parameter value is then drawn by taking a random jump from the first value, and the third parameter value onwards is drawn by taking a random jump away from the best prior guess (the parameter value that has delivered the lowest criterion function up to that point). This way, the parameter estimate $\widehat{\theta}$ derived by randomly searching over the parameter space to find the parameter vector, which minimizes the criterion function. This simulated annealing random jumping approach is used because of the potential for discontinuities in the model and the discretization of the state space (so a gradient minimization approach may simply find a local rather than a global minimum). Finally, different initial values of $\theta$ are selected to ensure the solution converges to the global minimum.

\section{EXECUTIVE PAY AND MANAGEMENT}

We discussed the relationship between payments to senior management and management practices in the main text in sub-section 4.4. This Appendix gives more details on the data collection and analysis.

Compensation data was collected for executives in publicly listed firms in four countries: the US, UK, India, and China. There is an overall measure of CEO Compensation as well as a disaggregation into salary, bonus and equity. In some cases, an executive's total compensation exceeds the sum of the components-e.g. in cases where the executive received separate perquisites such as retirement benefits. Stock options are valued using the Black-Scholes formula. Data on equity compensation is not available for executives in Indian firms, and data on bonus compensation are not available for executives in Chinese firms. Due to these data limitations for Indian and Chinese firms, regressions that use the total compensation measure include only executives from firms the US and UK. Executive Compensation in the US is from S\&P Capital IQ's ExecuComp and the UK the data is taken from BoardEx. For India we use Prowess, and for China we use the China Stock Market \& Accounting Research database. For comparability across time and across countries, all compensation values are converted to 2006 PPP-adjusted dollars.

We focus on the relationship between a firm's managerial quality and the compensation of its top executive. In American firms, the top executive is typically the Chief Executive Officer. In other

\footnotetext{
${ }^{69}$ The efficient choice for $W$ is the inverse of the variance-covariance matrix of $\left[\Psi^{A}-\Psi^{S}(\theta)\right]$, which Lee and Ingram (1991) show under the null can be calculated from the variance-covariance of the empirical moments.
} 
countries, the exact title of the top executive varies. We use "CEO" to refer to each firm's top executive. After merging these data with the WMS we have a sample of 532 firms: 242 in the US, 107 in the UK, 132 in India, and 51 in China. Unless otherwise specified, we use each firm's management score and compensation data from the year in which the management survey was conducted for the firm.

Table A6 shows the results of regressing $\ln (\mathrm{CEO}$ salary) on our management score and country dummies in all four countries. There a positive and significant association between higher management scores and higher CEO pay. Column (2) controls for a number of other variables such as firm size, age and skills. This reduced the coefficient on management from 0.309 to 0.189 , but it remains significant. The final two columns repeat these specifications but use a measure of total compensation that includes stock options, long-term incentive plans and bonuses. This data is only available in the UK and US. Despite the loss of sample, the management remains positively and significantly associated with CEO compensation with a similar pattern of coefficients to the earlier columns

The Social Security Data comes directly from Song et al (2017), which in turn is obtained from the Master Earnings File in the Social Security Earnings, which contains the labor (W2) earnings (uncapped) of all employees in the US from 1978 to 2013. The values provided in text are for 2013 for all firms defined as a single Employee Identification Number in a given year.

\section{References}

[1] Autor, David, David Dorn, Larry Katz, Christina Patterson and John Van Reenen (2017) "The Rise of Superstar firms and the fall of the Labor Share" NBER Working Paper 23396

[2] Axtell, Robert. 2001. "Zipf Distribution of U.S. Firm Sizes." Science, 293(5536): 1818-1820.

[3] Bloom, Nicholas, Raffaella Sadun, and John Van Reenen. 2012b. "The Organization of Firms Across Countries." Quarterly Journal of Economics 127(4): 1663-1705.

[4] Bond, Stephen and Mans Soderbom. 2005. "Adjustment costs and the identification of CobbDouglas production functions" IFS Mimeo

[5] Citino, Luca, Jonathan Haskel and John Van Reenen. 2016. "Accounting for the U.K. Productivity Gap." London School of Economics mimeo.

[6] Garicano, Luis, Claire Lelarge and John Van Reenen. 2016. "Firm Size Distortions and the Productivity Distribution: Evidence from France" American Economic Review 106(11): 343979

[7] Johnson, Norman, Adrienne Kemp and Samuel Kotz. 1993. Continuous Univariate Distributions. New York, N.Y.: John Wiley \& Sons. 
[8] Kalemli-Ozcan, Sebnem, Bent Sorensen, Carolina Villegas-Sanchez, Vadym Volosovych, Sevcan Yesiltas. 2015. "How to Construct Nationally Representative Firm level data from the ORBIS Global Database" NBER Working Paper 21558.

[9] Lee, Bong-Soo and Beth Ingram. 1991. "Simulation Estimation of time series models" Journal of Econometrics 47(2-3) 197-205

[10] Lemos, Renata and Daniela Scur. 2015. "A snapshot of mid-sized firms in Africa, Asia and Latin America." Oxford University mimeo, http://worldmanagementsurvey.org/wpcontent/images/2010/08/lemos_scur_snapshot_dec20151.pdf.

[11] Levinsohn, James and Amil Petrin. 2003. "Estimating Production functions using inputs to control for unobservables" Review of Economic Studies 70(2) 317-341

[12] Sutton, John and Bennet Kpentey. 2012. Enterprise Map of Kenya. London: IGC.

[13] Sutton, John, Jeque Pimpao, Félix Simione, Qi Zhang and Samuel Zita. 2014. Enterprise Map of Ghana. London: IGC.

[14] Sutton, John and Donath Olomi. 2012. Enterprise Map of Mozambique. London: IGC

[15] Sutton, John and Gillian Langmead. 2013. Enterprise Map of Zambia., London: IGC, London: IGC.

[16] Tanaka, Mari. 2015. "Exporting Sweatshops: Evidence from Myanmar." Stanford University mimeo. 
Figure A1: Foreign multinationals vs. domestic firms

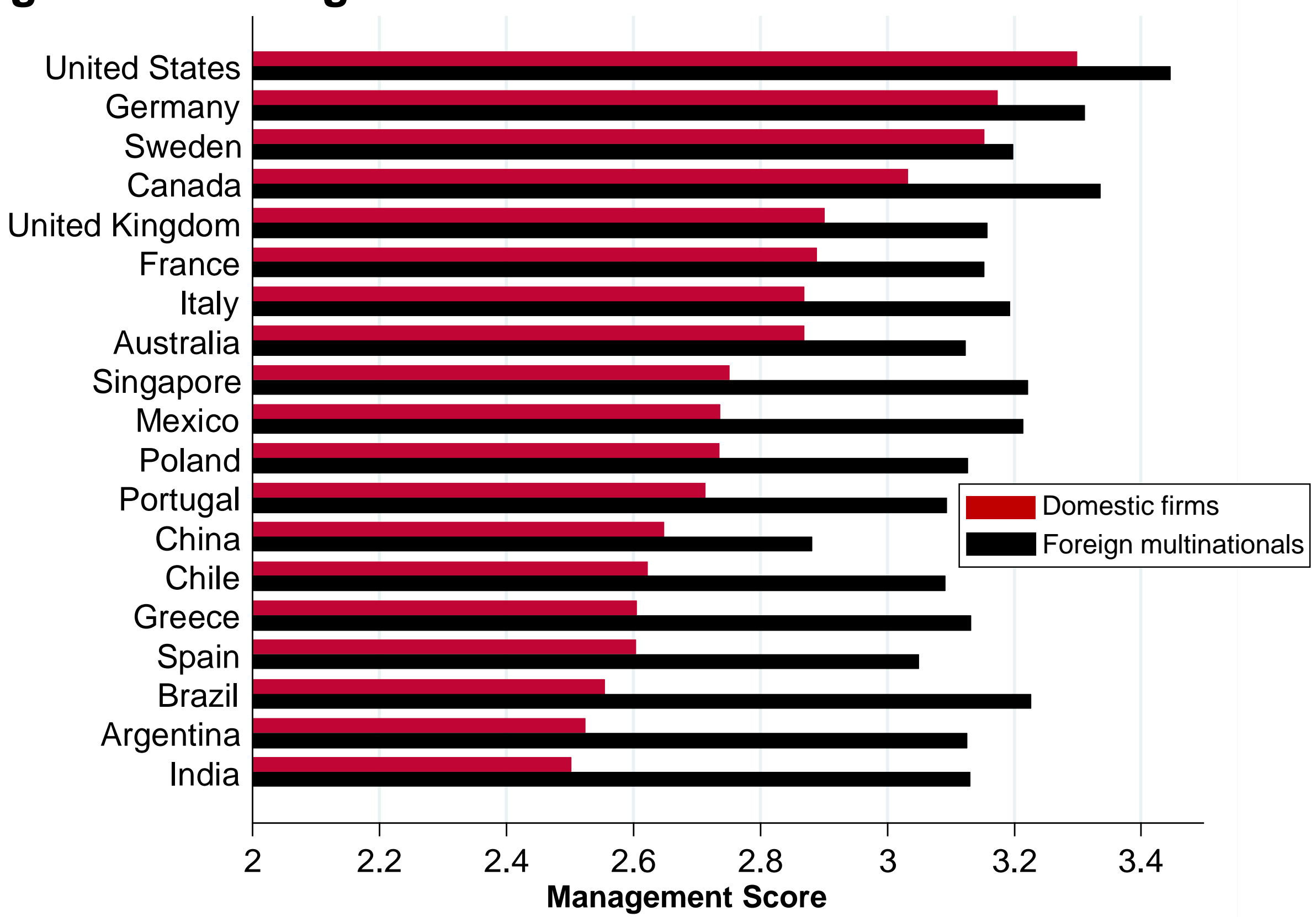

Notes: Unweighted means of management scores by companies belonging to foreign multinationals vs. domestic firms (including domestic multinationals). Countries with 60 or more + foreign multinationals only (sample of 13,544 interviews). 


\section{Figure A2: Firm Size is increasing in management}

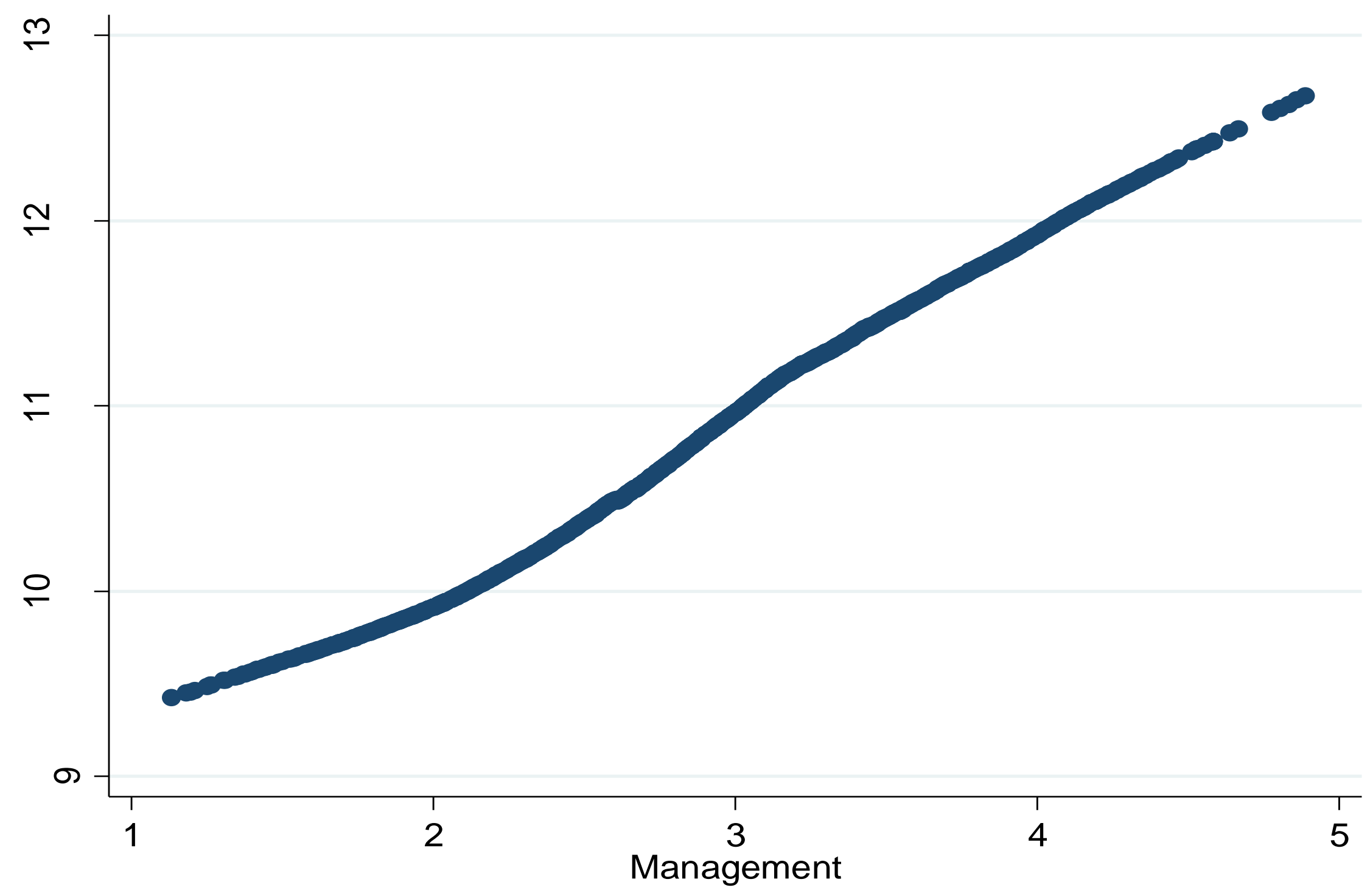

Notes: This plots the lowess predicted values of log(sales) against management (bandwidth=0.5). Sales is log(sales) in US $\$ . N=13,854$ 
Figure A3: Firm TFP is increasing in management

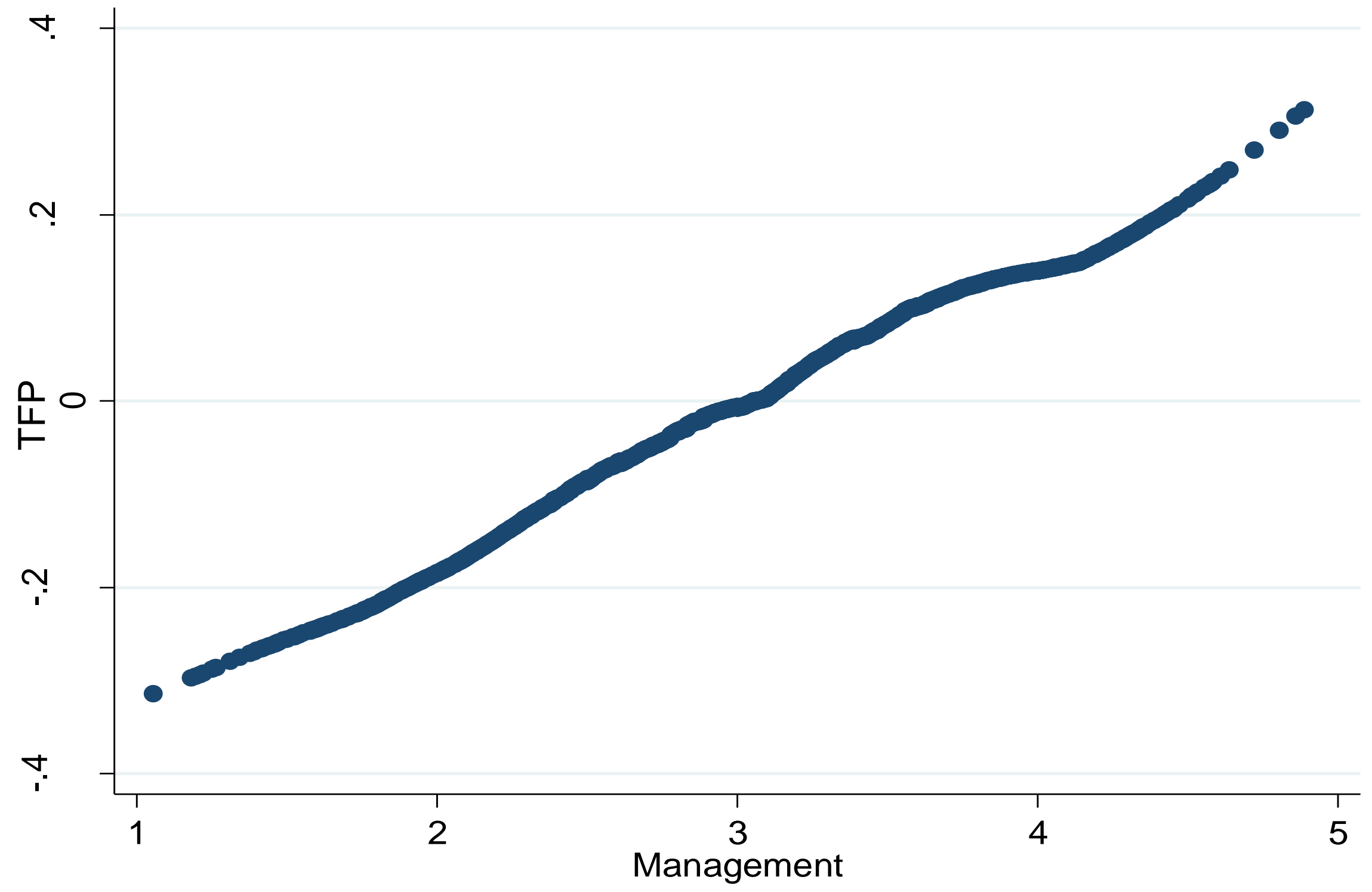

Notes: This plots the lowess predicted valued of TFP against management (bandwidth=0.5). TFP calculated as residual of regression of $\operatorname{In}$ (sales) on $\operatorname{In}$ (capital) and $\operatorname{In}$ (labor) plus a full set of 3 digit industry, country and year dummies controls. $N=10,900$ 


\section{Figure A4: Firms with higher management scores have higher CEO compensation}

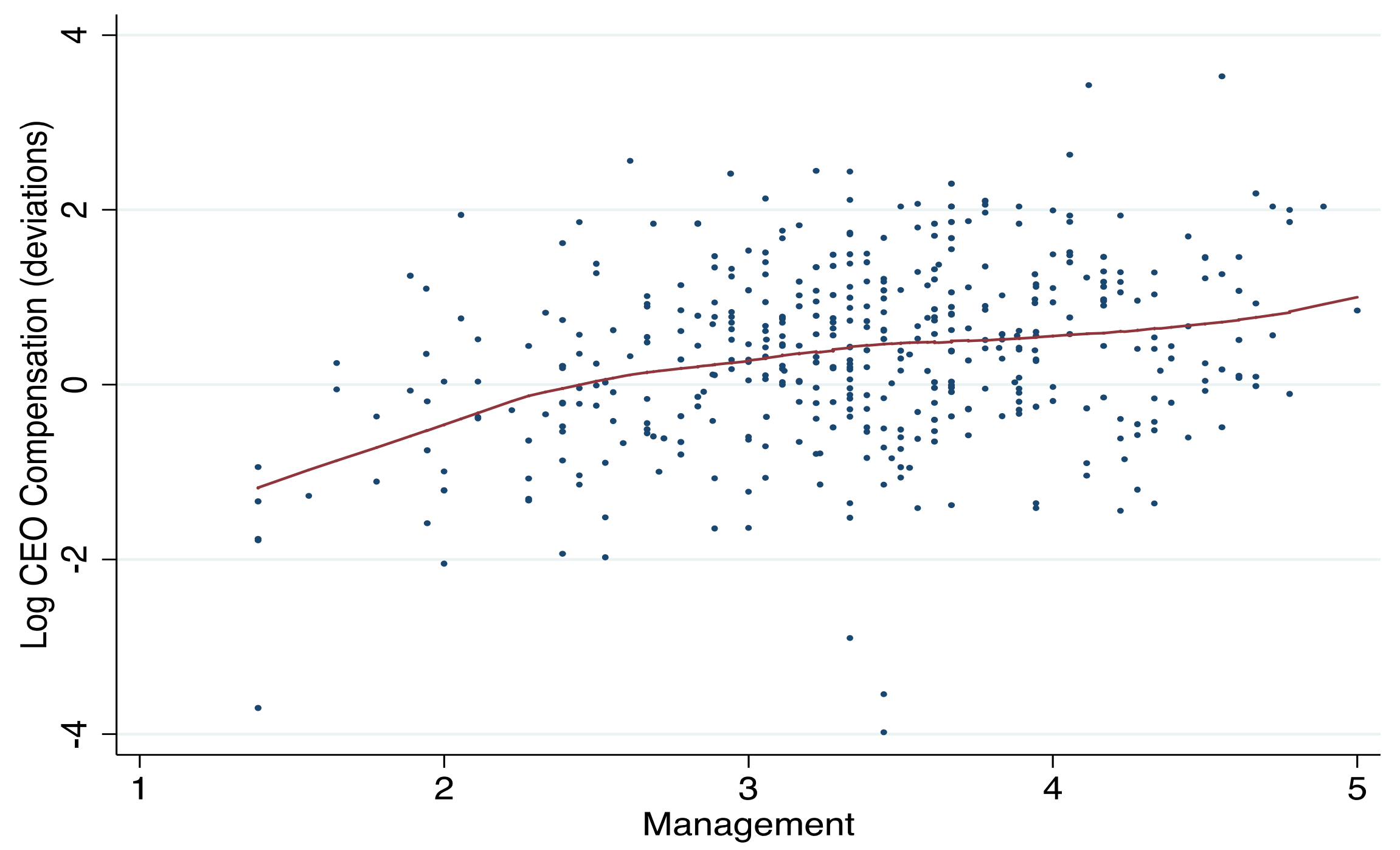

Notes: These are 413 publicly firms in the UK and US. The line is the lowess predicted valued of the log of total CEO compensation including salaries, bonuses and equity (in deviations from country averages) and the management score. 
Figure A5: TFP Gap accounted for by management

\% of TFP gap accounted for by management

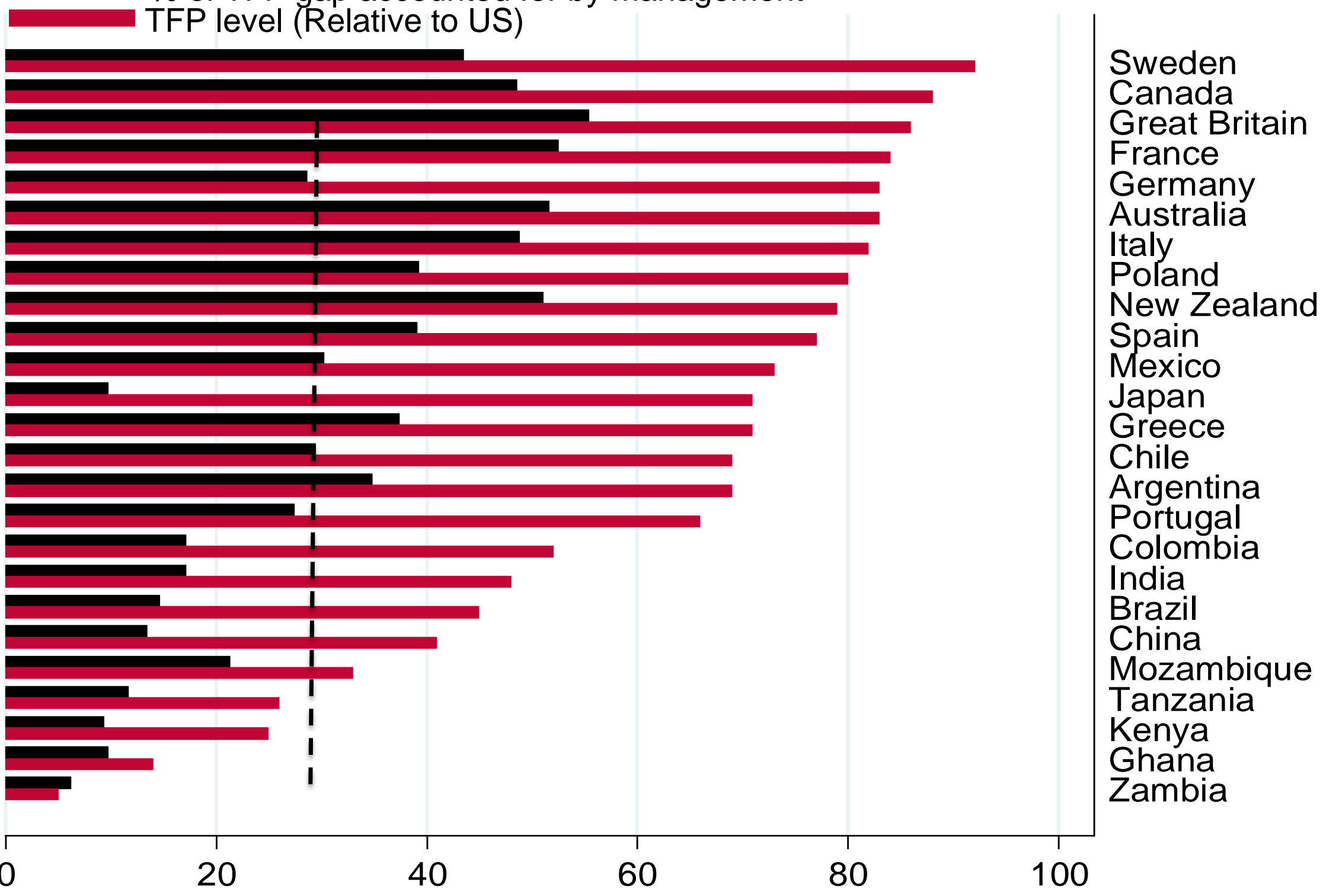

Notes: TFP gaps from Penn World Tables; fraction accounted for by management uses the weighted average management scores and an assumed 10\% impact of management on TFP. See Table 7 for details of calculations. Vertical line indicates the mean effect $(30 \%)$. 


\section{TABLE A1: MANAGEMENT PRACTICES QUESTIONNAIRE}

Any score from 1 to 5 can be given, but the scoring guide and examples are only provided for scores of 1,3 and 5 . The survey also includes a set of Questions that are asked to score each dimension, which are included in Bloom and Van Reenen (2007).

\begin{tabular}{|c|c|c|c|}
\hline Scoring grid: & $\begin{array}{l}\text { Score 1 } \\
\text { Other than Just-In-Time (JIT) delivery from } \\
\text { suppliers few modern manufacturing } \\
\text { techniques have been introduced, (or have } \\
\text { been introduced in an ad-hoc manner) }\end{array}$ & $\begin{array}{l}\text { Score } 3 \\
\text { Some aspects of modern manufacturing } \\
\text { techniques have been introduced, through } \\
\text { informal/isolated change programs }\end{array}$ & $\begin{array}{l}\text { Score } 5 \\
\text { All major aspects of modern manufacturing have been } \\
\text { introduced (Just-In-Time, autonomation, flexible } \\
\text { manpower, support systems, attitudes and behaviour) in } \\
\text { a formal way }\end{array}$ \\
\hline \multicolumn{4}{|c|}{ (2) Modern manufacturing, rationale } \\
\hline & Score 1 & Score 3 & Score 5 \\
\hline Scoring grid: & $\begin{array}{l}\text { Modern manufacturing techniques were } \\
\text { introduced because others were using them. }\end{array}$ & $\begin{array}{l}\text { Modern manufacturing techniques were } \\
\text { introduced to reduce costs }\end{array}$ & $\begin{array}{l}\text { Modern manufacturing techniques were introduced to } \\
\text { enable us to meet our business objectives (including } \\
\text { costs) }\end{array}$ \\
\hline \multicolumn{4}{|c|}{ (3) Process problem documentation } \\
\hline Scoring grid: & $\begin{array}{l}\text { Score 1 } \\
\text { No, process improvements are made when } \\
\text { problems occur. }\end{array}$ & $\begin{array}{l}\qquad \text { Score } 3 \\
\text { Improvements are made in one week } \\
\text { workshops involving all staff, to improve } \\
\text { performance in their area of the plant }\end{array}$ & $\begin{array}{l}\text { Score } \mathbf{5} \\
\text { Exposing problems in a structured way is integral to } \\
\text { individuals' responsibilities and resolution occurs as a } \\
\text { part of normal business processes rather than by } \\
\text { extraordinary effort/teams }\end{array}$ \\
\hline \multicolumn{4}{|c|}{ (4) Performance tracking } \\
\hline Scoring grid: & $\begin{array}{l}\quad \text { Score 1 } \\
\text { Measures tracked do not indicate directly if } \\
\text { overall business objectives are being met. } \\
\text { Tracking is an ad-hoc process (certain } \\
\text { processes aren't tracked at all) }\end{array}$ & $\begin{array}{l}\quad \text { Score } 3 \\
\text { Most key performance indicators are tracked } \\
\text { formally. Tracking is overseen by senior } \\
\text { management. }\end{array}$ & $\begin{array}{l}\text { Score } 5 \\
\text { Performance is continuously tracked and communicated, } \\
\text { both formally and informally, to all staff using a range of } \\
\text { visual management tools. }\end{array}$ \\
\hline
\end{tabular}




\section{(5) Performance review}

Scoring grid:

Performance is reviewed infrequently or in an un-meaningful way, e.g. only success or failure is noted.
Score 3

Performance is reviewed periodically with successes and failures identified. Results are communicated to senior management. No clear follow-up plan is adopted.

\section{Score 5}

Performance is continually reviewed, based on indicator tracked. All aspects are followed up ensure continuous improvement. Results are communicated to all staff

(6) Performance dialogue

Scoring grid:

information for a constructive discussion is often not present or conversations overly focus on data that is not meaningful. Clear agenda is not known and purpose is not stated explicitly

Scoring grid

Score 1

Failure to achieve agreed objectives does not carry any consequences

Score 1

Goals are exclusively financial or operational

\section{Score 3}

Review conversations are held with the appropriate data and information present.

Objectives of meetings are clear to all

participating and a clear agenda is present.

Conversations do not, as a matter of course,

drive to the root causes of the problems.

\section{(8) Target balance}

Scoring grid:

\section{(9) Target interconnection}

\section{Score 3}

Failure to achieve agreed results is tolerated for a period before action is taken.

\section{Score 5}

Regular review/performance conversations focus on problem solving and addressing root causes. Purpose, agenda and follow-up steps are clear to all. Meetings are an opportunity for constructive feedback and coaching.

Score 3

Goals include non-financial targets, which form part of the performance appraisal of top management only (they are not reinforced throughout the rest of organization)

\section{Score 5}

A failure to achieve agreed targets drives retraining in identified areas of weakness or moving individuals to where their skills are appropriate

\section{Score 5}

Goals are a balance of financial and non-financial targets. Senior managers believe the non-financial targets are often more inspiring and challenging than financials alone. 
Scoring grid:

Goals are based purely on accounting figures (with no clear connection to shareholder value)
Corporate goals are based on shareholder value but are not clearly communicated down to individuals
Corporate goals focus on shareholder value. They increase in specificity as they cascade through business units ultimately defining individual performance expectations.

\section{Score 5}

Long term goals are translated into specific short term targets so that short term targets become a "staircase" to reach long term goals

There are short and long-term goals for all levels of the organization. As they are set independently, they are not necessarily linked to each other

\section{Score 3}

In most areas, top management pushes for aggressive goals based on solid economic rationale. There are a few "sacred cows" that

are not held to the same rigorous standard

\section{Score 5}

Goals are genuinely demanding for all divisions. They are grounded in solid, solid economic rationale achieve; managers provide low estimates to ensure easy goals

\section{(12) Performance clarity}

Scoring grid:

Score 1

Performance measures are complex and not clearly understood. Individual performance is not made public

\section{Score 3}

Performance measures are well defined and communicated; performance is public in all levels but comparisons are discouraged

\section{Score 5}

Performance measures are well defined, strongly communicated and reinforced at all reviews; performance and rankings are made public to induce competition

\section{Score 3}

Senior management believe and communicate that having top talent throughout the organization is a key way to win

hat attracting, retaining and developing talent throughout the organization is a top priority

\section{(14) Rewarding high-performance}

\section{Score 1}

Scoring grid: $\quad$ People within our firm are rewarded

equally irrespective of performance level

\section{Score 3}

Our company has an evaluation system for the awarding of performance related rewards

\section{Score 5}

Senior managers are evaluated and held accountable on the strength of the talent pool they actively build

\section{Score 5}

We strive to outperform the competitors by providing ambitious stretch targets with clear performance related accountability and rewards 


\begin{tabular}{|c|c|c|c|}
\hline \multicolumn{4}{|c|}{ (15) Removing poor performers } \\
\hline Scoring grid: & $\begin{array}{l}\qquad \text { Score } 1 \\
\text { Poor performers are rarely removed from } \\
\text { their positions }\end{array}$ & $\begin{array}{l}\text { Score } \mathbf{3} \\
\text { Suspected poor performers stay in a position } \\
\text { for a few years before action is taken }\end{array}$ & $\begin{array}{l}\text { Score } 5 \\
\text { We move poor performers out of the company or to less } \\
\text { critical roles as soon as a weakness is identified }\end{array}$ \\
\hline \multicolumn{4}{|c|}{ (16) Promoting high performers } \\
\hline Scoring grid: & $\begin{array}{l}\text { Score } \mathbf{1} \\
\text { People are promoted primarily upon the } \\
\text { basis of tenure }\end{array}$ & $\begin{array}{l}\text { Score } \mathbf{3} \\
\text { People are promoted upon the basis of } \\
\text { performance }\end{array}$ & $\begin{array}{l}\text { Score } \mathbf{5} \\
\text { We actively identify, develop and promote our top } \\
\text { performers }\end{array}$ \\
\hline \multicolumn{4}{|c|}{ (17) Attracting human capital } \\
\hline Scoring grid: & $\begin{array}{l}\text { Score } 1 \\
\text { Our competitors offer stronger reasons for } \\
\text { talented people to join their companies }\end{array}$ & $\begin{array}{l}\text { Score } 3 \\
\text { Our value proposition to those joining our } \\
\text { company is comparable to those offered by } \\
\text { others in the sector. }\end{array}$ & $\begin{array}{l}\text { Score } \mathbf{5} \\
\text { We provide a unique value proposition to encourage } \\
\text { talented people join our company above our competitors }\end{array}$ \\
\hline \multicolumn{4}{|c|}{ (18) Retaining human capital } \\
\hline Scoring grid: & $\begin{array}{c}\text { Score } \mathbf{1} \\
\text { We do little to try to keep our top talent. }\end{array}$ & $\begin{array}{c}\text { Score } \mathbf{3} \\
\text { We usually work hard to keep our top talent. }\end{array}$ & $\begin{array}{c}\text { Score } \mathbf{5} \\
\text { We do whatever it takes to retain our top talent. }\end{array}$ \\
\hline
\end{tabular}

Source: Bloom and Van Reenen (2007) 
TABLE A2:

SAMPLING FRAME SOURCES AND SAMPLE RESPONSE RATES BY COUNTRY

\begin{tabular}{|c|c|c|c|c|c|}
\hline CODE & Name & Primary Source & $\%$ responding & $\begin{array}{c}(5) \\
\text { \#Contacted } \\
\text { \& eligible }\end{array}$ & Years \\
\hline AR & Argentina & BVD ORBIS & 42.26 & 892 & $2010 ; 2013$ \\
\hline $\mathrm{AU}$ & Australia & Dun \& Bradstreet & 33.24 & 1357 & 2009 \\
\hline BR & Brazil & BVD ORBIS & 45.45 & 1727 & $2008 ; 2013$ \\
\hline $\mathrm{CA}$ & Canada & BVD ORBIS & 34.4 & 1218 & 2008 \\
\hline CL & Chile & ENIA & 70.55 & 550 & 2009 \\
\hline $\mathrm{CN}$ & China & BVD ORBIS & 43.91 & 1273 & $2007 ; 2010$ \\
\hline $\mathrm{CO}$ & Colombia & Business Ministry & 49.28 & 345 & 2013 \\
\hline ES & Spain & BVD ORBIS & 29.8 & 708 & 2013 \\
\hline ET & Ethiopia & IGC Enterprise Map & 60.65 & 216 & 2013 \\
\hline FR & France & BVD ORBIS & 41.93 & 1047 & $2004 ; 2006 ; 2009 ; 2014$ \\
\hline GB & Great Britain & BVD ORBIS & 29.2 & 2661 & $2004 ; 2006 ; 2009 ; 2014$ \\
\hline GE & Germany & BVD ORBIS & 33.81 & 1121 & $2004 ; 2006 ; 2009 ; 2014$ \\
\hline GH & Ghana & IGC Enterprise Map & 78.69 & 122 & 2013 \\
\hline GR & Greece & BVD ORBIS & 53.96 & 782 & $2006 ; 2010 ; 2014$ \\
\hline IN & India & CMIE FIRSTSOURCE 2005 & 43.42 & 1177 & 2006,$2008 ; 2010$ \\
\hline IR & Ireland & BVD ORBIS & 42.97 & 384 & 2008 \\
\hline IT & Italy & BVD ORBIS & 48.31 & 888 & $2006 ; 2010 ; 2014$ \\
\hline JP & Japan & BVD ORBIS & 17.33 & 554 & $2006 ; 2010$ \\
\hline $\mathrm{KE}$ & Kenya & BVD ORBIS & 66.91 & 272 & 2013 \\
\hline MM & Myanmar & PEDL Enterprise Map & 65.04 & 226 & 2014 \\
\hline MX & Mexico & BVD ORBIS & 39.81 & 967 & $2010 ; 2013$ \\
\hline MZ & Mozambique & IGC Enterprise Map & 81.06 & 132 & 2013 \\
\hline $\mathrm{NC}$ & Nicaragua & Business Directories & 80.2 & 101 & 2013 \\
\hline NG & Nigeria & BVD ORBIS & 90.98 & 122 & 2013 \\
\hline NI & Northern Ireland & BVD ORBIS & 62.98 & 181 & 2008 \\
\hline NZ & New Zealand & Dun \& Bradstreet & 44.19 & 344 & 2009 \\
\hline $\mathrm{PO}$ & Poland & BVD ORBIS & 37.44 & 649 & $2006 ; 2010$ \\
\hline PT & Portugal & BVD ORBIS & 53.72 & 363 & 2006;2010;2014 \\
\hline SG & Singapore & Trade \& Industry Ministry & 66.08 & 398 & 2012 \\
\hline SW & Sweden & BVD ORBIS & 40.42 & 819 & $2006 ; 2010$ \\
\hline TR & Turkey & BVD ORBIS & 81.92 & 177 & 2013 \\
\hline $\mathrm{TZ}$ & Tanzania & IGC Enterprise Map & 29.14 & 3092 & 2013 \\
\hline US & United States & BVD ORBIS & 38.92 & 388 & $2004 ; 2006 ; 2009 ; 2014$ \\
\hline VN & Viet Nam & BVD ORBIS & 64.36 & 101 & 2014 \\
\hline $\mathrm{ZM}$ & Zambia & IGC Enterprise Map & 42.26 & 892 & 2013 \\
\hline ALL & & & 40.93 & 25,345 & \\
\hline
\end{tabular}

Notes: This tables contains some descriptive statistics of the countries in our database and the primary source of the sampling frame (more details are in Appendix A). Column (3) is the response rate (proportion of eligible and contacted firms who responded). "All" in the last row is the average across the entire sampling frame - i.e. weighted by number of firms contacted rather than simple unweighted average across countries (not including Singapore). Final column is main years included in survey. 
TABLE A3:

DISTRIBUTION OF WORKERS IN DIFFERENT FIRM SIZE CLASSES ACROSS COUNTRIES

\begin{tabular}{|c|c|c|c|c|c|c|c|c|c|c|c|}
\hline$\%$ workers in firms with: & France & Germany & Greece & Ireland & Italy & Japan & Poland & Portugal & Sweden & GB & US \\
\hline Under 50 employees & $30.1 \%$ & $17.8 \%$ & $41.4 \%$ & $28.3 \%$ & $45.2 \%$ & $23.9 \%$ & $27.2 \%$ & $51.4 \%$ & $23.8 \%$ & $36.2 \%$ & $16.2 \%$ \\
\hline Between 50 and 5,000 employees & $48.6 \%$ & $52.8 \%$ & $53.9 \%$ & $71.7 \%$ & $48.6 \%$ & $58.6 \%$ & $71.0 \%$ & $47.8 \%$ & $54.4 \%$ & $49.3 \%$ & $49.1 \%$ \\
\hline Over 5,000 employees & $21.3 \%$ & $29.4 \%$ & $4.6 \%$ & $0.0 \%$ & $6.2 \%$ & $17.5 \%$ & $1.8 \%$ & $0.7 \%$ & $21.9 \%$ & $14.5 \%$ & $34.7 \%$ \\
\hline
\end{tabular}

Notes: This table displays estimates of the distribution of employment in manufacturing across firms in different size classes. The WMS sampling frame covers medium sized firms (between 50 and 5,000 workers) which usually covers half or more of total workers. The US (2006) and Japanese (2007) data are from published Census Bureau data and UK data (2010) is our analysis of unpublished Census data. For the other countries we use Eurostat data (which is based on Census) for the proportion of employment in firms with under 50 employees. For disclosure reasons, the proportion of employees in firms in over 5,000 employees is not reported in public use tables, however. Consequently, we used other data sources to estimate this fraction since we know the total manufacturing employment and we have access to the employment of the largest firms in every country from ORBIS company accounts data. Details are in Appendix B. 
TABLE A4: RESPONSE RATES TO SURVEY

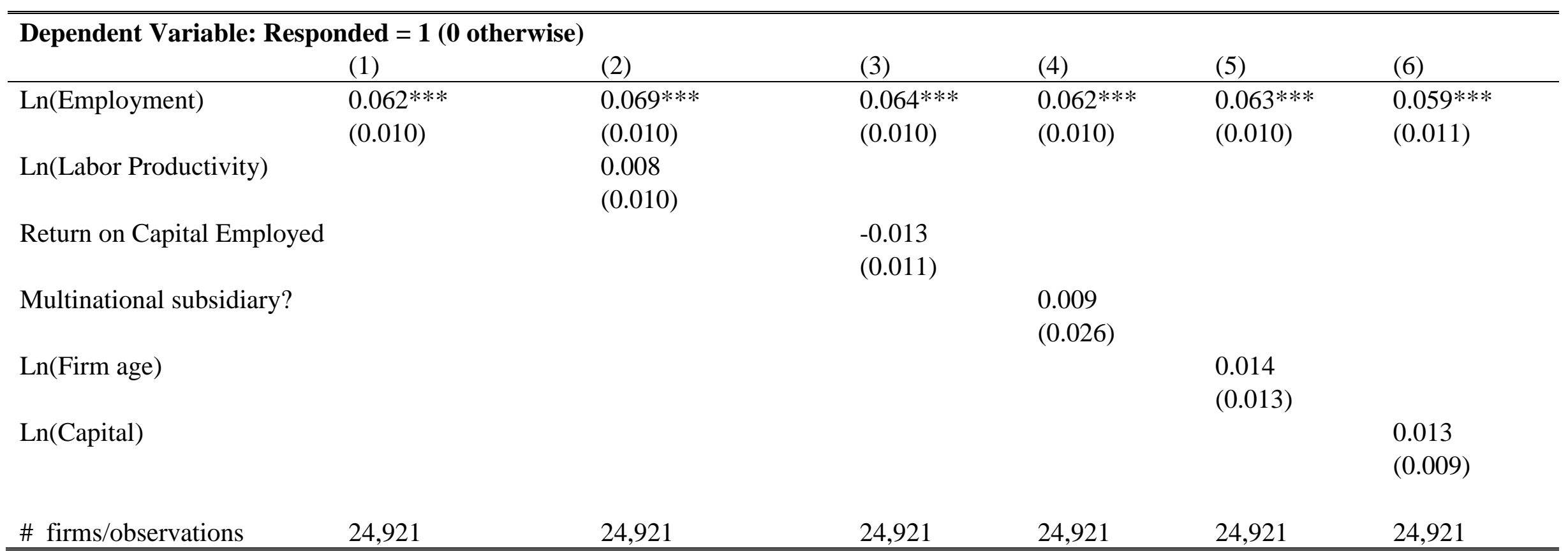

Notes: $* * *$ denotes significance at the $1 \%$ level, $* * 5 \%$ level and $* 10 \%$ level. Marginal effects and standard errors from Probit ML. The dependent variable $=1$ if the firm responded to our survey and zero otherwise. An observation is the first a firm was contacted (so subsequent panel observations are not included, not are multiple plants in the same year which is why there are fewer observations than in the entire database). Years are 2006 to 2014 (see Bloom and Van Reenen, 2007 , for analysis of the 2004 data). All regressions include three digit industry dummies, country dummies and year dummies (for survey response year and year that accounting data is taken from). Missing values on accounting variables are set to zero and a dummy for missing value included in the regression. Number of observations is 1,534 less than Table A1 because Singapore not included since we do not have details on covariates of non-responders from sampling frame. 


\section{TABLE A5: ROBUSTNESS OF PRODUCTION FUNCTIONS}

\begin{tabular}{|c|c|c|c|c|c|c|c|c|c|c|c|c|c|}
\hline & (1) & (2) & (3) & (4) & (5) & (6) & (7) & (8) & (9) & (10) & (11) & (12) & (13) \\
\hline $\begin{array}{l}\text { Dependent } \\
\text { variable: }\end{array}$ & $\begin{array}{c}\text { Solow } \\
\text { Residual }\end{array}$ & $\begin{array}{c}\text { Ln } \\
\text { (Value } \\
\text { Added) }\end{array}$ & $\begin{array}{c}\text { Ln } \\
\text { (Value } \\
\text { Added) }\end{array}$ & $\begin{array}{c}\text { Ln } \\
\text { (Value } \\
\text { Added) }\end{array}$ & $\begin{array}{c}\text { Ln } \\
\text { (Sales) }\end{array}$ & $\begin{array}{c}\text { Ln } \\
\text { (Sales) }\end{array}$ & $\begin{array}{c}\text { Ln } \\
\text { (Sales) }\end{array}$ & $\begin{array}{c}\text { Ln } \\
\text { (Sales) }\end{array}$ & $\begin{array}{c}\text { Ln } \\
\text { (Sales) }\end{array}$ & $\begin{array}{c}\text { Ln } \\
\text { (Sales) }\end{array}$ & $\begin{array}{c}\text { Ln } \\
\text { (Sales) }\end{array}$ & $\begin{array}{c}\text { Ln } \\
\text { (Sales) }\end{array}$ & $\begin{array}{c}\text { Ln } \\
\text { (Sales) }\end{array}$ \\
\hline Method & & $\begin{array}{c}\text { Blundell } \\
\text { Bond }\end{array}$ & Lev-Pet & $\begin{array}{l}\mathrm{OP}+ \\
\mathrm{ACF}\end{array}$ & OLS & OLS & $\begin{array}{l}\text { Fixed } \\
\text { Effects }\end{array}$ & OP & $\begin{array}{c}\text { Blundell } \\
\text { Bond }\end{array}$ & OLS & $\begin{array}{l}\text { Fixed } \\
\text { effects }\end{array}$ & $\mathrm{OP}$ & $\begin{array}{c}\text { Blundell } \\
\text { Bond }\end{array}$ \\
\hline $\begin{array}{l}\text { Management } \\
\text { (z-score) }\end{array}$ & $\begin{array}{c}0.080 * * * \\
(0.015)\end{array}$ & $\begin{array}{c}0.046^{* *} \\
(0.018)\end{array}$ & $\begin{array}{c}0.138 * * * \\
(0.013)\end{array}$ & $\begin{array}{c}0.091 * * * \\
(0.013)\end{array}$ & $\begin{array}{c}0.134 * * * \\
(0.014)\end{array}$ & $\begin{array}{c}0.118 * * * \\
(0.016)\end{array}$ & $\begin{array}{c}0.026 * * \\
(0.011)\end{array}$ & $\begin{array}{c}0.094 * * * \\
(0.013)\end{array}$ & $\begin{array}{c}0.055^{* *} \\
(0.019)\end{array}$ & $\begin{array}{c}0.158 * * * \\
(0.016)\end{array}$ & $\begin{array}{c}0.034 * * * \\
(0.013)\end{array}$ & $\begin{array}{c}0.116 * * * \\
(0.014)\end{array}$ & $\begin{array}{r}0.046 * * * \\
(0.017)\end{array}$ \\
\hline Ln(Labor) & & $\begin{array}{c}0.435 \text { *** } \\
(0.035)\end{array}$ & $\begin{array}{c}0.548 * * * \\
(0.027)\end{array}$ & $\begin{array}{c}0.629 * * * \\
(0.004)\end{array}$ & $\begin{array}{c}0.536 * * * \\
(0.026)\end{array}$ & $\begin{array}{c}0.525 * * * \\
(0.030)\end{array}$ & $\begin{array}{c}0.360 * * * \\
(0.059)\end{array}$ & $\begin{array}{c}0.447 * * * \\
(0.025)\end{array}$ & $\begin{array}{c}0.356 * * \\
(0.039)\end{array}$ & $\begin{array}{c}0.633 * * * \\
(0.026)\end{array}$ & $\begin{array}{c}0.412 * * * \\
(0.060)\end{array}$ & $\begin{array}{c}0.550 * * * \\
(0.030)\end{array}$ & $\begin{array}{c}0.381 * * * \\
(0.033)\end{array}$ \\
\hline Ln(Capital) & & $\begin{array}{c}0.318^{* * * *} \\
(0.025)\end{array}$ & $\begin{array}{c}0.353 * * * \\
(0.007)\end{array}$ & $\begin{array}{c}0.403 * * * \\
(0.003)\end{array}$ & $\begin{array}{c}0.253 * * * \\
(0.019)\end{array}$ & $\begin{array}{c}0.233 * * * \\
(0.022)\end{array}$ & $\begin{array}{c}0.166^{* * *} \\
(0.041)\end{array}$ & $\begin{array}{c}0.361 * * * \\
(0.011)\end{array}$ & $\begin{array}{c}0.268 * * * \\
(0.028)\end{array}$ & $\begin{array}{c}0.296^{* * * *} \\
(0.019)\end{array}$ & $\begin{array}{c}0.195 * * * \\
(0.041)\end{array}$ & $\begin{array}{c}0.428 * * * \\
(0.006)\end{array}$ & $\begin{array}{c}0.323 * * * \\
(0.026)\end{array}$ \\
\hline Ln(Materials) & & & & & $\begin{array}{c}0.286 * * * \\
(0.015)\end{array}$ & $\begin{array}{c}0.319 * * * \\
(0.017)\end{array}$ & $\begin{array}{c}0.217 * * * \\
(0.032)\end{array}$ & $\begin{array}{c}0.323 * * * \\
(0.014)\end{array}$ & $\begin{array}{c}0.208 * * * \\
(0.027)\end{array}$ & & & & \\
\hline
\end{tabular}

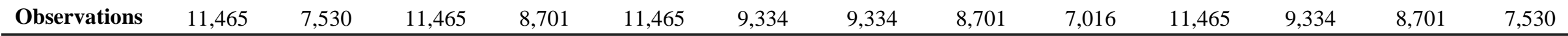

Notes: *** denotes significance at the $1 \%$ level, ** denotes $5 \%$ significance and $*$ denotes $10 \%$ significance. All columns with standard errors in parentheses under coefficients (clustered by firm except (3), (4), (8) and (12) which are bootstrapped with 150 replications). All columns use OLS except columns (2), (9) and (10) that use the Blundell and Bond (2000) method; columns (4), (8) and (12) uses the Olley-Pakes ("OP”) estimator (column (4) with the Ackerberg et al, "ACF” correction), column (3) the Levinsohn-Petrin ("Lev-Pet") approach. Columns (3) and (4) restrict to firms which were surveyed in at least two different years. "Management" is the firm's normalized z-score of management (the z-score of the average $\mathrm{z}$-scores of the 18 management questions). All columns include "General controls" comprising of firm age and the proportion of employees with college degrees (from the survey), plus a set of survey noise controls which are interviewer dummies, the seniority and tenure of the manager who responded, the duration and day of the interviews and an indicator of the reliability of the information as coded by the interviewer 
TABLE A6: CEO PAY AND MANAGEMENT PRACTICES

\begin{tabular}{|c|c|c|c|c|}
\hline & (1) & (2) & (3) & (4) \\
\hline Dependent variable: & Ln(Salary) & Ln(Salary) & $\begin{array}{c}\text { Ln(Total } \\
\text { Compensation) }\end{array}$ & $\begin{array}{c}\text { Ln(Total } \\
\text { Compensation) }\end{array}$ \\
\hline Countries & $\begin{array}{c}\text { China, India, US and } \\
\text { UK }\end{array}$ & $\begin{array}{c}\text { China, India, US and } \\
\text { UK }\end{array}$ & US and UK & US and UK \\
\hline Management & $\begin{array}{c}0.309 * * * \\
(0.060)\end{array}$ & $\begin{array}{c}0.189 * * * \\
(0.058)\end{array}$ & $\begin{array}{l}0.335 * * * \\
(0.083)\end{array}$ & $\begin{array}{l}0.171 * * \\
(0.083)\end{array}$ \\
\hline General Controls & No & Yes & No & Yes \\
\hline Observations & 913 & 913 & 441 & 441 \\
\hline
\end{tabular}

Notes: $* * *$ significance at the $1 \%, 5 \%(* *)$ or $10 \%(*)$ level. Estimates by OLS with standard errors clustered by firm. All columns include country dummies. General Controls are firm and plant employment, firm age, skills, ownership types, seniority, noise controls, industry and time dummies. 